University of South Florida

DIGITAL COMMONS

@ UNIVERSITY OF SOUTH FLORIDA
Digital Commons @ University of

South Florida

10-1-2005

\title{
Assessing the Hierarchy of Needs in Levels of Service
}

CUTR

Follow this and additional works at: https://digitalcommons.usf.edu/cutr_nctr

\section{Recommended Citation}

"Assessing the Hierarchy of Needs in Levels of Service," National Center for Transit Research (NCTR) Report No. CUTR-NCTR-RR-2003-10, Center for Urban Transportation Research, University of South Florida, 2005.

DOI: https://doi.org/10.5038/CUTR-NCTR-RR-2003-10

Available at: https://scholarcommons.usf.edu/cutr_nctr/185

This Technical Report is brought to you for free and open access by the National Center for Transit Research (NCTR) Archive (2000-2020) at Digital Commons @ University of South Florida. It has been accepted for inclusion in Research Reports by an authorized administrator of Digital Commons @ University of South Florida. For more information, please contact digitalcommons@usf.edu. 


\section{Assessing Hierarchy of Needs in Levels of Service}

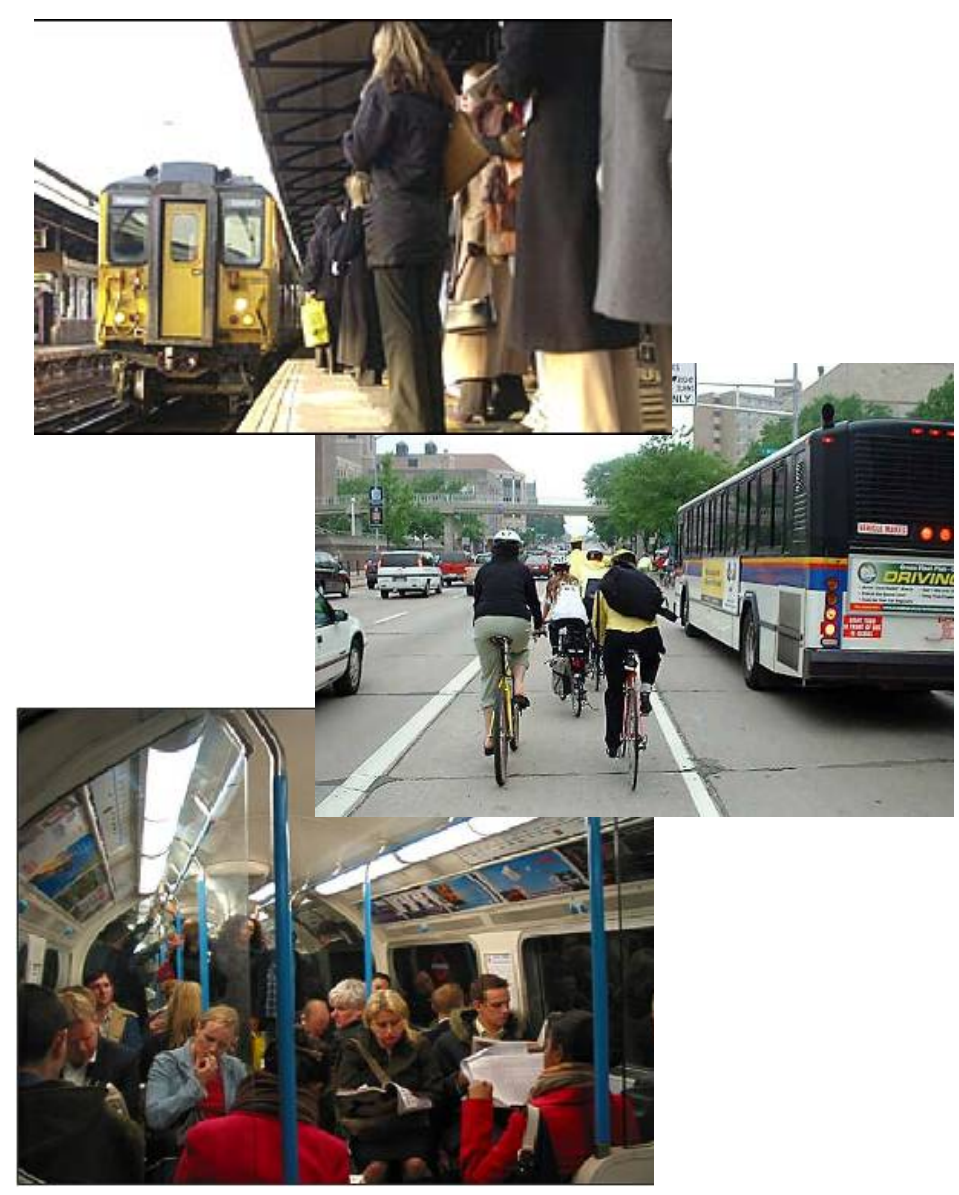

Final Report

October 2005

FDOT BD 549-1

NCTR 527-08 



\title{
Assessing Hierarchy of Needs in Levels of Service
}

\section{Final Report}

Principal Investigator:

Jennifer S. Perone, Research Associate

\section{CUTR Staff:}

Philip L. Winters, TDM Program Director Melissa Read, Graduate Research Assistant Isaac Sankah, Graduate Research Assistant

\author{
National Center for Transit Research \\ Center for Urban Transportation Research \\ University of South Florida \\ 4202 East Fowler Avenue, CUT 100 \\ Tampa, FL 33620-5735
}

(813) 974-3120
Florida Department of Transportation
Public Transit Office
605 Suwannee Street
Tallahassee, FL 32399-0450
(850) $414-4500$

Project Manager:

Martin Guttenplan, FDOT

October 2005

\section{FDOT Project BD 549-1 \\ NCTR Project 527-08}

\footnotetext{
The opinions, findings, and conclusions expressed in this publication are those of the author(s) who are responsible for the facts and accuracy of the data presented herein. The contents do not necessarily reflect the views or policies of the Florida Department of Transportation or the Research and Special Programs Administration. This report does not constitute a standard, specification, or regulation. The report is prepared in cooperation with the State of Florida Department of Transportation and the U. S. Department of Transportation.
} 


\begin{tabular}{|c|c|c|c|c|}
\hline $\begin{array}{l}\text { 1. Report No. } \\
\text { NCTR 527-08; FDOT BD 549-1 }\end{array}$ & \multicolumn{2}{|c|}{ 2. Government Accession No. } & \multicolumn{2}{|l|}{ 3. Recipient's Catalog No. } \\
\hline \multirow{2}{*}{\multicolumn{3}{|c|}{$\begin{array}{l}\text { 4. Title and Subtitle } \\
\text { Assessing Hierarchy of Needs in Levels of Service }\end{array}$}} & \multicolumn{2}{|l|}{$\begin{array}{l}\text { 5. Report Date } \\
\text { October } 2005\end{array}$} \\
\hline & & & \multicolumn{2}{|c|}{ 6. Performing Organization Code } \\
\hline \multicolumn{3}{|c|}{$\begin{array}{l}\text { 7. Author(s) } \\
\text { Perone, Jennifer; Winters, Philip; Read, Melissa; Sankah, Isaac }\end{array}$} & \multicolumn{2}{|c|}{ 8. Performing Organization Report No. } \\
\hline \multirow{2}{*}{\multicolumn{3}{|c|}{$\begin{array}{l}\text { 9. Performing Organization Name and Address } \\
\text { National Center for Transit Research } \\
\text { Center for Urban Transportation Research } \\
\text { University of South Florida } \\
\text { 4202 E. Fowler Ave. CUT } 100 \\
\text { Tampa, FL 33620-5375 }\end{array}$}} & \multicolumn{2}{|l|}{ 10. Work Unit No. (TRAIS) } \\
\hline & & & \multicolumn{2}{|l|}{$\begin{array}{l}\text { 11. Contract or Grant No. } \\
\text { DTRS98-G-00329 }\end{array}$} \\
\hline \multicolumn{3}{|c|}{$\begin{array}{l}\text { 12. Sponsoring Agency Name and Address } \\
\text { Office of Research and Special Programs, U.S. Department of } \\
\text { Transportation, Washington, DC } 20590\end{array}$} & \multicolumn{2}{|c|}{ 13. Type of Report and Period Covered } \\
\hline \multicolumn{3}{|c|}{ Florida DOT, 605 Suwannee, Tallahassee, Florida 32399} & \multicolumn{2}{|c|}{ 14. Sponsoring Agency Code } \\
\hline \multicolumn{5}{|c|}{$\begin{array}{l}\text { 15. Supplementary Notes } \\
\text { Supported by a Grant from the USDOT Research and Special Programs Administration, and the } \\
\text { Florida Department of Transportation. }\end{array}$} \\
\hline \multicolumn{5}{|c|}{$\begin{array}{l}\text { 16. Abstract } \\
\text { The primary focus of this research project was in providing empirical evidence of a Hierarchy of Transportation } \\
\text { Needs. The experimental procedure, methodology, and materials for this project were designed using both } \\
\text { transportation stated preferences studies as well as the work of Alderfer and his Existence, Relatedness, and } \\
\text { Growth (ERG) Theory (1972, 1985). The final product of this research work is the empirical evidence of the ERG } \\
\text { theory in transportation needs. }\end{array}$} \\
\hline \multicolumn{5}{|c|}{$\begin{array}{l}\text { This project was a definitive success in providing evidence for the existence of a Hierarchy of Transportation } \\
\text { Needs. Without a doubt, participants responded to the survey questions in a manner which supports the } \\
\text { existence of a hierarchy in which most participants chose Existence needs over Relatedness needs over Growth } \\
\text { needs. It also demonstrated that a lower motivator need not be substantially satisfied before one can move onto } \\
\text { higher motivators. }\end{array}$} \\
\hline \multicolumn{5}{|c|}{$\begin{array}{l}\text { Overall, these results are a breakthrough in the LOS literature, in that it can be stated that people will make } \\
\text { certain mode choices and transportation choices based upon a psychological need hierarchy. Future research } \\
\text { strategies are suggested to complete the transformation from ERG hierarchy of needs to multi-modal LOS } \\
\text { ranking. }\end{array}$} \\
\hline \multicolumn{2}{|c|}{$\begin{array}{l}\text { 17. Key Word } \\
\text { Level of Service, LOS, Hierarchy of Needs, } \\
\text { Maslow, Alderfer, Attitude, Modeling, Decision- } \\
\text { making, Multi-modal LOS }\end{array}$} & \multicolumn{3}{|c|}{$\begin{array}{l}\text { 18. Distribution Statement } \\
\text { No Restriction } \\
\text { This report is available to the public through the } \\
\text { NTIS, Springfield, VA } 22161\end{array}$} \\
\hline $\begin{array}{l}\text { 19. Security Classif. (of this report) } \\
\text { Unclassified }\end{array}$ & $\begin{array}{r}\text { 20. Security Cla } \\
\text { Uncl }\end{array}$ & $\begin{array}{l}\text { of this page) } \\
\text { ified }\end{array}$ & \begin{tabular}{|c} 
21. No. of Pages \\
129
\end{tabular} & 22. Price \\
\hline
\end{tabular}




\section{Table of Contents}

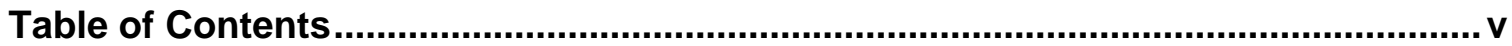

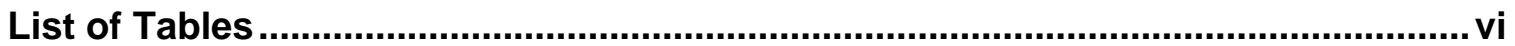

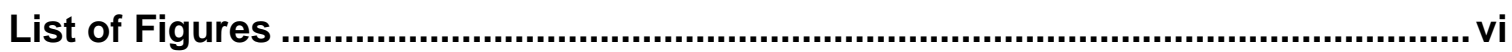

Executive Summary ......................................................................................... vii

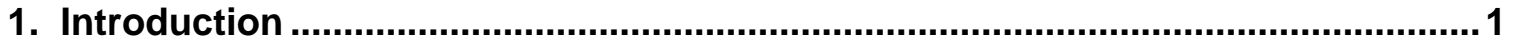

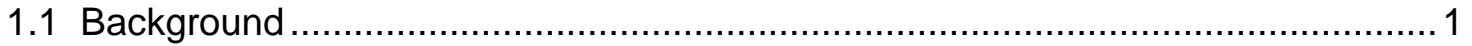

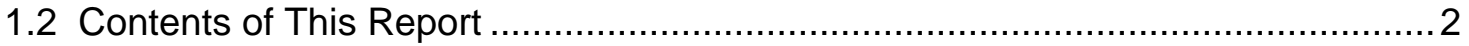

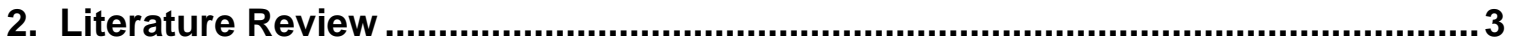

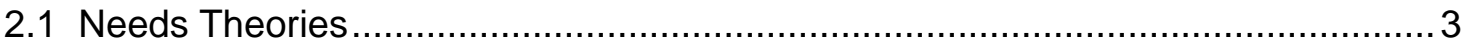

2.1.1 Maslow's Theory of Human Motivation ...................................................

2.1.2 Alderfer's Existence, Relatedness and Growth Theory ................................

2.2 Defining the Characteristics of Both Hierarchy of Needs and LOS for Each Mode. 9

2.3 Psychological Needs and Transportation Choice .............................................. 11

2.4 The Role of Motivational Factors in Mode Choice …........................................ 12

3. Empirical Testing of ERG in Transportation ...............................................15

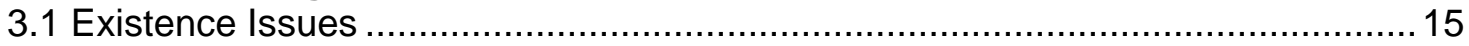

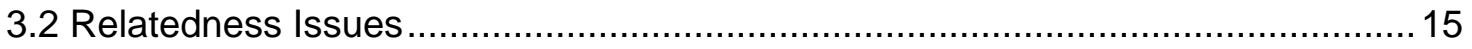

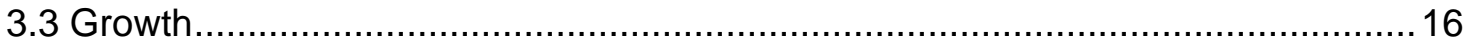

4. Development of the Questionnaire....................................................................17

4.1 Three Levels of Transportation Attributes ………....................................... 17

4.2 Pilot Testing of the Original Questionnaire.................................................. 18

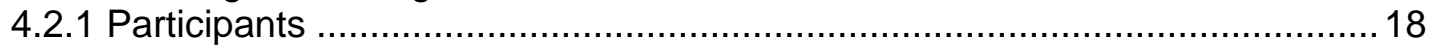

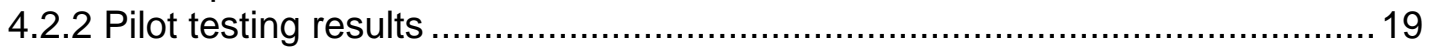

4.2.3 Problematic Relatedness versus Growth Questions: ....................................19

5. Methodology of the Final Questionnaire Administration ...................................23

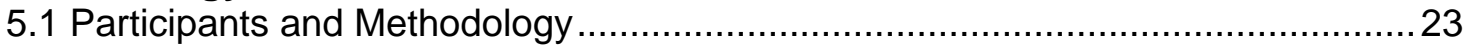

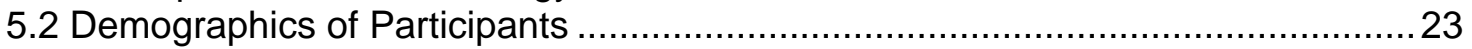

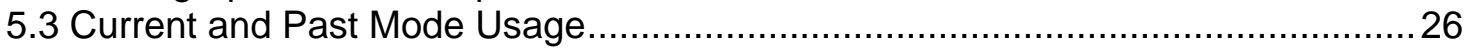

6. Results of the Final Questionnaire Administration ..........................................29

6.1 Overall Rankings of Importance of Existence, Relatedness, and Growth for Each

Set of Comparison Questions ..................................................................... 32

6.1.1 Overall Rankings of Importance of Existence, Relatedness, and Growth for

Existence versus Relatedness Comparison Questions....................................... 33

6.1.2 Overall Rankings of Importance of Existence, Relatedness, and Growth for

Existence versus Growth Comparison Questions ............................................. 34

6.1.3 Overall Rankings of Importance of Existence, Relatedness, and Growth for

Relatedness versus Growth Comparison Questions............................................ 34

6.2 Three Simple ERG Questions (Triad Comparisons) Compared to Categorical

Existence, Relatedness, and Growth Questions (Dyad Comparisons) …………........ 35

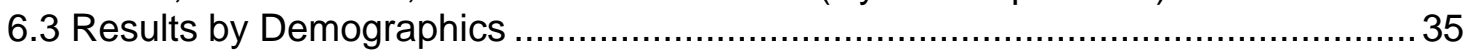

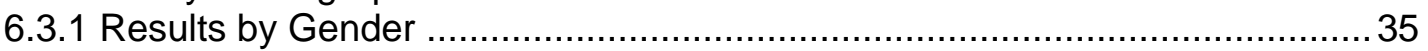

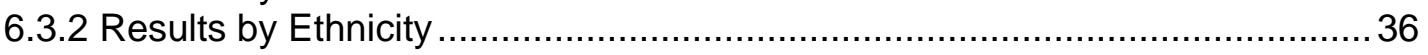

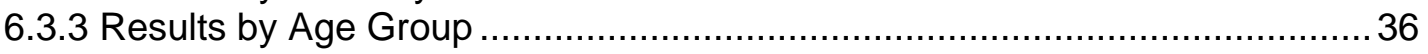

6.3.4 Results by Number of Children under Age 16 Years ..................................37

6.3.5 Results by Employment and Student Status ……....................................3

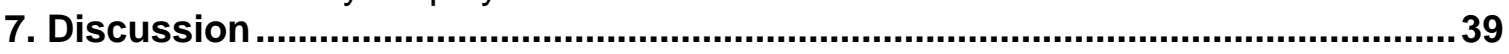

7.1 Discussion of Each Item as a Part of the Hierarchy Theory ..................................39

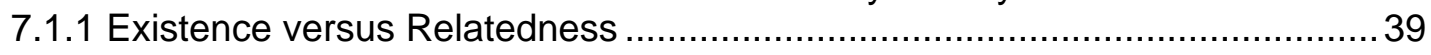




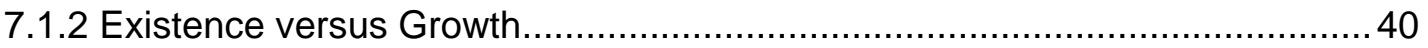

7.1.3 Relatedness versus Growth .............................................................. 41

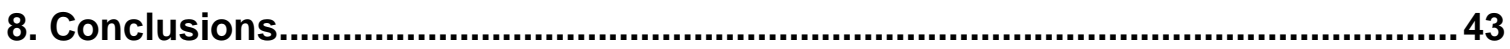

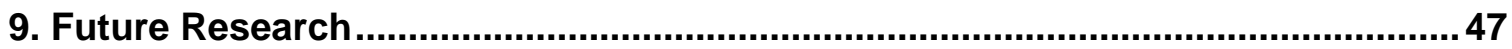

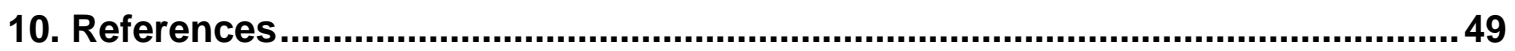

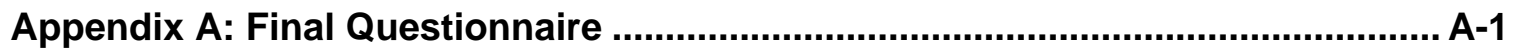

Appendix B: Survey Response Summary ........................................................... B-1

\section{List of Tables}

Table 1. Item Rankings

Table 2. Overall comparison of secondary Existence, Relatedness, and Growth

questions by item type.

Table 3. Gender difference for ratings of $E, R$, and $G$ items for first scenario questions 36

Table 4. Gender differences on Existence Items Overall and by cluster membership.... 36

Table 5. Gender differences on Relatedness Items Overall and by cluster membership36

Table 6. Gender differences on Growth Items Overall and by cluster membership........ 36

Table 7. Ratings of $E, R$, and $G$ (A versus $B$ ) items by employment status ....................37

Table 8 . Ratings of $E, R$, and $G$ (A versus $B$ ) items by employment status ....................37

\section{List of Figures}

Figure 1. Maslow's Hierarchy of Needs ................................................................ 4

Figure 2. Transportation Hierarchy of Needs Source: (Winters et al., 2001) ................... 7

Figure 3. Distribution of Participants by age and gender ......................................... 24

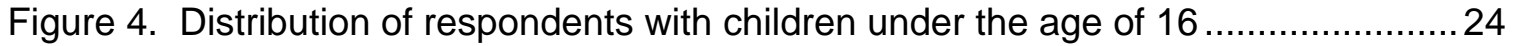

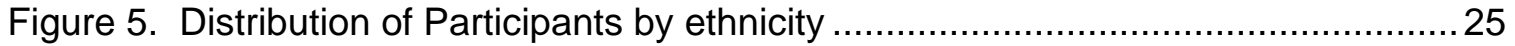

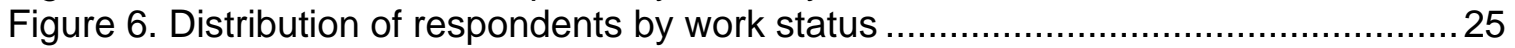

Figure 7. Distribution of respondents by student status ..........................................26

Figure 8. Number of cars available per respondent household ...............................27

Figure 9. Listing of Question RG as an Example for Reading Results .........................33 


\section{Executive Summary}

The primary focus of this research project was in providing empirical evidence of a Hierarchy of Transportation Needs. The experimental procedure, methodology, and materials for this project were designed using both transportation stated preferences studies as well as the work of Alderfer and his Existence, Relatedness, and Growth (ERG) Theory $(1972,1985)$. The final products of this research work are two-fold: the empirical evidence of the ERG theory in transportation needs and the modeling of decision-making in various transportation scenarios.

This project was a definitive success in providing evidence for the existence of a Hierarchy of Transportation Needs. Without a doubt, participants responded to the survey questions in a manner which supports the existence of a hierarchy in which participants chose Existence needs over Relatedness needs over Growth needs. It also demonstrated that a lower motivator need not be substantially satisfied before one can move onto higher motivators.

Overall, these results are a breakthrough in the LOS literature, in that it can be stated that people will make certain mode choices and transportation choices based upon a psychological need hierarchy. Future research strategies are suggested to complete the transformation from ERG hierarchy of needs to multi-modal LOS ranking. 


\section{Introduction}

\subsection{Background}

The primary focus of this research project is to set the stage for the development of an equivalent assessment of Level of Service between modes. For this to occur, it must be empirically shown that a hierarchy of transportation needs, like those found in the hierarchy of needs put forth by humanistic psychologists (Maslow, 1943a, 1943b; Alderfer, 1974), exists. Once it has been proven that there is a hierarchy of transportation needs, with some needs being placed higher into the hierarchy than others, the framework will be in place to model the multi-modal LOS according to needs for all modes.

The importance of this type equivalent type of measurement is discussed in-depth in the predecessor to the current research report Assessing Level of Service Equally Across Modes (Winters, Cleland, Mierzejewski, and Tucker, 2001). It is hard to understand LOS across several modes because each mode assesses LOS differently. And thus, it is difficult for transportation professionals to navigate among measurements and assessments of LOS between modes.

Level of Service (LOS) is a measure that describes the operational conditions within a traffic stream, generally in terms of travel time, speed, freedom to maneuver, traffic interruptions, comfort and convenience $(\mathrm{HCM}, 2000)$. There are currently six letter grades from $A$ to $F$ that describe the LOS of a roadway facility, with " $A$ " indicating the highest standard and "F" representing the worst. In the Florida Department of Transportation's (FDOT) 2002 Quality/Level of Service Handbook, LOS for auto, transit, pedestrian, and bicycle modes are based on a variety of criteria and are not calculated on a comparable scale. Automobile LOS is determined by using average stopped delay for intersections, average speed for arterials, and density for freeway segments. Bicycle LOS is measured by roadway conditions, bicycle facilities, and perceived safety and comfort. Transit LOS measurements are based upon frequency of service and delay compared to single occupancy vehicle (SOV) service; pedestrian LOS is determined in much the same manner as bicycle LOS.

An " $F$ " for Automobile LOS means heavy congestion and slow moving traffic. An "F" for Bicycle LOS means serious personal peril for the bicyclist due to safety concerns or lack of facilities. Current classification methodologies make it impossible to quantify the differences between Automobile, Bicycle, Pedestrian, and Transit LOS. It is important to develop a system that is standard across all modes so that everyone can understand what an "A" means and what an " $F$ " means, regardless of transportation mode.

LOS is largely associated with assessing the capacity of roadways for motor vehicles. Bicycle and pedestrian LOS are based on comfort and safety measurements, and transit LOS measurements are based upon frequency of service and delay compared to single occupancy vehicle (SOV) service. Some stakeholders in the previous study claimed that too much emphasis has been placed upon automobiles and too little emphasis has been placed upon transit, bike, and pedestrian modes. In the Winters et al. (2001) report, it was agreed that it is possible to measure LOS equally across modes, that LOS could be calculated for all modes, and that LOS should be based upon user perception instead of traffic flow or congestion ratings. The positives of pursuing multi-modal LOS systems 
are that it makes it easier to for the general population to understand LOS ratings, provides consistency in ratings, it is more environmentally sensitive and balanced, and it should inform developers of how to design more livable communities.

Many assessments were considered in the Winters et al. (2001) assessment study, such as a weighted slide rule, community-standard-based measurement, sensory options, the Modified Miami Method, and the Icon method. All had both favorable and unfavorable characteristics in assessment of LOS across modes. However, the researchers concluded that the current LOS measurement methods make the roadway facility performance and multimodal tradeoff decisions difficult to measure based upon the current methodology. Therefore, the researchers hypothesized that transportation system users may have a hierarchy of needs common to all modes. This hypothesized hierarchy of needs idea is based upon the humanistic theories of Abraham Maslow (1943). Maslow's hierarchy states that once a person has met his/her most basic, lowerlevel needs, then he/she begins to consider higher level needs. For instance, if a potential transit user feels safer from physical harm on one route versus another, it wouldn't matter if the route that made the person feel less safe was more convenient than the route that made the person feel safer. The transit user will choose the route which makes him/her feel safer.

In what follows, Maslow's hierarchy of needs and Alderfer's Existence, Relatedness and Growth (ERG) Theory were examined. Next, the possibility that needs theories have motivated mode choice in the past was explored within the existing transportation literature. Finally, an experiment was conducted to empirically test if such a hierarchy of transit needs actually exists.

\subsection{Contents of This Report}

This report contains the outcomes and theories based upon humanistic research motivation studies from the past three decades, in particular, those motivation theories put forth by both Maslow (1967) and Alderfer $(1972,1985)$. These theories are usually referred to as Hierarchy of Needs theories in the psychological literature. In particular, Alderfer $(1972,1985)$ defines three levels in his Hierarchy of Needs: Existence, Relatedness, and Growth (ERG). Existence needs are defined by attributes of survival, such as eating and sleeping, as well as safety needs, such as being safe from harm in your every day life. Relatedness needs are defined as self-esteem needs and the need to have fulfilling and enriching relationships with people, as well as being safe from damage to the self-esteem in said relationships and encounters with others. Growth needs are defined as higher level attributes such as the altruistic desire to help the environment by riding a bike and reducing vehicle emissions.

In the first part of the report, the ERG theory by Alderfer $(1972,1985)$ and other motivation theories are examined and applied within a transportation framework. These motivation theories will be used to provide a multi-modal measurement of LOS, so that all modes of transportation can be equivalently measured and understood within the same framework. Then, the methodologies and development of this study are examined and described. The results and conclusions of this study are presented with a discussion of the implications on what applying these motivations to mode choice could mean. Finally, future research ideas are discussed based upon the results of this study. 


\section{Literature Review}

The psychological underpinnings that motivate mode choice have been carefully examined in a variety of research studies (Seethaler and Rose, 2003; Thomas, 2003; Ulleberg, 2004). Thomas (2003) investigated the psychological factors that motivate people to choose to fly with particular airlines. In his review, Thomas asserts that people are more likely to choose particular airlines if these airlines are advertised as giving people a sense of social belonging. Further, in a special issue of Community Transportation published in the Summer of 2004 (Wilson, 2004), Amtrak's usage of MTV to promote feelings social belonging amongst teens and college students, was discussed as an example of a good marketing strategy in attracting new demographic groups. It is suggested by both of the studies that airline and bus advertisements that encourage passengers to use that particular mode to reconnect with family members are most likely to encourage people to use that mode. In these studies, the psychological factor of "social belongingness" motivates mode choice with respect to flying or riding the bus. That is, it has been found that people are attracted to mode choices to reconnect with or to please their family members and also to feel connected with the young, "hip" crowd.

The outcomes of the studies detailed above have revealed that psychology often can serve as an explanation for why riders are motivated to use particular transportation modalities. From this, it reasonable to conclude that psychology also may be used as a predictor to determine which modality a rider will try and adopt in the future. For this reason, the continued examination of psychological factors is critical to transportation research.

In this study, a set of psychological principles that has been relatively unexplored within the domain of transportation research was examined: The humanistic hierarchy of needs theories. Needs theories have been explored relative to motivations behind a variety of topics including, but not limited to the influence of choice on team performance (Peters, 1997), employee productivity (Ajila, 1997) and the development of small countries (Hagerty, 1999). However, needs theories have not been examined with respect to the psychological motivations of mode choice.

\subsection{Needs Theories}

Theorists in the area of psychology have long been interested in the possibility of explaining human motivation for particular behaviors and the motivators of choice. Two such theorists have given this topic a great deal of consideration: Abraham Maslow and Clayton Alderfer. In what follows, the theories developed by both Maslow and Alderfer are detailed. Maslow's theory of human motivation is discussed first and then Alderfer's Existence, Relatedness and Growth Theory is presented as a more modern perspective.

\subsubsection{Maslow's Theory of Human Motivation}

Abraham Maslow proposed that human behavior could be explained by the process of satisfying needs (Maslow, 1943a; Maslow, 1948b). He detailed a hierarchy of specific needs: physiological, safety, belongingness, esteem and self actualization needs (Maslow, 1948a; Maslow, 1955). His hierarchy often has been depicted as a pyramid. The base of this pyramid is comprised of the most basic and primitive needs, physiological and safety needs. Belongingness, esteem and self-actualization needs 
comprise the upper levels of the pyramid. For this reason, basic needs are often referred to as "lower level" needs whereas less basic needs, such as self-actualization and selfesteem, have been referred to as "upper level" needs.

\title{
Maslow's Hierarchy of Needs
}

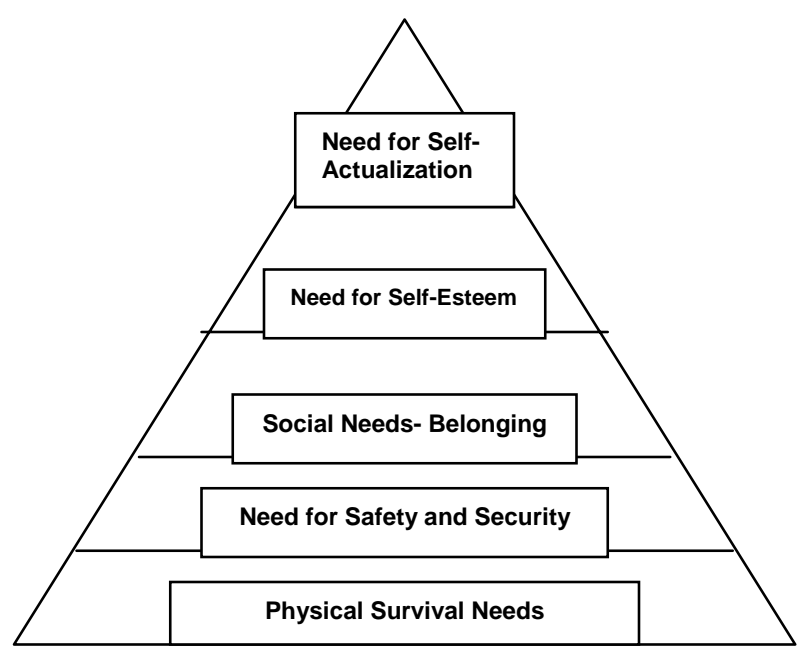

\author{
Challenging projects. Opportunities for \\ innovation and creativity \\ Important projects. Recognition of \\ strength-intelligence. Status. Prestige. \\ Acceptance. Group membership. Love \\ and affection. \\ Physical safety. Economic security. \\ Freedom from threats. Comfort. \\ Water. Food. Sleep. Health
}

Figure 1. Maslow's Hierarchy of Needs

Maslow postulated that humans are motivated to satisfy lower level needs like physiological and safety needs before higher level needs such as belongingness, esteem and self-actualization (Maslow, 1956). Understanding which needs must be satisfied first can help explain human behavior. For example, if a human was both thirsty and lonely this individual would likely seek water before friendship. The behavior could be explained by the idea that physiological needs are the most basic and, therefore, need to be satisfied first. To understand how Maslow's hierarchy of needs can potentially motivate mode choice, one must first come to understand each specific need in detail. In what follows, each of Maslow's needs is explored.

\subsection{1a Physiological Needs}

The lowest level of Maslow's hierarchy is comprised of physiological needs (Maslow, 1954). Physiological needs are biologically motivated and include the need for oxygen, food, water, constant body temperature and sleep (Maslow, 1943b). When our physiological needs are not met, we experience physical discomfort. For example, when a human is deprived of water, he/she experiences the bodily discomfort of thirst. Humans are motivated to alleviate physical discomfort to return to a more pleasant physical state. The thirsty human is motivated to find water and drink. The human's behavior of water-seeking stems from his/her physiological need.

Maslow believed that humans would consider the alleviation of physical discomfort to be a priority amongst all other needs. Humans would not be motivated to satisfy other needs until physiological needs had been met. For example, if the thirsty person in our example also needed the safety of shelter, the search for water would continue to be a priority until the lower level need to quench thirst was satisfied. The need for safety and security would take a back seat to the homeostatic need to maintain hydration. 


\subsection{1b Safety Needs}

Once physiological needs have been satisfied, the next level of the hierarchy is comprised of safety needs. Safety needs help humans achieve stability in the environment by keeping them out of danger (Maslow, 1943b). Humans can experience safety if they are protected from the elements, live in a secure area and live in an environment in which laws and limits are respected. When a thirsty human drinks water, he/she can turn his/her attention toward finding shelter from the elements, thus fulfilling the need for safety.

According to Maslow, if security is threatened, needs that are higher up the pyramid will not receive attention. The person without shelter is expected to engage in a shelterseeking behavior until his/her safety need is satisfied. His/her behavior originates from the basic need for safety. Higher level needs will be attended to only when the need for safety has been resolved. For example, if the person seeking shelter also is in need of friendship, shelter seeking (a lower level need) will continue to be a priority until a shelter is found because friendship would fulfill a higher level need.

\subsection{1c Belongingness Needs.}

If physiological and safety needs are met, humans can focus their attention on higher levels of Maslow's hierarchy. The next level up in the hierarchy of needs is belongingness. Belongingness needs relate to our social interactions (Maslow, 1943b). These can include the sense of loving and being loved, the sense of belonging, the sense of acceptance from others and the sense of not being lonely or alienated from society. When a person is able to find water and shelter, his/her physiological needs are satisfied. If he/she needs a sense of friendship, he/she will be motivated to come out of isolation and spend time with others. This motivation is born out of the need for belongingness.

When people are able to experience belongingness, they can move on to higher level needs. The person who finds the comfort of friends and experiences an emergence from isolation will behave in a way that will help him/her reach higher level needs. These new behaviors that the person exhibits will lead the way to higher level esteem and selfactualization needs.

\subsection{1d Esteem Needs}

According to Maslow, when the more basic physiological, safety, and belongingness needs are fulfilled, humans then experience motivation to fulfill higher level needs (Maslow, 1943b). Esteem needs are the second to highest level of the hierarchy. Esteem needs can be classified into two groups: internal and external.

Internal esteem needs include attaining self respect and achievement. External needs include attaining a high social status, positive recognition, attention, and a good reputation. The person who is able to satisfy thirst, find shelter, and experience friendship from others may be motivated to behave in a way that satisfies needs for esteem. For example, if this person had always wanted to learn how to play the violin, he/she might enroll in music lessons. Enrolling in such lessons will satisfy internal esteem needs because the person may be able to experience the achievement of learning to play an instrument. If a person wanted for others to perceive him/her as an altruistic person, he/she might engage in volunteering behaviors. Volunteering would serve to satisfy an external need because he/she may receive positive recognition and a good reputation by engaging in such behaviors. 
Maslow suggests that once esteem needs are met, humans are motivated to turn their attention to the highest level of the needs hierarchy, self-actualization. Once the person in the previous example has fulfilled his/her needs for internal and external esteem and all other basic needs, he/she may turn his/her attention to very high level needs that have not been met due to the demand of the lower level needs on his behavior.

\subsection{1e Self Actualization Needs}

When all lower level needs are satisfied, humans may experience the highest level need, that of self-actualization. Self-actualization is marked by the desire to realize one's highest potential (Maslow, 1950; Maslow, 1967). People who are motivated to selfactualize seek things like truth, knowledge, peace, wisdom, and justice. Maslow believed that humans could never completely fulfill their self-actualization needs. In addition, he believed that relatively few people ever find themselves in a position to self-actualize because most are working on the fulfillment lower level needs. If the person is able to behave in a way that fulfills all lower level needs, he/she may modify his/her behavior to begin self actualizing. To self-actualize, perhaps this person would study and become an expert. These types of behaviors would bring the person closer to reaching his/her fullest potential.

Maslow's hierarchy of needs has received much attention in the area of psychology. Theorists have analyzed and assessed each need in a variety of settings. It has become clear that Maslow was correct in asserting that some needs could take precedence over others (Alderfer, 1972, 1985). Certainly, the need to satisfy physiological thirst is a much more basic motivator than reaching one's highest potential by engaging in selfactualization. However, what is not clear is whether Maslow's hierarchy motivates behavior in the exact order that Maslow has specified level for level. For example, it is reasonable to question whether humans always behaviorally give preference to thirst, a physiological need, before shelter from the elements, a safety need. Consider a situation in which a tornado is coming towards an individual. This approaching tornado is threatening the individual's safety needs. Consider further, however, that this individual is also thirsty, a threat to a physiological need. The individual would probably seek shelter from the storm to deal with the present danger of a tornado, satisfying a safety need, rather than putting his/her head out in the rain for a drink of water to satisfy his/her more basic physiological need. In this example, the need for safety is given precedence over the need to satisfy physiological thirst. This is not the specific order of behaviors that Maslow proposed.

Maslow asserted that physiological needs would take precedence over needs for safety. Despite this, it seems reasonable to think that behaviors satisfying safety needs would be expressed before those satisfying physiological needs in this project. From this example, it becomes clear that perhaps behavior cannot be specifically predicted from levels of Maslow's hierarchy, particularly when those levels are close to one another in the hierarchy. For levels that are close, like those representing safety and physiological needs, perhaps there really is no predicable precedence for either motivator.

For the above reasons, it has been rather difficult for psychologists to test Maslow's hierarchy empirically. To deal with this dilemma, modern theorists have come up with slight modifications to Maslow's hierarchy. These modifications give Maslow's hierarchy more flexibility for explaining human behavior. One such modern theorist is Clayton Alderfer. 
In the previous study by Winters et al. (2001), a Transportation System User Hierarchy of Needs was postulated, consisting of five levels of needs: safety and security (the most basic needs), time, social acceptance, cost, and comfort and convenience. The traveler's safety and security is considered the most basic need in this particular hierarchy.

Transportation Hierarchy of Needs, based on Maslow

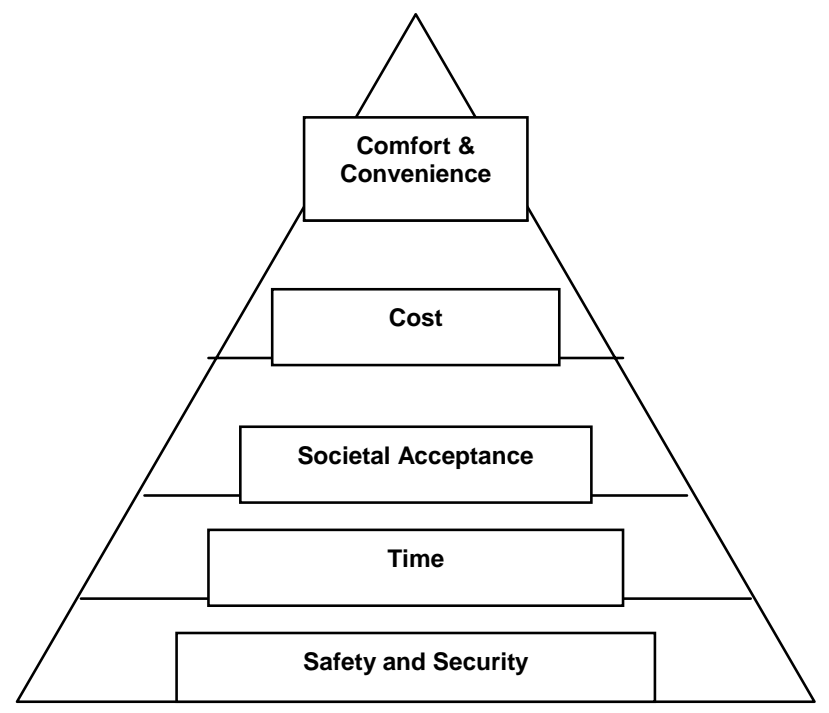

Better travel experience. Comfort. More reliability. Easy access.

Best value. Fixed (vehicle, insurance) and variable (gas, care, tolls, parking).

Acceptance. Personal and peer/society attitudes toward modes (for or against).

Trip efficiency. In-vehicle time. Waiting time. Transfers. Walk time. Trip chaining.

Personal safety. Security for personal property. Familiarity with route, mode and destination.

Figure 2. Transportation Hierarchy of Needs Source: (Winters et al., 2001)

The hierarchy levels suggested in Figure 2 are very similar to the ones in Maslow's hierarchy. However, it is suggested that this hierarchy, modeled after Maslow's (1943a, 1943b), be modified once more to reflect Alderfer's Existence, Relatedness, and Growth (ERG) Theory of Needs. The next section describes Alderfer's ERG theory and how it has been operationalized in an industrial/organizational setting (Alderfer, 1969), whereas Maslow's Hierarchy has not.

\subsubsection{Alderfer's Existence, Relatedness and Growth Theory}

Like many theorists of his time, Clayton Alderfer could see shortcomings in Maslow's hierarchy (Schneider and Alderfer, 1973). Maslow's hierarchy was not easily applied to the real world. As a graduate student, Alderfer searched for a way to make Maslow's hierarchy more useful for empirical research.

To give Maslow's hierarchy more utility, Alderfer modified Maslow's theory and developed a new perspective called the ERG Theory (Alderfer, 1967; Alderfer, 1972; Alderfer, 1985). Alderfer chose to name the theory ERG to represent Existence, Relatedness and Growth. According to Alderfer, the existence, relatedness and growth categories of the ERG Theory were more appropriate than the levels of Maslow's hierarchy to describe human behavior. According to the ERG theory, focusing exclusively on one need at a time will not effectively motivate changes in behavior. Alderfer's theory influenced this study more than Maslow's theory because Alderfer's theory has been empirically tested and provided a framework for empirically testing a 
hierarchy via stated preference, whereas Maslow's did not offer any of these advantages. Maslow's hierarchy, stating that humans will choose physiological needs over safety needs, is not supported by Alderfer's research. For example, a person would not select getting a drink over seeking shelter during a thunderstorm $(1972,1985)$. Additionally, Alderfer had effectively reduced the number of hierarchy levels from five to three, simplifying the structure of any comparisons between hierarchy levels. In what follows, the hierarchy of needs that Alderfer presented are examined in detail.

There are several key differences with Maslow. ERG accounts for differences in need preferences between cultures as the order of needs can be different for different people. As the example above illustrated, Alderfer's theory provides more flexibility that allows for a wider range of observed behaviors. He also acknowledges that if a higher-order need is frustrated, an individual may regress to increase the satisfaction of a lower-order need which appears easier to satisfy.

\subsection{2a Existence}

Alderfer used the term Existence to describe the general human concern with primary material existence requirements. The term Existence is used to encompass Maslow's physiological and safety needs. Alderfer believed that basic existence requirements such as the need for oxygen, food, water, constant body temperature, sleep, protection from the elements, and a secure living area all were needs that existed on the same level. Threats to these types of needs were presumed to be addressed first behaviorally. Already, one can see that Alderfer's description of the needs hierarchy is more flexible than that of Maslow's. Alderfer's hierarchy allows for a situation in which a man would seek shelter from a tornado before finding a glass of water to satisfy his thirst. Both the safety need for shelter and the physiological need for water are in the same existence level, according to Alderfer, so either could motivate behavior first. Once the existence needs are satisfied, Alderfer believed that humans can move on to the next level of his hierarchy, relatedness needs.

\subsection{2b Relatedness}

Alderfer used the term Relatedness to describe the human desire for maintaining interpersonal relationships. The term Relatedness encompasses Maslow's belongingness and esteem needs such as loving and being loved, the sense of belonging, the sense of acceptance from others and the sense of not being lonely or alienated from society. Additionally, relatedness includes attaining self respect, achievement, high social status, positive recognition and a good reputation. Again, it can be seen that Alderfer has created a very general category of needs when compared to Maslow's hierarchy. Here, either belongingness or self esteem needs can take precedence at one time or another. Alderfer believed that humans would be motivated to go on and satisfy higher level needs only when relatedness needs had been satisfied.

\subsection{2c Growth}

Alderfer used the term Growth was used to describe the innate desire for personal development. The term Growth encompassed self actualization. According to Alderfer, Growth is considered to be the highest level need. This would include things like the desire to realize one's highest potential and to seek things like truth, knowledge, peace, wisdom and justice.

As one can see, Alderfer had created a hierarchy, much like Maslow's. The difference between the two was that Alderfer's hierarchy was less specific and therefore more 
flexible. Alderfer found that ERG theory was useful in applied settings, particularly business settings (Alderfer, Kaplan, Smith, 1974). Alderfer's ERG theory would lend itself much more easily to empirical research. And, as specified above, it is easier to test for the existence of three more general versus five more specific hierarchy levels.

\subsection{Defining the Characteristics of Both Hierarchy of Needs and LOS for Each Mode}

The next process in the study involved searching all pertinent LOS literature for each mode and to defining a specific methodology for the calculation of each type of LOS that could be linked to the ERG hierarchy. For each mode, it was important to recognize the important elements of defining LOS. From that point, each of the characteristics which were identified for each mode was placed into a discrete category, either Existence, Relatedness, or Growth.

In the pertinent studies (Landis, Vattikuti, Ottenberg, Petritsch, Guttenplan \& Crider, 2001; Steiner, Landis, Vattikuti, Miller, 2002), it was found that pedestrian LOS could be defined by personal safety, personal security, architectural interest in surroundings, pathway or sidewalk shade, pedestrian scale lighting and amenities, presence of other pedestrians, closeness of buildings and structures to the walk area, and conditions at intersections. Pedestrians actually defined a safe walking environment by the presence of a sidewalk, lateral separation from motor vehicle traffic, barriers and buffers between pedestrians and motor vehicle traffic, motor vehicle volume, motor vehicle travel speed. Researchers found that cyclists defined safety in much the same way as pedestrians (Guttenplan, Landis, Crider, \& McLeod, 2001; Guttenplan, Davis, Steiner, \& Miller, 2003). Cyclists defined LOS by the presence of a bike lane or paved shoulder, their proximity to motorized vehicles, motorized vehicle volume and speed, the percent and number of large or heavy vehicles, pavement condition, and percent of on-street parking. Transit Level of Service (Transit LOS) key factors include service frequency, span of service (i.e., how many hours of the day that service is provided), pedestrian crossing difficulty, obstacles to transit stops, and sidewalk connection to transit stop (Guttenplan et al., 2001; Guttenplan et al., 2003). Further, Guttenplan et al. (2003) have suggested an area wide methodology for determining Multimodal LOS:

1. Define major modal facilities;

2. Establish service areas by mode;

3. Determine percentage of households and employment within the user service area by modal facility;

4. Determine the LOS for each mode on each facility;

5. Determine length-weighted average LOS for each of the modes;

6. Compare average modal LOS with the percentage of households and employment located within the user service area;

7. Report the adjusted area wide LOS for each mode.

Some transit systems include exclusive Right Of Way (ROW) facilities, such as Bus Rapid Transit (BRT) or light rail. Both of these types of transit systems have simple route structure, frequent service, less frequent stops, level boarding and alighting, colorcoded vehicles and stations/stops, ROW signal priority, exclusive lanes, modern vehicle interiors, high-capacity vehicles, multiple door boarding and alighting, off-vehicle fare payment, Intelligent Transportation Systems (ITS)/Advanced Public Transportation 
Systems (APTS) on vehicles and at stations, and coordinated land use planning (Baltes, 2003).

Further, researchers have defined certain multimodal characteristics that make travelers feel safer in their environment. The first of these is the feeling of ownership; an environment that appears that it belongs to someone and is well-maintained feels safer than one which appears abandoned. In addition, facilities should appear to support transit stops, bike facilities, and pedestrian facilities, as well as accommodating personal vehicle travel. For example, a transit hub should be designed in the middle of a busy, well-populated area, such as a mall. That is, land use and function must be complementary. All transit stops, bicycle facilities and pedestrian facilities should have good visibility, to both users and observers, with a lack of hedges and foliage that would obscure views. All multimodal facilities should support mobility, the freedom of movement to avoid unsafe or threatening situations. Transit stops should not be walled in against an alley or contain any elements which prohibit freedom of movement. Finally, facility users need to know where they are going and need to have facilities with easy readability. Transit facilities should be color coded and well marked. Bike lanes and pedestrian facilities should be set apart from motor vehicle facilities and there should be an obvious separation between the two. Construction zones on highways should have very easy readability in marking the new "under construction" path through cones and barriers (Vogel \& Pettinari, 2002).

In line with the position of Alderfer (1972, 1985), safety issues were listed most frequently by travelers, whether they use their car, transit, walk, or bicycle to their destinations. However, it is also important to ascertain other qualities which travelers might find important in a multi-modal environment and to place them into their proper position on the ERG hierarchy. Previous customer satisfaction surveys that were conducted by the Center for Urban Transportation Research reinforce these conclusions (Cleland \& Thompson, 2001; Baltes, 2003; Tucker \& Perone, 2003). A composite of the result of these transit surveys shows that customers were most concerned about the following areas:

- Safety walking/biking to the bus/waiting for the bus/riding the bus/walking from the bus stop.

- Concerns about other passengers

- Concerns about being able to use the system easily and efficiently

- Concerns about crime around bus stops

- Personal image concerns.

- Terrorism concerns

- General safety concerns

- Weather

- Wait and travel times

- Unsafe distances between transit stop and roadway.

- Availability of seats on bus/comfort

- Dependability, reliability of buses.

- Travel time on buses

- Hours, frequency, and span of transit service.

- Availability of information/maps.

- Convenience of routes.

- Cost of riding transit. 
In those same surveys, participants made the following suggestions for improving security as well as bus service in general:

- Increase marketing and improve public relations;

- Separate and safer pedestrian and bicycle facilities;

- Special event/cultural center transportation;

- Increase availability of route and schedule information;

- Feeder services;

- Increase frequency of service;

- Improve lighting at bus stops;

- Security cameras on buses;

- Security personnel on buses; and,

- Increase police presence/monitoring of bus stops

As can be seen from the previous lists and discussion, most of the travel needs revolve around safety issues, with a few higher order needs thrown in. From this literature review, it could be concluded that safety and security issues are probably the most important and pervasive of all the needs in transportation. They are the bottom rung of the transportation hierarchy and will comprise the Existence needs rung of the ERG hierarchy which will be tested in this research. Relatedness is the next highest rung on Alderfer's ERG ladder and deals with the sense of belonging and needs like loving and being loved, the sense of belonging. According to Alderfer (1969), the term Relatedness encompasses Maslow's belongingness and esteem needs. Relatedness includes belongingness needs such as loving and being loved, the sense of belonging, the sense of acceptance from others and the sense of not being lonely or alienated from society. So, Relatedness in the hierarchy would include things like personal image concerns, worrying if those who are significant in your life approve of your choices, wondering if you fit into and with the people in the various environments encountered in your day to day life.

Relatedness needs will be discussed in the next section as a part of what motivates people to use certain modes in their commutes. The following section will first introduce principles of persuasion in transit as conceptualized by Seethaler and Rose (2003) and then there will be a discussion of the Theory of Planned behavior and how it affects behavior on the middle rung of Alderfer's ERG hierarchy.

\subsection{Psychological Needs and Transportation Choice}

The purpose of the literature review of both Needs Theories and LOS was to shed light on how characteristics of roadways and other facilities are both graded and perceived. It is important to understand that every characteristic of a roadway, bike, transit, or pedestrian facility is linked in some way to needs that travelers have. Currently, Levels of Service of roadways for motor vehicle use are calculated using a percentage of capacity versus congestion, not necessarily safety or security issues. This was one of the problems in trying to compare roadways to other mode facilities, that all of the other mode facilities' LOS grades were linked more to safety and security than using one's own personal vehicle (Winters et al., 2001). People traveling in single occupancy vehicles (SOVs) seem to feel less vulnerable to a myriad of troubles that they may experience using all other transportation modes. Therefore, it seems that it is not the 
transit, pedestrian, or bicycle LOS that needs to be converted to reflect "needs theories" as auto LOS. Researchers have begun to examine the psychological motivations of transit choice. In review of these studies, it has become clear that need theories can already explain transit choice. For example, Seethaler and Rose (2003) highlighted six psychological principles of persuasion that relate to travel behavior and change. These principles, including reciprocation, commitment or consistency, social proof, liking, authority and scarcity, seem to fit well with the theories of Abraham Maslow and Clayton Alderfer.

In review of research by Seethaler and Rose (2003), it becomes clear that the principles of persuasion used to describe mode choice may have origins that are explained by needs theories. What would be most interesting is information on which of these persuasion principles is most effective in changing transit behavior. It seems likely that those principles which originate from lower level needs, scarcity for example (that is presumed to originate from existence /physiological needs), would have a greater effect on changing transit behavior than those that originate from needs higher up on the hierarchy like the commitment-consistency mechanism (that is presumed to originate from relatedness/belongingness and relatedness/esteem needs). Unfortunately, Seethaler and Rose did not address these issues.

The application of needs theory does not only extend to transit and psychology studies. It extends to non-psychological work as well. For example, Landis, Vattikuti, \& Brannick (1997) developed a statistically calibrated model of bicyclist LOS. These researchers found that pavement-surface conditions and striping of bicycle lanes correlate with the ranking of bicycle LOS. When striping is taken away from bicycle lanes, perhaps some drivers do not recognize these lanes as bicycle lanes. In the reported study, lanes that had a stripe had LOS scores that were up to $40 \%$ higher than those that did not. When pavement-surface conditions are poor, perhaps cyclists felt more prone to having crashes.

How can these results be further interpreted within the context of needs theory? Perhaps these results indicate that LOS ratings are determined in part by whether various needs are threatened. Perhaps changes to bike lanes that threaten personal safety, for example, would result in very poor LOS scores by cyclists. Conversely, perhaps changes to bike lanes that threaten self esteem and self actualization needs would not elicit such poor LOS scores. These factors seem to have origins that can be explained by needs theory.

\subsection{The Role of Motivational Factors in Mode Choice}

While the principles of persuasion have not yet been tested empirically in transit, the Theory of Planned Behavior (TPB) has been tested extensively for transit mode choice (Bamberg \& Schmidt, 1998, 2003; Bamberg, Rolle, \& Weber, 2003). TPB (Ajzen, 1991) stipulates that when people are confronted with the need to decide a course of action, they consider all likely consequences of available alternatives (behavioral beliefs), weigh the normative expectations of important reference individuals or groups (normative beliefs), and then consider required resources and potential obstacles (control beliefs) in fulfilling their course of action (Bamberg \& Schmidt, 2003). These considerations result in the formation of attitudes toward the behavior of interest (behavioral beliefs), subjective norms with respect to the behavior (normative beliefs), and perceived 
behavioral control (control beliefs). TPB assumes that people form behavioral intentions based on their own attitudes, subjective norms, and perceptions of behavioral control. TPB assumes that when an individual is confronted with a choice between two behavioral alternatives, the individual will select the alternative associated with the most positive behavioral consequences.

The study by Bamberg \& Schmidt (2003) had 608 students complete a commute diary for 8 working days. Subjects were assessed on various key components of TPB, such as behavioral beliefs, normative beliefs, and control beliefs. For example, questions such as "When I use the car/transit/bicycle for university routes next time, most people who are important to me would support this," and "Using the car for university routes next time would be (easy/difficult) for me," respectively, to assess normative and control beliefs. In their study, the relationships between attitude, subjective norm, and perceived behavioral control explain 60 percent of the variance in intention to use a certain transportation mode.

TPB and the six principles of persuasion also address the role that habit plays in mode choice. Most people have a certain habit of mode choice and only when there is a change of environment, when goals change, or when new goals are adopted is there the chance to change habits. In the face of changed employment status or changed residence, for example, people would be more amenable to changing modes (Bamberg, Rolle \& Weber, 2003). In their study in which they offered a free transit pass to people who were moving to a different community, they found that attitude, subjective norm, and perceived behavioral control accounted for 67 percent of variance in intention to perform the behavior. They also found that TPB accurately predicted intentions to use public transit and the actual use of public transit. 


\section{Empirical Testing of ERG in Transportation}

\subsection{Existence Issues}

There are three levels of elements in any transportation mode. The first level deals with existence issues, such those related to safety and security, as well as wait time and comfort. These needs address such issues as worry about going out at night, waiting for the train at night or in a vacant area, driving alone at night or in a deserted area, being the victim of a crime while accessing transit, having shelter from the elements, having proper shelter from the elements, being able to sit while waiting, having good lighting and line of sight in the transit stop area, multimodal safety of intersections and areas, etcetera. Ease of way finding and ease of use of transit system or bike facilities or pedestrian facilities will also be included in this particular rung. When we feel lost or unsure of how to proceed, it causes fear and uncertainty and certainly discomfort (Winters et al., 2001).

Wait time is also included into this particular rung of the hierarchy because wait time on transit is when people feel most vulnerable to crime. The actual travel time on the transit vehicle is the shortest perceived time for any transit trip ( $\mathrm{Li}, 2003)$. Transfer times are somewhere in between wait time and transit vehicle travel time. Also, people are more averse to losing time than to losing money in their commute (Leclerc, Schmitt, \& Dube, 1995), so a high value is attached to a stable commute travel time.

The main reason that auto travel is so attractive is that while using it, people to attend to more nontemporal cues than when people are using public transit. People using public transit are made aware of temporal cues via wait time and the importance of making their transfers on time. However, walking, as well as cycling causes people to attend to nontemporal cues as well, such as keeping their balance, posture, maintaining their vehicle or body position, and watching the roadway environment for their own personal survival needs (Li, 2003).

\subsection{Relatedness Issues}

The second rung of the ERG hierarchy is Relatedness needs. This level encompasses belongingness needs like loving and being loved, the sense of belonging, the sense of acceptance from others and the sense of not being lonely or alienated from society. Additionally, Relatedness includes attaining self respect, achievement, high social status, positive recognition and a good reputation. Some of the principles of persuasion fit in under this particular rung, such as reciprocity, consistency, social proof, authority, and liking. Scarcity seems to be more of a lower level need. In the TPB studies by Bamberg and Colleagues (Bamberg \& Schmidt, 1998, 2003; Bamberg, Rolle, \& Weber, 2003), it was found that if people thought that their mode choice would be accepted and approved by others important to them that they had more of an intention to perform the behavior. That is, if they had the normative belief that this was an acceptable mode choice to make, they would be more likely to use that particular mode. Further, if the mode choice is accepted by others, it will heighten the esteem and respect that the person has for him/herself, especially if the mode is recommended by an authority figure. 
In U.S. culture, except in major cities with large public transit systems, the car is the most acceptable mode. In fact, in the studies listed above, many respondents said that they would worry about their personal image if they were seen using transit or walking or riding their bike as opposed to driving an automobile (Tucker \& Perone, 2003). Therefore, only if the desired peer group accepted a certain mode, would it increase the likelihood that a person would take an alternative mode. Also, if the person felt that he or she belonged in a particular transportation mode, would the person be encouraged to use that mode. Otherwise, the person would probably feel that there were too many obstacles to overcome in order to use the alternative mode (Bamberg \& Schmidt, 2003).

\subsection{Growth}

The final rung of the transportation hierarchy is Growth. As discussed previously, the term Growth was used to describe the innate desire for personal development. The term Growth encompassed self actualization. According to Alderfer, Growth is considered to be the highest level need. This would include things like the desire to realize ones highest potential and to seek things like truth, knowledge, peace, wisdom and justice. We will also include such characteristics as cost and convenience into this rung. Cost is included in this rung because it consistently rated in various satisfaction surveys as being less important than issues such as safety, security, and comfort (Cleland and Thompson, 2001; Tucker and Perone, 2003). Environmental concern is also included in this particular rung. People might choose to use alternative modes such as transit or biking or walking in order to protect the environment. 


\section{Development of the Questionnaire}

This particular area of study is somewhat new in transportation studies. Therefore, a new methodology had to be developed in order to test the hypothesis that there is a transportation hierarchy of needs. The development process started with the development and definition of transportation attributes to fit Maslow's Hierarchy of Needs for each mode of transportation. As an example, if a person were defining each level of the hierarchy for transit, then the first level, physical survival needs, would have been food/water depletion while riding and accessing transit and the second level, need for safety and security, would be defined by safety and security while traveling to and on transit. The third level, social belongingness, would be defined by the presence/absence of peers or adverse parties while traveling to and on transit. The fourth level, selfesteem, was defined as the state of social status, prestige, intelligence, and personal strength that one would feel while using a transit system. As an example of the fourth level of Maslow's hierarchy, it could be said that a young person who does not have a driver's license yet might feel more self-esteem, strength, intelligence, and independence versus a middle-aged person who cannot use his/her driver's license due to financial or legal constraints. Finally, the highest level of Maslow's hierarchy is considered to be self-actualization. In this case, the attributes of using transit that would be positive and self-actualizing could be that the person feels a responsibility to use transit in order to preserve the environment, to reduce congestion, to feel that you have a higher and more altruistic reason for using transit.

As described in the previous paragraphs, however, Maslow's hierarchy of needs has never been empirically tested. And, this is a shortcoming that had to be addressed in the design of this particular study. In searching for options, several studies by Alderfer (1972, 1985), which had operationalized the ERG hierarchy were identified and the current study was modeled after these. These modifications of methodology and testing were a welcome introduction into the study because Alderfer's studies proved simpler than Maslow's Hierarchy and also addressed the shortcomings of Maslow's theory. In light of the Alderfer studies $(1972,1985)$, it was decided that whatever the methodology used, it should use the ERG theory to test the existence of a hierarchy of needs in transportation. Additionally, the study by Seethaler and Rose (2003) about principles of social persuasion, along with the Alderfer (1985) study, and various other stated preference studies, helped to produce the idea of an on-line stated preference survey. A stated preference survey was produced with the following testing dyads: existence versus relatedness; existence versus growth; and relatedness versus growth. In producing the situations for the survey, we utilized the original Hierarchy of Needs attributes produced with the Maslow hierarchy design and simply placed each of the attributes into three categories instead of five.

\subsection{Three Levels of Transportation Attributes}

As described earlier, the first level of Alderfer's (1972) ERG theory is Existence. Existence covers the first two levels of Maslow's Hierarchy of Needs: Physiological Needs and Safety and Security Needs. In terms of transportation needs, the researchers in this study defined six basic areas which were culled from a literature review of on-board and telephone surveys for several different transit systems as to primary and secondary preferences (Cleland \& Thompson, 2001; Winters et al., 2001; 
Baltes, 2003; Perone \& Tucker, 2003). The following six categories were placed into the Existence level of transportation needs, according to the literature review:

- Concern about victimization during travel

- Being able to have comfortable accommodations./shelter from the elements

- Relative safety of roadway and facilities by mode

- Ease of way finding/navigation in the system

- Ease of use of transit system, bike facilities, pedestrian facilities, or roadway

The next rung of Alderfer's hierarchy is Relatedness. Relatedness covers both relationships and self-esteem in Maslow's hierarchy. Relatedness was categorized into the following from the literature review:

- Reciprocity, consistency, social proof, authority, and liking

- If mode choice is accepted by important others

- Belongingness while using a certain transportation mode (Seethaler \& Rose, 2003).

The final rung of Alderfer's hierarchy is Growth and covers Maslow's self-actualization. The attributes found in the Growth category are luxury amenities and altruistic behaviors involving transportation:

- Aesthetic amenities

- Cost

- Convenience

- More altruistic reasons for using a certain mode

- Promoting alternative modes to help social justice

From these categories, the dyadic situations comparing Existence, Relatedness, and Growth were constructed. The first questionnaire consisted of more general situations and through internal focus groups at CUTR, it was decided that the situations should be more realistic in order to present more believable situations to participants. The main point of the questionnaire and the methodology was to cause participants to imagine themselves in the situations presented in the questionnaire, through imagery and attitudinal manipulations. The questionnaire was modified according to the results of the pilot testing as well as the internal focus groups. The next section will explain how the pilot testing of the original survey influenced the final configuration of the questionnaire.

\subsection{Pilot Testing of the Original Questionnaire}

The original questionnaire was based upon the Existence/Relatedness, Relatedness/Growth, and Existence/Growth comparison dyads. In discussing the pilot results, all questions and expected theoretical answers, as well as aggregate results will be covered, so that the reader will have an understanding and appreciation of the evolution of this project.

\subsubsection{Participants}

The original questionnaire was pilot tested on 10 people who were either CUTR faculty, students, or staff members. Being that the purpose of the pilot testing was to test the content of the questionnaire; no demographic data was collected for the pilot testing. 


\subsubsection{Pilot testing results}

Most of the Existence versus Relatedness and Existence versus Growth results confirmed the ERG theory. However, there were many problematic questions in the Relatedness versus Growth comparison results. These results resulted in researchers taking a hard look at those questions which defied the ERG theory for the possible problems with those questions. These six questions comparing relatedness and growth were closely examined and rewritten for the final questionnaire. Those six questions are as follows:

\subsubsection{Problematic Relatedness versus Growth Questions:}

1. You take a bus into work every day. You have a choice of two bus routes.

A: This route is not perceived by your friends as the one that classy people in the town most often use. However, this route is interesting and beautiful because it passes by some very scenic neighborhoods.

B: This route is perceived by your friends as the one that classy people in the town most often use. However, this route is along the backside of row housing and not all that interesting or beautiful.

2. You want to ride a train visit your family. You have a choice of two trains to ride.

A: Your family would prefer that you not take this train. However, tickets to ride this train are a great price.

B: Your family would prefer that you take this train. However, tickets to ride this train are very expensive.

4. You would like to take a series of buses to get to a special weekend event taking place in a town that you have not visited before. You have a choice between two bus lines.

A: You usually like the mix of people on this bus and feel that you fit in. However, you will have to switch buses twice in order to reach your destination.

B: You usually don't like the mix of people on this bus and feel that you do not fit in. However, you will have to switch buses only once to reach your destination.

7. You would like to ride a bike on a $\mathbf{1 0 0}$ mile path. You have a choice between two bikes.

A. This bike was made for two people. You can pick up your friend and you will not have to ride the path alone. However, this bike has expensive upkeep costs.

B. This bike was made for one person. You cannot pick up your friend and you will have to ride the path alone. However, this bike is very inexpensive to maintain.

8. You would like to ride a car to the mall. The mall is $\mathbf{1 0}$ miles from your house and it is about to storm.

A. This car has great gas mileage and you will not have to pay much to fill up the tank. However, many people are not impressed by this car.

B. This car has terrible gas mileage and it is going to cost a fortune for you to fill up the tank. However, many people are impressed by this car.

9. You would like to walk to the store. You have two paths to choose from.

A. This path would not allow you to walk in front of places where your friends work and you could not say hello. However, this path would allow you to see beautiful trees and birds. This path is far more beautiful. 
B. This path would allow you to walk in front of places where your friends work and you could say hello. However, this path would not allow you to see beautiful trees and birds. This path is far less beautiful.

Due to the pilot results from the above questions, it was decided that the situations had to be more realistic and less generic. For instance, in question 2 of the Relatedness versus Growth set, the participants don't know why their parents prefer one train over the other. All that they know is that they can save money by not choosing the option that the parents want. It was important to define why and also to make the situations highly relatable. And, based upon feedback from our 10 pilot participants, many of the situations did not make sense to them and therefore, they could not imagine themselves in those situations. All of the loose ends of every one of the questions had to be tied up for the final version of the questionnaire. The participants could not be left to wonder about any anomaly in the survey items. In addition, many pilot and focus group participants claimed that it was very hard to imagine themselves within the simple written passages and that pictures should also be added to help participants to imagine themselves in each particular situation.

In many instances on the pilot questionnaire, the Relatedness versus Growth section results were the exact opposite of what was expected from the ERG theory. In order to redesign the questionnaire, data was collected on the 'hows' and 'whys' of the answers. Data on these issues was collected from both pilot participants and focus group participants. The focus groups consisted of several CUTR faculty members who had been asked to take the original pilot test and to comment upon the content and structure of the questionnaires. The overwhelming majority of the comments from both focus groups and pilot participants indicated that the item situations were too bland or generic, as one pilot participant put it, "too vanilla." Based upon these data, the researchers set to reconstructing the questions on the same structure of the original item, but with more believable details.

Overall for the results of the pilot, the mean ratings split for each of the pilot items was significantly different for six of the Existence versus Relatedness questions, five of the Existence versus Growth questions, and four of the Relatedness versus Growth questions. It is important to note that all the Relatedness versus Growth (RG) items with significant differences have a mean differential that is in the opposite direction than would be expected by ERG theory. That is, the "RG" means were significantly higher on the Growth activation choice than the Relatedness activation choice. However, each of the choice splits match the overall mean of each choice's rating in that when less people chose a certain situation option, it also had the lower mean.

All of these issues were weighed and assessed in the development of the final questionnaire. In this study, it was important to ensure that participants would be able to relate to the questions and to place themselves into the position of protagonist in each item. To achieve this goal, a great deal of research was put into developing believable situations.

In the first Existence versus Relatedness comparison question, there is a passage about terrorists. The focus group said that they could not relate to terrorist situations on buses, even though America has been attacked by terrorists. In Israel, it is commonplace for terrorists to attack mass transportation, such as buses, as well as common gathering places in the cities. In the United States, we haven't quite felt the sting of terrorism as an 
every day event. For the next incarnation of the questionnaire, each of the questions was analyzed for how they could be made more believable and more relatable. For example, in question "ER1" a scenario about terrorists and a bus and classy versus nonclassy neighborhoods was presented. However, in focus groups, participants took issue with the use of the word classy. The participants felt that the word classy was very subjective and it should be replaced with another word or situation that was more quantifiable and/or universally understood. In the next reincarnation of item ER1, an actual scenario about the PATH line, a transit line that runs between New Jersey and Lower Manhattan replaced the generic, city-less bus line and pressure to help a spouse replaced the peer pressure from the friend to be classy. Data on the believability of each situation was not collected in the original pilot data. However, it was important to know how believable the participants found each situation of the final questionnaire and if this affected their choice of $A$ or $B$ in the situation and their ranking of $A$ and $B$. 


\section{Methodology of the Final Questionnaire Administration}

\subsection{Participants and Methodology}

The participants in this survey were 138 persons recruited from 1) a psychology course at Armstrong-Atlantic State University in Savannah, Georgia; 2) a local church; and 3) people who responded to a request on the University of South Florida Talk Listserv. The respondents were instructed to access a specific website and then to choose the number 1,2 , or 3 . This choosing allowed a random assignment of each of the participants to each of the three groups. There were three different versions and the order of the Existence versus Relatedness (ER), Existence versus Growth (EG), and Relatedness versus Growth (RG) types of questions were ordered in such a way so that fatigue effects and order effects could be controlled. That is, in one version of the test, everything was in straight order, just interspersed. In another version, the questions went from the "ER10" to "ER1", with "EG10" to "EG1" and "RG10" to "RG1" interspersed with them, so that the last questions were first in this version. And, finally, in the third version of the ordering, the questions were ordered from the middle out.

Participants were presented with a certain scenario and asked which situation they would choose. The second part of the question was rank Existence, Relatedness, and Growth variables written to apply to that scenario. The first portion of the item will be called the "Dyad comparison" portion and the second portion of the item will be called the "Triad comparison" portion. These names are given to avoid confusion over the two ranked portions of each item.

After choosing version 1, 2, or 3 of the questionnaire, the participants were instructed to answer all of the specified questions by choosing the appropriate radio button for that item. There were 30 items on the questionnaire and it is listed in its entirety in Appendix $A$ at the end of this report. As discussed above, there were three separate versions of the questionnaire, each with a different order to the questions. In an analysis of results for all 30 items, there is no significant difference when comparing the means of the items for each different version. This means that the version of test did not influence how people answered the questions and it also means that order effects and fatigue effects are not a confounding variable in this study. When the participant had answered all 30 questions, they were instructed to click the "Submit" button at the bottom of the page. This action sent the final answers of each questionnaire to a database for further analysis.

\subsection{Demographics of Participants}

Figure 9 gives the distribution of participants by age and gender. As seen in Figure 9 , the majority of participants were in the 18-24 and 25-34 age groups. Forty-two percent of the participants were male and 58 percent were female. The majority of respondents do not have children under the age of 16 years living at home. In addition, the majority of respondents are white. Almost one-fourth of respondents were Black and another 10 percent were Hispanic. Approximately 40 percent of respondents work full-time, with another 35 percent who work part-time and approximately one-fourth who do not work at all. More than 60 percent of the respondents were full-time students and another 15 percent said that they were part-time students. 


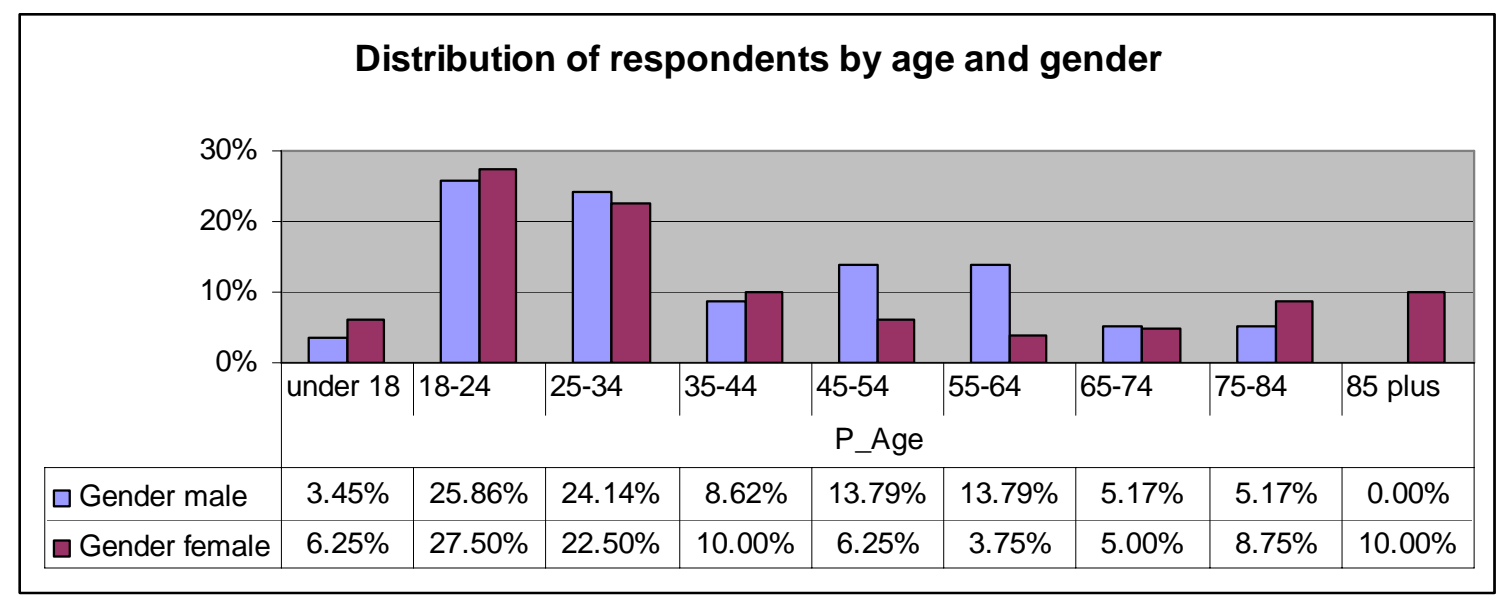

Figure 3. Distribution of Participants by age and gender

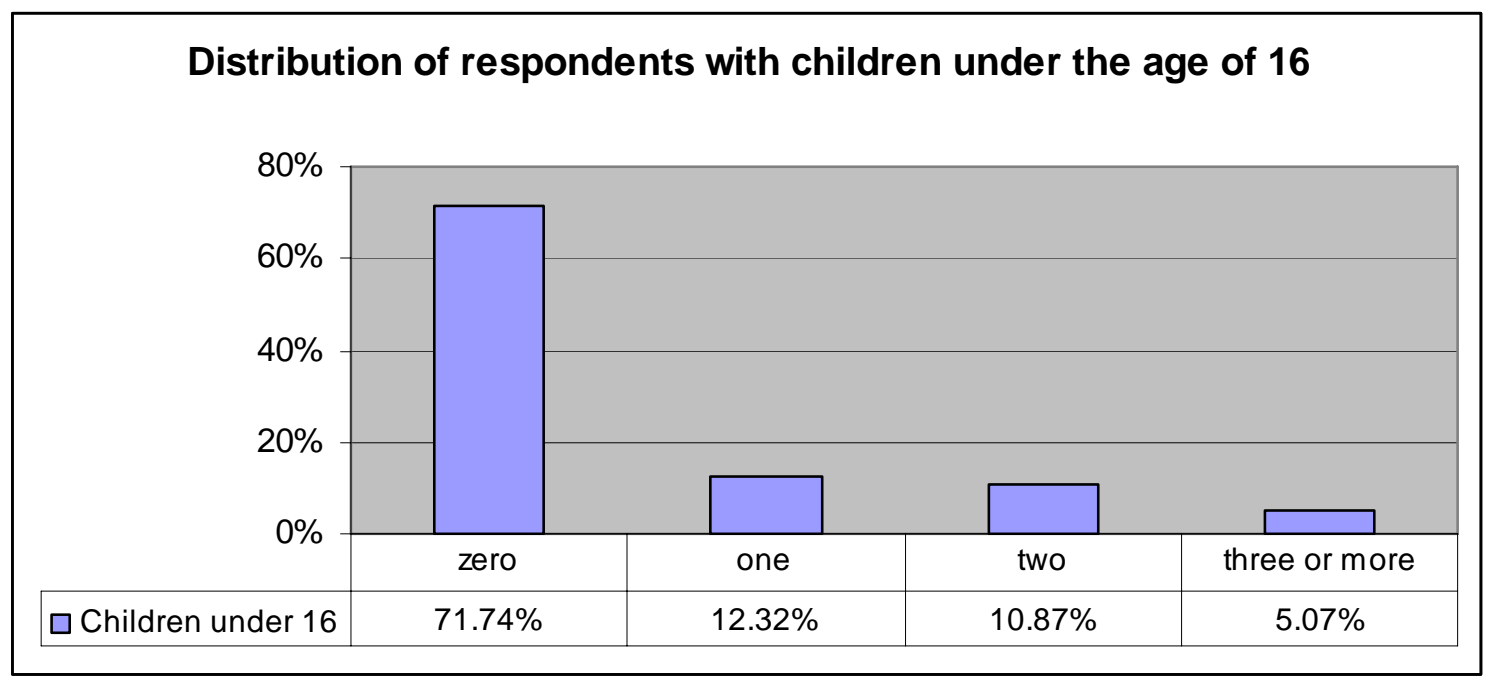

Figure 4. Distribution of respondents with children under the age of 16 


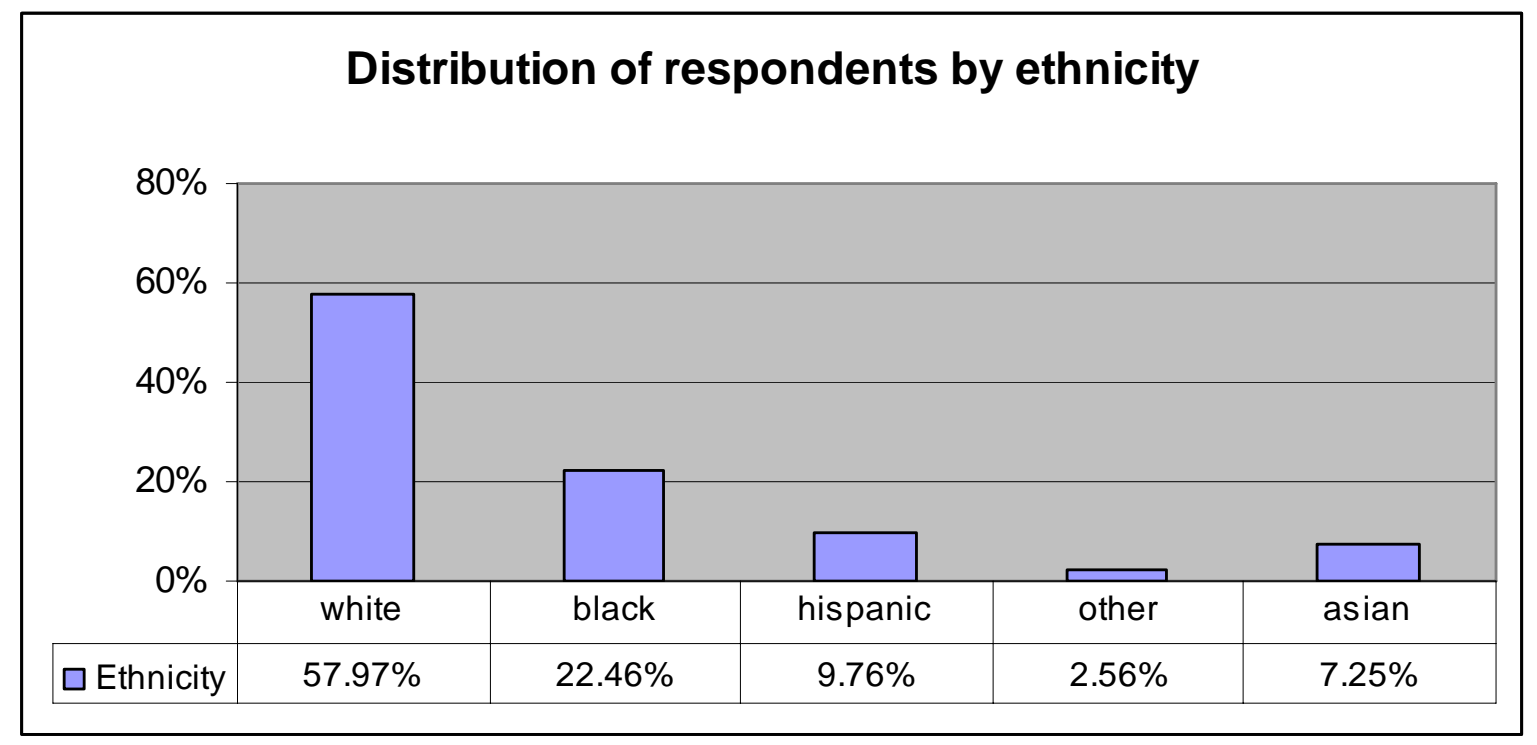

Figure 5. Distribution of Participants by ethnicity

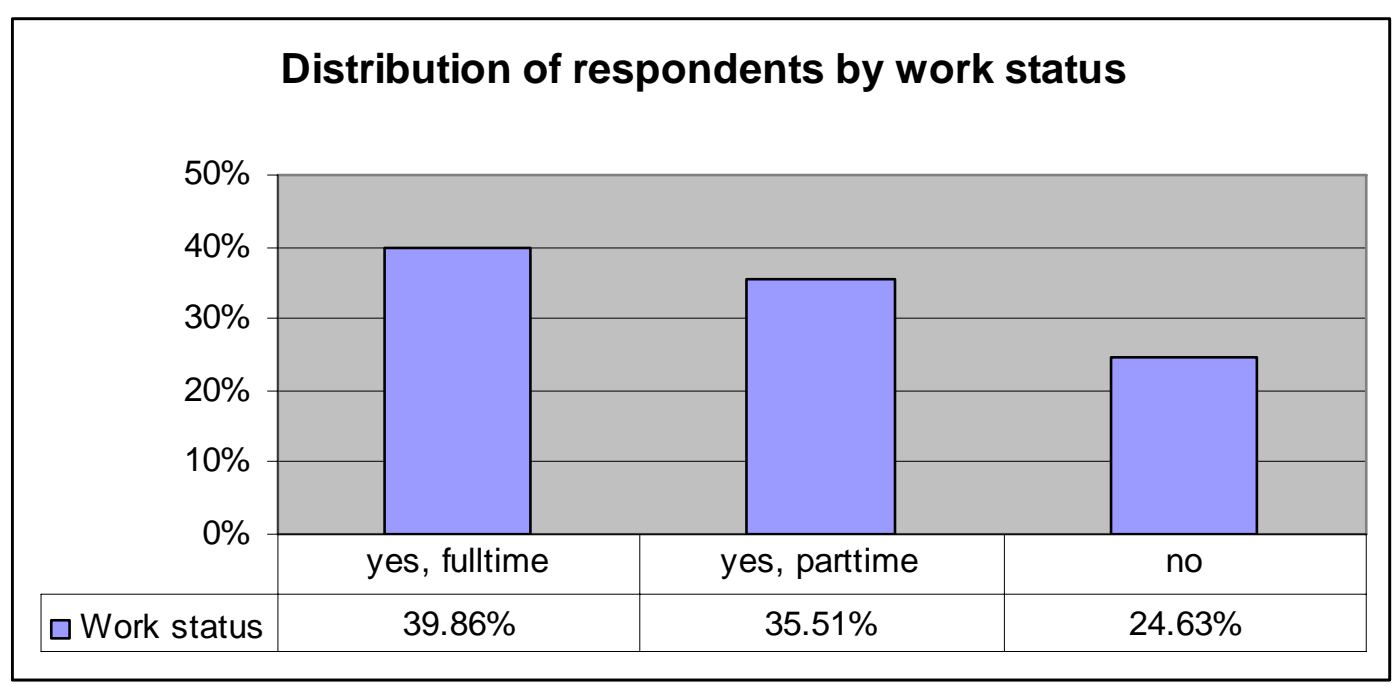

Figure 6. Distribution of respondents by work status 


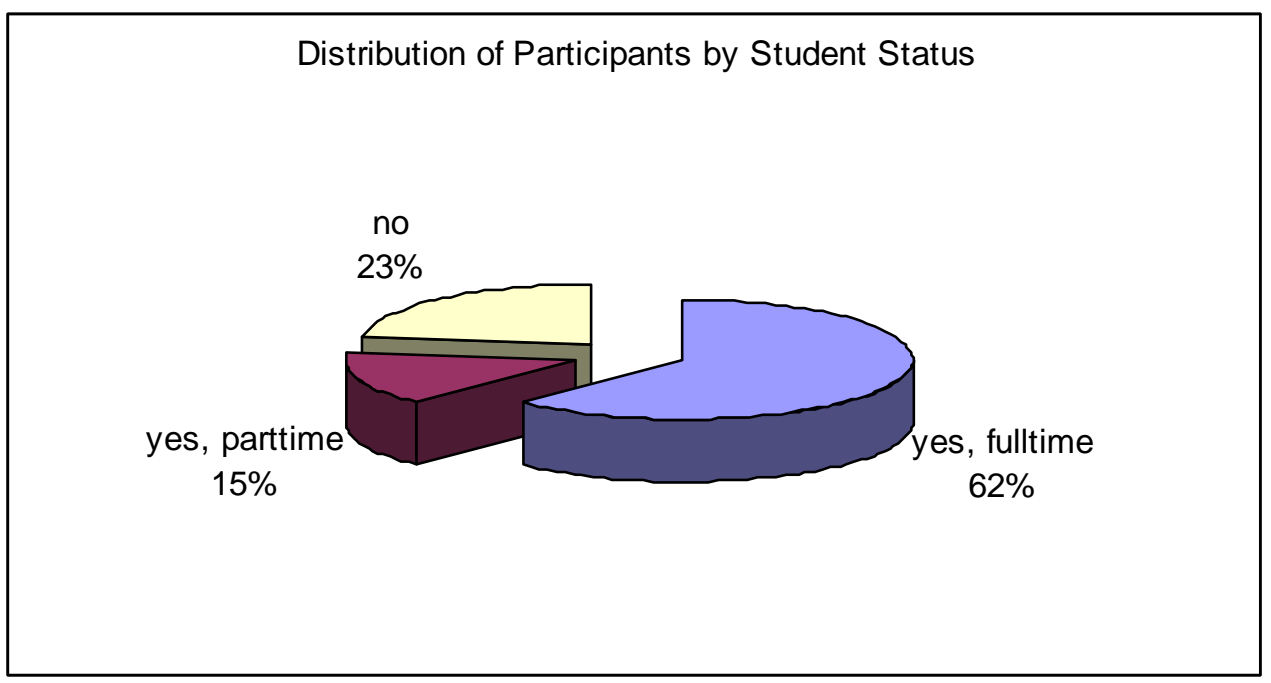

Figure 7. Distribution of respondents by student status

\subsection{Current and Past Mode Usage}

Background information was collected from each participant on current and past travel behavior. Responses were neither limited to a particular trip purpose (e.g., commuting) nor a particular location (e.g., Florida). Almost 30 percent of respondents said that they currently used transit and out of those, 5 percent said that they currently used local transit and 2.5 percent said that they currently used paratransit services. Three-fourths of respondents said that they had used transit in the past and out of these, 27 percent said that they had used transit in the past, 36 percent said that they had used the bus in the past and 17 percent said that they had used long distance train in the past. The majority of the respondents said that they almost never use vanpooling, train, trolley, walking, or biking. And, approximately 7 percent of respondents said that they rode a motorcycle or telecommuted several times a week.

Every one of the respondents claimed to have a valid drivers' license. And, the majority of respondents also claimed to have one or two cars available in their households. The average number of cars per each household in this survey was 2.02. In addition, almost 90 percent of respondents said that they drove alone on a daily basis. One-third of respondents said that they carpooled several times a week. All participants were asked which mode they used the most for these questions. 


\section{Number of cars available in your household}

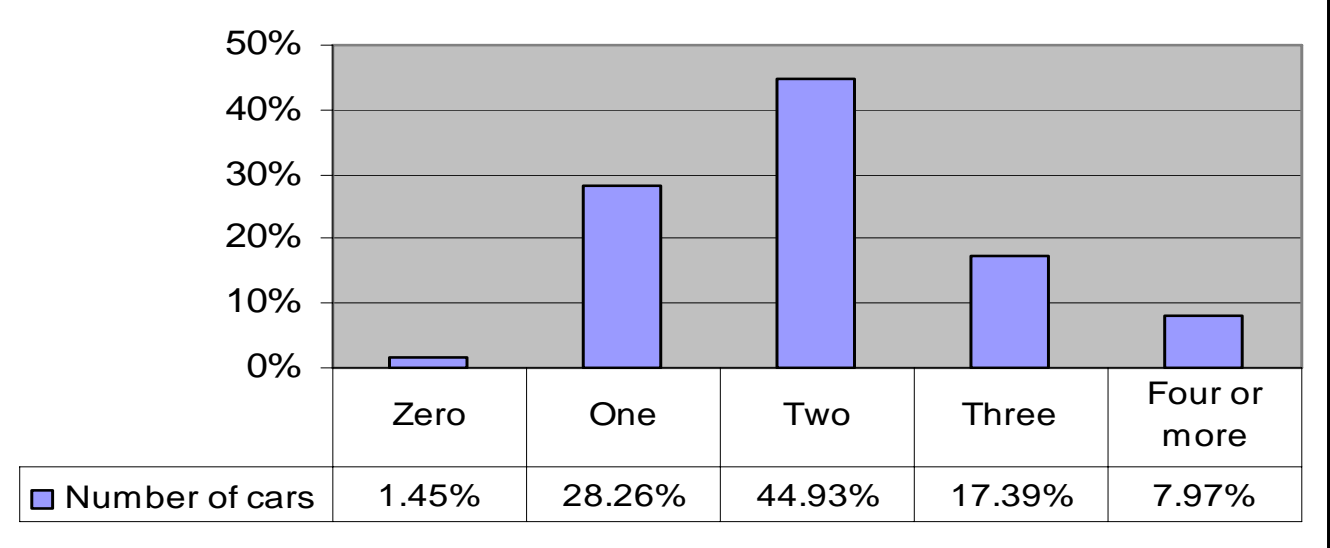

Figure 8. Number of cars available per respondent household 


\section{Results of the Final Questionnaire Administration}

As can be seen in Table 1, the majority of results support the ERG theory, that participants will choose Existence over Relatedness, Existence over Growth, and Relatedness over Growth. There are some exceptions to this rule and these are very interesting in the context of the ERG theory and are discussed further in depth in the "Discussion" in section 7.

Some important points to help the navigation of Table 1 are that the "Item" column refers for each type of question. Item "ER1" refers to the first question that compares Existence versus Relatedness and Item "EG1" refers to the first question that compares Existence versus Growth. The columns labeled "Choice A Ranking" and "Choice B Ranking" refer to the attractiveness ranking given to each choice after the participant chose A or B. The attractiveness ranking of each choice was calculated by taking the mean ranking for each item.

The column referring to "Theoretical Choice" gives the choice that would be expected under ERG theory. If the letter listed in the "Theoretical Choice" column has an asterisk listed next to it, this signifies that the theoretical choice and the observed choice outcome in the final administration of the questionnaire was opposite of what was theoretically expected.

The "Significance" column refers to if the means of the attractiveness rankings listed in columns "Choice A Ranking" and "Choice B Ranking" are significantly different from one another. If the answer listed under "Significance" is "Yes," then the mean difference between the attractiveness rankings for "Choice A Ranking" and "Choice B Ranking" are significantly different at the $\mathrm{p} \leq 0.05$ level, which is standard in both psychological and transit research studies and literature.

There are two other columns that begin with Choice $A$ and Choice $B$ and are named "Choice A Percent" and "Choice B Percent." These are the columns that designate what percentage of respondents chose Choice $A$ and Choice $B$, respectively. For items "ER1," "ER2," "ER4," "EG1," "EG7," "EG8," "RG3," and "RG10," these percentages are the opposite of what was expected according to ERG theory and this result is also verified by the asterisk next to the letter in the "Theoretical Choice" column for that item. In the section of Table 1 that lists the results for the questions that compare Existence versus Relatedness, 70 percent of items are answered in a way that is consistent with ERG theory. That is, the majority of respondents chose the item that corresponded to a preference for fulfilling an Existence issue over a Relatedness issue. The problems with items "ER1," "ER2," and "ER4" are discussed at length in section 7 below. In the section of Table 1 that lists the results for the items which compare Existence versus Growth issues, 70 percent of the items are also answered in a way that is consistent with ERG theory, to fulfill an Existence need over a Growth need. The problematic results for items "EG1," "EG7," and "EG8" are discussed further in section 7 as well. In the section of Table 1 that lists the results for the questions that compare Relatedness versus Growth issues, 80 percent of the items are answered in a way that is consistent with ERG theory, to fulfill a Relatedness need over a Growth need. The problems the results of two of the items in this section, "RG3" and "RG10" are further discussed as well in the section 7 below. While there might be concern that only 70 percent of these results the 
Existence versus Relatedness section, 70 percent in the Existence versus Growth section, and 80 percent in the Relatedness versus Growth section, these are significant results. The majority of answers in all comparisons, Existence versus Relatedness, Existence versus Growth, and Relatedness versus Growth, show evidence for a hierarchy of transportation needs. The ERG hierarchy does exist in the realm of transportation.

The final column in Table 1 is the "Believability" rating. As discussed previously, when the pilot questionnaire was being constructed, there were many comments that the scenarios needed to be more believable so that people could realistically imagine themselves in these situations. The overall mean for believability is 3.27. An independent t-test was run for each item, comparing it with the overall mean of 3.27. The means that are shown with two asterisks after them are significantly greater than the overall mean at a $\mathrm{p}<0.05$ level and those means that have one asterisk after them are significantly lower than the overall mean at a $p<0.05$ level. Surprisingly, the believability is significantly above the mean for item "ER1." So, in this situation it doesn't seem that the believability or lack thereof is causing the problematic results. The problematic results, in which the results show a trend opposite the ERG theory predictions, do not seem to be a function of problems with believability of the scenario. And, as discussed in section 8 on modeling of each type (ER, EG, or RG) of scenario, the believability scores are important in the regression equations. 
Table 1. Item Rankings

\begin{tabular}{|c|c|c|c|c|c|c|c|}
\hline Item & $\begin{array}{c}\text { Choice } \\
\text { A } \\
\text { Ranking }\end{array}$ & $\begin{array}{c}\text { Choice } \\
\text { B } \\
\text { Ranking }\end{array}$ & $\begin{array}{l}\text { Theoretical } \\
\text { Choice }\end{array}$ & Significance & $\begin{array}{c}\text { Choice } \\
\text { A } \\
\text { Percent }\end{array}$ & $\begin{array}{l}\text { Choice } \\
\text { B } \\
\text { Percent }\end{array}$ & Believability \\
\hline ER1 & 3.88 & 2.49 & $B^{*}$ & Yes & $80 \%$ & $20 \%$ & 3.70 ** \\
\hline ER2 & 2.97 & 3.48 & $\mathrm{~B}^{*}$ & Yes & $81 \%$ & $19 \%$ & 3.16 \\
\hline ER3 & 3.95 & 2.92 & A & Yes & $89 \%$ & $11 \%$ & $2.91^{*}$ \\
\hline ER4 & 2.86 & 3.76 & $A^{*}$ & Yes & $30 \%$ & $70 \%$ & 3.22 \\
\hline ER5 & 2.32 & 4.31 & B & Yes & $12 \%$ & $88 \%$ & $3.57^{* *}$ \\
\hline ER6 & 3.07 & 3.64 & $\mathrm{~B}$ & Yes & $36 \%$ & $64 \%$ & 3.12 \\
\hline ER7 & 3.02 & 3.67 & $\mathrm{~B}$ & Yes & $33 \%$ & $67 \%$ & 3.35 \\
\hline ER8 & 3.69 & 3.10 & A & Yes & $70 \%$ & $30 \%$ & 3.22 \\
\hline ER9 & 1.62 & 4.15 & B & Yes & $24 \%$ & $76 \%$ & 3.29 \\
\hline ER10 & 3.81 & 2.60 & A & Yes & $85 \%$ & $15 \%$ & $3.54^{\star *}$ \\
\hline EG1 & 3.51 & 3.22 & $\mathrm{~B}^{*}$ & No & $50 \%$ & $50 \%$ & 3.20 \\
\hline EG2 & 2.50 & 4.35 & B & Yes & $11 \%$ & $89 \%$ & 3.20 \\
\hline EG3 & 3.82 & 2.95 & A & Yes & $78 \%$ & $22 \%$ & $2.49^{*}$ \\
\hline EG4 & 3.43 & 3.40 & A & No & $61 \%$ & $39 \%$ & 3.33 \\
\hline EG5 & 2.85 & 4.04 & B & Yes & $14 \%$ & $86 \%$ & 3.64 \\
\hline EG6 & 3.51 & 3.29 & B & No & $36 \%$ & $64 \%$ & 3.25 \\
\hline EG7 & 3.34 & 3.62 & $A^{*}$ & No & $50 \%$ & $50 \%$ & 3.17 \\
\hline EG8 & 2.85 & 3.96 & $A^{*}$ & Yes & $27 \%$ & $73 \%$ & 3.20 \\
\hline EG9 & 2.91 & 3.62 & $\mathrm{~B}$ & Yes & $24 \%$ & $76 \%$ & 3.30 \\
\hline EG10 & 3.67 & 3.20 & A & Yes & $78 \%$ & $22 \%$ & 3.24 \\
\hline RG1 & 3.66 & 2.95 & B & Yes & $43 \%$ & $57 \%$ & $2.91^{*}$ \\
\hline RG2 & 3.70 & 3.62 & A & No & $80 \%$ & $20 \%$ & 3.46 \\
\hline RG3 & 2.59 & 3.70 & $A^{*}$ & Yes & $18 \%$ & $82 \%$ & $2.66^{\star}$ \\
\hline RG4 & 3.72 & 3.09 & A & Yes & $54 \%$ & $46 \%$ & 3.30 \\
\hline RG5 & 3.30 & 3.81 & B & Yes & $24 \%$ & $76 \%$ & 3.17 \\
\hline RG6 & 3.79 & 3.39 & A & Yes & $66 \%$ & $34 \%$ & $3.58^{\star *}$ \\
\hline RG7 & 3.46 & 4.14 & B & Yes & $25 \%$ & $75 \%$ & 3.34 \\
\hline RG8 & 3.35 & 3.91 & B & Yes & $13 \%$ & $87 \%$ & $3.54^{\star *}$ \\
\hline RG9 & 3.64 & 3.10 & A & Yes & $96 \%$ & $4 \%$ & 3.30 \\
\hline RG10 & 3.33 & 3.49 & $A^{*}$ & No & $50 \%$ & $50 \%$ & $3.79^{\star \star *}$ \\
\hline
\end{tabular}




\subsection{Overall Rankings of Importance of Existence, Relatedness, and Growth for Each Set of Comparison Questions}

In each item, there was a choice between scenario A or B, a ranking of both choice $A$ and $B$ and a ranking of the importance of an Existence issue, a Relatedness issue, and a Growth issue on a scale from 1 to 5 , with 1 being least and 5 being most important in this particular situation. These rankings were inserted into the questionnaire as a type of double-check of the testing system, to ensure that participants were responding in an appropriate manner. As an example, Question RG9 is shown below. For brevity, only the text of this question is shown. The entire questionnaire, including pictures, is available in Appendix A. A description of the scenario is followed by a choice of $A$ or $B$, and the ranking of Choices $A$ and $B$. Also shown are responses to the three questions on Existence, Relatedness, and Growth for that particular item.

In the example, the Existence question is "How important is it for you to be safe on your evening walk?," the Relatedness question is "How important is it to make your parents happy with your choice of walking route?," and the Growth question is "How important is it to have a scenic route to your destination?" The example of Question 9RG was shown to help the reader navigate Table 2 and also to understand how these rankings are to different questions than those listed in Table 1.

It is important to understand that there are comparisons of items via the choice and rankings of $A$ and/or $B$ in the scenarios and then there are the three simple questions, asking people how important Existence, Relatedness, and Growth are to them in that particular scenario. It would have been expected that people ranking the Existence, Relatedness, and Growth questions in the Existence versus Relatedness scenarios would have totally ignored the Growth questions and etcetera. However, they did not ignore those questions and those questions, being that they are simpler, may not have activated the same problems as the more "realistic" scenarios and, therefore, may be more valid in establishing the hierarchy of transportation needs. 
Question RG9

You are going on a walk with your parents down Bayshore Boulevard in Tampa. You have the choice of two routes. One route is significantly longer than the other route. The shorter route takes you past a vacant lot that just is so ugly you feel it spoils the walk for you. The longer route has some areas that aren't as beautiful as you would like, but not as blighted as you think the vacant lot is. However, your parents do not want to walk two miles instead of one mile just so that you don't have to look at the vacant lot. It's not dangerous, it's just ugly, they tell you, and they want to get to beautiful Bayshore more quickly. You know that your parents are capable of walking the two miles, but it means that they will not be able to enjoy the walk along Bayshore for as long. The main goal of the walk is to enjoy the beauty of Bayshore. What do you do?

A. You choose to take the route that takes you by the vacant lot, keeping your eyes straight ahead on the sidewalk and diverting them from the ugly lot. You know that your parents appreciate the fact that you will walk past a small blighted area in order for your family to get to Bayshore more quickly for your evening walk.

Ca

B. You decide that you just can't deal with that vacant lot and decide to make your parents walk the two mile route as opposed to the one mile route. Your parents are very unhappy that you are making them waste time that they could spend walking on Bayshore, walking along the Downtown streets in Tampa and aren't very nice company on the walk.

Directions: Please answer the following questions for this situation. For each of the following questions 1 is the lowest and 5 is the highest rating.

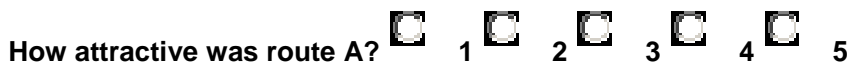

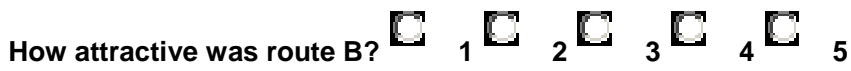

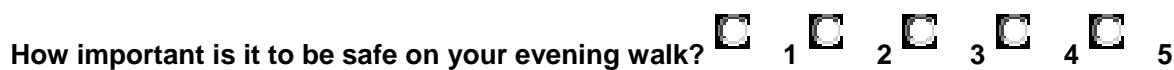

How important is it to make your parents happy with your choice of walking route?

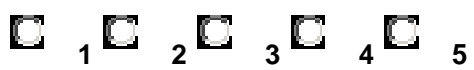

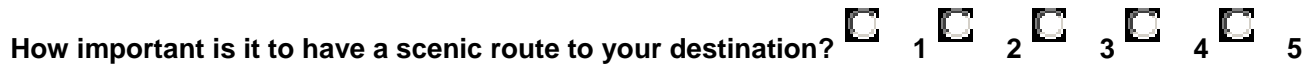

How believable is this scenario? ${ }_{1}{ }_{1}{ }_{2}{ }_{3}{ }_{3}{ }_{4}{ }_{5}$

Figure 9. Listing of Question RG as an Example for Reading Results

6.1.1 Overall Rankings of Importance of Existence, Relatedness, and Growth for Existence versus Relatedness Comparison Questions

Overall, in the scenarios comparing Existence and Relatedness, participants ranked Existence significantly higher than Relatedness and Existence significantly higher than Growth on the five point scale. However, they did not rank the Relatedness significantly higher than Growth in these scenarios. 
6.1.2 Overall Rankings of Importance of Existence, Relatedness, and Growth for Existence versus Growth Comparison Questions

Overall, in the scenarios comparing Existence and Growth, participants ranked Existence significantly higher than Relatedness, Existence significantly higher than Growth, and Relatedness significantly higher than Growth.

6.1.3 Overall Rankings of Importance of Existence, Relatedness, and Growth for Relatedness versus Growth Comparison Questions

Overall, in the scenarios comparing Relatedness and Growth, participants ranked Existence significantly higher than Relatedness, Existence significantly higher than Growth, and Relatedness significantly higher than Growth.

Table 2. Overall comparison of secondary Existence, Relatedness, and Growth questions by item type.

\begin{tabular}{|c|c|c|c|c|c|c|}
\hline Item & Existence & Relatedness & Growth & $\begin{array}{c}\text { Existence } \\
\text { vs. } \\
\text { Relatedness }\end{array}$ & $\begin{array}{c}\text { Existence } \\
\text { vs. } \\
\text { Growth }\end{array}$ & $\begin{array}{c}\text { Relatedness } \\
\text { vs. } \\
\text { Growth }\end{array}$ \\
\hline ER1 & 4.38 & 4.23 & 3.38 & No & Yes & Yes \\
\hline ER2 & 3.62 & 4.14 & 3.36 & Yes & Yes & Yes \\
\hline ER3 & 4.28 & 2.44 & 3.36 & Yes & Yes & Yes \\
\hline ER4 & 4.20 & 3.70 & 3.14 & Yes & Yes & Yes \\
\hline ER5 & 4.49 & 3.49 & 3.64 & Yes & Yes & Yes \\
\hline ER6 & 4.14 & 3.30 & 3.46 & Yes & Yes & No \\
\hline ER7 & 4.23 & 3.08 & 3.13 & Yes & Yes & No \\
\hline ER8 & 3.87 & 3.13 & 3.42 & Yes & Yes & Yes \\
\hline ER9 & 4.44 & 2.72 & 2.96 & Yes & Yes & No \\
\hline ER10 & 4.52 & 2.83 & 2.86 & Yes & Yes & No \\
\hline MEANS ER & 4.22 & 3.31 & 3.27 & Yes & Yes & No \\
\hline EG1 & 3.88 & 3.12 & 2.88 & Yes & Yes & No \\
\hline EG2 & 4.24 & 3.00 & 3.3 & Yes & Yes & Yes \\
\hline EG3 & 4.30 & 2.12 & 3.07 & Yes & Yes & Yes \\
\hline EG4 & 3.97 & 3.64 & 3.63 & Yes & Yes & No \\
\hline EG5 & 4.41 & 2.14 & 3.49 & Yes & Yes & Yes \\
\hline EG6 & 4.26 & 3.43 & 3.48 & Yes & Yes & No \\
\hline EG7 & 4.23 & 2.97 & 3.52 & Yes & Yes & Yes \\
\hline EG8 & 4.04 & 3.65 & 3.62 & Yes & Yes & No \\
\hline EG9 & 4.38 & 2.99 & 3.02 & Yes & Yes & No \\
\hline EG10 & 4.56 & 2.95 & 2.91 & Yes & Yes & No \\
\hline
\end{tabular}




\begin{tabular}{|c|c|c|c|c|c|c|}
\hline MEANS EG & 4.23 & 3.00 & 3.29 & Yes & Yes & Yes \\
\hline RG1 & 3.96 & 3.78 & 3.14 & No & Yes & Yes \\
\hline RG2 & 4.32 & 3.73 & 2.73 & No & Yes & Yes \\
\hline RG3 & 4.16 & 2.33 & 3.78 & Yes & Yes & Yes \\
\hline RG4 & 4.18 & 3.50 & 4.04 & Yes & No & Yes \\
\hline RG5 & 4.36 & 3.15 & 3.43 & Yes & Yes & Yes \\
\hline RG6 & 4.32 & 3.70 & 3.31 & Yes & Yes & Yes \\
\hline RG7 & 4.38 & 4.21 & 3.46 & Yes & Yes & Yes \\
\hline RG8 & 3.89 & 3.12 & 3.54 & No & Yes & Yes \\
\hline RG9 & 4.42 & 4.09 & 3.21 & Yes & Yes & Yes \\
\hline RG10 & 4.79 & 3.30 & 2.62 & Yes & Yes & Yes \\
\hline MEANS RG & 4.28 & 3.49 & 3.33 & Yes & Yes & Yes \\
\hline
\end{tabular}

\subsection{Three Simple ERG Questions (Triad Comparisons) Compared to Categorical Existence, Relatedness, and Growth Questions (Dyad Comparisons)}

The interesting results from the set of questions that assess Existence, Relatedness, and Growth are that all results of comparison except for the comparison of questions ER2B and ER2Existence, ER4B and ER4Relatedness, ER5B and ER5Existence, ER7A and ER7Relatedness, ER8A and ER8Existence, ER8B and ER8Relatedness, ER10B and ER10Relatedness, EG2B and EG2Existence, EG3B and EG3Growth, EG6A and EG6Growth, EG7B and Growth, EG9A and EG9Growth, RG2A and RG2Relatedness, RG3A and RG3Relatedness, RG5A and RG5Relatedness, RG6A and RG6Relatedness, RG6B and RG6Growth, RG7B and RG7Relatedness, RG8B and RG8Relatedness, RG9B and RG9Growth, and RG10B and RG10 Relatedness are significant. That means that the mean responses of almost all of the Existence, Relatedness, and Growth simple questions are significantly different from those of the dyad comparison questions.

The above results are very interesting because it could be that the situations and scenarios in the questions are problematic and that people are choosing Existence over Relatedness and Growth and Relatedness over Growth if the question is simpler. Perhaps some of the questions developed from the pilot questionnaire activated too many variables in the Choice between $A$ or $B$ and also the rankings between Choice $A$ and $\mathrm{B}$.

\subsection{Results by Demographics}

\subsubsection{Results by Gender}

In order to assess overall trends in the data, an ESCORE, RSCORE, and GSCORE were computed based upon the choice that each person made of either $A$ or $B$ for each item. When the person made a rating for either $A$ or $B$, they also made a rating of $E, R$, and $G$ for that particular item. Each rating was averaged between genders and these scores were computed. It was found that there was a significant difference between genders on the Existence score overall and the Growth score overall. On the whole, female participants tended to rate Existence $(F(1,137)=25.69, p<0.05)$ and Growth $(\mathrm{F}(1,137)=12.40, \underline{p}<0.05)$ choices higher than their male counterparts. 
Table 3. Gender difference for ratings of $E, R$, and $G$ items for first scenario questions

\begin{tabular}{|l|r|r|r|}
\hline Male & $3.37^{\star}$ & 3.19 & $3.11^{\star}$ \\
\hline Female & $3.74^{\star}$ & 3.28 & $3.39^{\star}$ \\
\hline
\end{tabular}

In addition, a total score was added for the three $\mathrm{E}, \mathrm{R}$, and $\mathrm{G}$ ratings positioned at the end of each item, before the believability rating. Further, the $E, R$, and $G$ ratings were divided according to which cluster of items they occurred in. Tables 4, 5 and 6 show the results and the significance of these ratings. An asterisk next to a mean signifies that it is significantly different from the mean of the other group.

Table 4. Gender differences on Existence Items Overall and by cluster membership

\begin{tabular}{|c|c|c|c|c|}
\hline & Escore2 & eERscore2 & eEGscore2 & eRGscore2 \\
\hline Male & $4.04^{*}$ & 4.06* & 4.03* & 4.01* \\
\hline Female & $4.42^{*}$ & 4.33* & $4.37^{*}$ & $4.57^{*}$ \\
\hline
\end{tabular}

Table 5. Gender differences on Relatedness Items Overall and by cluster membership

\begin{tabular}{|l|r|r|r|r|}
\hline & Rscore2 & \multicolumn{1}{r|}{ rERscore2 } & rEGscore2 & \multicolumn{1}{r|}{ rRGscore2 } \\
\hline male & 3.23 & 3.27 & 2.99 & 3.44 \\
\hline female & 3.31 & 3.33 & 2.96 & 3.55 \\
\hline
\end{tabular}

Table 6. Gender differences on Growth Items Overall and by cluster membership

\begin{tabular}{|l|r|r|r|r|} 
& Gscore2 & \multicolumn{2}{r|}{ gERscore2 } & \multicolumn{2}{c|}{ gEGscore2 } & gRGscore2 \\
\hline male & 3.17 & $3.09^{*}$ & 3.25 & 3.18 \\
\hline female & 3.35 & $3.39^{*}$ & 3.32 & 3.35 \\
\hline
\end{tabular}

Overall, in the separate, secondary Existence ratings, females rated the Existence items as more important over all item clusters (ER, EG, and RG) as more important than males ranked them. There was no significant difference between males and females on their ranking of Relatedness secondary items. However, on Growth secondary items, females ranked Growth characteristics as more important in the ER cluster of Growth items than males did. As Alderfer assets, clearly the order of needs can be different for different people as the ER cluster was supposed to cause participants to focus more on $\mathrm{E}$ and $\mathrm{R}$ characteristics instead of Growth characteristics.

\subsubsection{Results by Ethnicity}

There were five demarcated ethnic groups in the study: White, Black, Hispanic, Asian, and Other. There were no significant differences in the rankings of $E, R$, and $G$ characteristics for ranking of choice A or B or of the secondary rankings.

\subsubsection{Results by Age Group}

There were no significant differences in means on the $E, R$, and $G$ ratings for either choices $\mathrm{A}$ or $\mathrm{B}$ or the secondary ratings between age groups. 


\subsubsection{Results by Number of Children under Age 16 Years}

There were no significant differences in means on the $E, R$, and $G$ ratings for either choices $\mathrm{A}$ or $\mathrm{B}$ or the secondary ratings between people with and without children under the age of 16 years.

\subsubsection{Results by Employment and Student Status}

Table 7. Ratings of $E, R$, and $G$ (A versus $B$ ) items by employment status (* signifies significant difference)

\begin{tabular}{|l|r|r|r|}
\hline & ESCORE & RSCORE & \multicolumn{1}{c|}{ GSCORE } \\
\hline Full-time worker & 3.62 & 3.16 & $3.13^{\star}$ \\
\hline Part-time worker & 3.59 & 3.33 & $3.38^{\star}$ \\
\hline Non-worker & 3.54 & 3.24 & $3.36^{\star}$ \\
\hline
\end{tabular}

As can be seen in Table 7, those who either did not work or were part-time workers scored growth characteristics higher overall in their ratings of $A$ versus $B$ for each item.

Table 8. Ratings of $E, R$, and $G$ (A versus $B$ ) items by employment status (* signifies significant difference)

\begin{tabular}{|c|c|c|c|}
\hline & ESCORE & RSCORE & GSCORE \\
\hline Full-time & 3.58 & $3.31^{\star}$ & $3.33^{\star}$ \\
\hline Part-time Student & 3.74 & $3.15^{\star}$ & $3.02^{\star}$ \\
\hline Not a student & 3.50 & $3.11^{\star}$ & $3.29^{\star}$ \\
\hline
\end{tabular}

In Table 8, it can be seen that Part-time students have lower R scores than Full-time students. Part-time students also have lower G-scores than both Full-time and nonstudents. Overall, part-time students tend to rank $R$ and $G$ characteristics with lower importance than full-time and non-students. 


\section{Discussion}

\subsection{Discussion of Each Item as a Part of the Hierarchy Theory}

As discussed previously, there were two parts of each item. One was asking which situation they would choose given a certain scenario and the other was just asking for a simple ranking of Existence, Relatedness, and Growth variables. The first portion of the item will be called the "Dyad comparison" portion and the second portion of the item will be called the "Triad comparison" portion. These names are given to avoid confusion over the two ranked portions of each item.

Overall, both the scenario comparisons (i.e., Existence versus Relatedness, Existence versus Growth, and Relatedness versus Growth), or the "Dyad comparison" as well as the more simple "Triad comparison" ratings in each item prove that there is a hierarchy of transportation needs much like the one described in the literature by Alderfer (1969, 1972). The Dyad and Triad comparisons each give a differing viewpoint for the results of the survey. Further, the Triad comparisons may be more informative as to the existence of the ERG hierarchy, mostly because they are simpler and less vulnerable to confusions over categorizations of the scenario characteristics.

\subsubsection{Existence versus Relatedness}

In the Existence versus Relatedness cluster of the questionnaire, questions ER1, ER5, and ER10 were rated as significantly more believable than the average believability of that cluster. Question ER3 was rated as significantly less believable than the other items in this cluster. Question ER1 is particularly interesting because of the fact that most of the participants decided to choose the Relatedness choice and to help out their spouse, even though they were imaging themselves as a 9/11 survivor. This finding is something interesting in that the participants probably made their decision based on a phenomenon of lightning not striking the same place twice. The analogy is that general knowledge says that such an unlikely event at the terrorists attacks might happen again, but not in the exact same place. In addition, in the ER item cluster, most participants chose relatedness over existence if the related party was a person of authority or a person of their immediate family, such as a parent or a spouse. In the other questions, in which the participant is asked to make a choice of existence versus relatedness, the other party was a friend or a boy/girlfriend and not a permanent part of that person's family. In Question ER2, participants chose to accommodate their mother. However, having to stand for 40 minutes may be a matter more of comfort than survival. There was some disagreement in the literature about if comfort was a lower or higher level need. From the results of this survey, there are two options: Either comfort is a Growth need or people will tend to follow the lead of a permanent and/or authoritative family member.

Question ER4 shows a pattern of results that was the opposite of what was theorized. The majority of respondents said that they would rather not be harassed by opposing fans. This is interesting, because in many studies, people discuss the fear of getting lost in a novel transit system (Winters et al., 2001). However, an explanation of these results could be that people do have a fear that harassment could turn into physical danger.

On all other questions, except for ER1, ER2, and ER4, participants answered in a way that is consistent with the first part of ERG theory, as proposed by Alderfer. People will 
predominantly choose Existence characteristics over Relatedness characteristics. However, Alderfer (1985) did not specify about the nature of the relationship in the decision-making process. The 3 anomalies in this case are explained by the fact that people don't expect an unexpected event to occur twice in the same place. Therefore, they may feel safer in an area in which an event has already occurred. Comfort may be considered a Growth level characteristic and, if so, participants should have chosen Relatedness over it. And, finally, it may be that participants are afraid in ER4 that opposing fans may become physical in their harassment and the physical safety would take precedence over the ability to successfully navigate the system.

In comparison with the simple triad questions, in item ER1, it was found that the rankings for Existence were significantly different from the ranking for Choice B, 4.38 versus 2.49. This means that given the scenario, people chose to help their spouse over worrying about if terrorists would strike that area again. However, people were significantly more concerned about their safety given the simple questions than what the Choice dyads show. In item ER2, it was found that the rankings for Existence in the triad questions were significantly different from the ranking for Choice $B, 3.48$ versus 3.62 , with the ranking for "comfort" being significantly higher than the ranking for Choice B. However, in this instance, people still chose to accommodate their mother than to be comfortable. So, the analysis of comfort perhaps not being an Existence need stands. In item ER4, it was found that the rankings for Existence in the triad questions were significantly different from Choice A, 2.86 versus 4.20. This means that people are concerned about navigation as well as safety in this instance. This item also has some problems because of the fact that participants may have read what was meant as a Relatedness choice as an Existence choice. And, the prospect of being assaulted by opposing fans is more frightening than the prospect of being lost.

\subsubsection{Existence versus Growth}

On this particular cluster of items, it would be expected that participants would choose Existence characteristics over Growth characteristics. The anomalies in this cluster are Questions EG1, EG7, and EG8.

Question EG1 was a 50/50 split for choice A and choice B and there was not a significant difference between the rankings of each choice, meaning that people were torn over these choices. However, there was a significant difference between ratings for the $E$ and $G$ ratings. This is an interesting item, especially when compared with the results for Question ER1, in which people chose to resume riding in the area of the terrorist attack in order to help their spouses. This result links to the phenomena of lightning not striking in the same place twice. However, lightning, or a terrorist attack, has not yet occurred in the Chicago area and people are split over what they might do. Some people always ignore the terrorist warnings and do not change their behavior while others will totally change their plans in the face of terrorist warnings or the change in the terror alert color chart. This would be an interesting study to undertake, to see how many people will change their plans according to terrorist warnings. In the comparison of the simple triad questions, the Existence choice was ranked significantly higher than the Growth choice on the triad and the Existence choice was also ranked significantly higher than Choice $\mathrm{B}$, which was the Existence choice of the dyad scenario. Also problematic in this instance is the use of "attractive." Of course, a beautiful view of the Chicago skyline and the Chicago River is more attractive than the backside of row housing. This result points out the fact that perhaps "attractive" is not the best choice to obtain the desired results. 
Question EG8 probably offered too many options to participants in an effort to be believable. Of course someone is going to choose to hop a cab over using transit if they are afraid of the transit facility. This question would need to be re-written for the next testing of the theory. Or, there would have to be more of a cost issue, perhaps $\$ 20$ for the cab over \$2.50 for using transit. In the dyad/triad comparison of questions, the triad Existence choice ranked significantly higher than the dyad Existence Choice A offered, 2.85 versus 4.04. In addition, the triad comparison between Existence and Growth were also significantly different, 4.04 versus 3.62 . The more simplistic questions only asked how important it was to be safe entering and exiting a transit system, versus how important it was to try a new restaurant. Just given those two choices, it is obvious that someone would choose Existence over Growth. However, given all of the variables of item EG8, it is more difficult to parse out the actual choice.

Overall, 70 percent of the results of this cluster agreed with the ERG theory. This is significant enough to provide evidence that the EG level of the ERG theory also exists.

\subsubsection{Relatedness versus Growth}

In the Relatedness versus Growth cluster of the questionnaire, respondents were asked to make a choice between Relatedness characteristics and Growth characteristics. There were two questions, RG3 and RG10, on which the results were opposite of expected or there was not a clear-cut majority.

On Question RG3, there was a clear-cut majority who wanted to use the basket to carry a board game, a convenience characteristic. However, this may also be considered to be a safety issue. If you can't safely carry the board game, then you may crash. The basket may be viewed as an Existence item rather than a Growth item of convenience. This question must be rewritten for the next phase of the study. Additionally, the mean for the Relatedness triad choice was significantly lower than the mean for the Growth triad choice on this item.

Finally, on Question RG10 there was not a significant difference between ratings for choice A or B and there was a 50/50 split on choosing A or B. Each choice was equally attractive, depending on whether the person felt that the exposition or making their boy/girlfriend happy was most important. This is another question that needs to be retooled prior to taking off into the next phase of testing. However, in the simple triad testing for this question, Relatedness came in with a greater importance score than the Growth triad comparison, 3.30 versus 2.62. The triad comparison breaks the tie on this item.

Overall, 80 percent of the results of this cluster agreed with the ERG theory. This is significant enough to provide evidence that the RG level of the ERG theory also exists. 


\section{Conclusions}

There is evidence from this project that the ERG theory exists on when applied to mode choice. It is important to make some statements about how the ERG theory works in these instances and how people's choices can be quantified by specific variables in the test set.

1. People will most often choose Existence over Relatedness over Growth, as evidenced by a 70 percent majority who chose Existence over Relatedness, the 70 percent majority who chose Existence over Growth, and 80 percent majority who chose Relatedness over Growth. These are all significant at a $p \leq 0.05$ level that these majorities are real results and not due to chance.

2. People will sometimes choose Relatedness over Existence if they feel that the possible event is highly unlikely or is unfamiliar to them in their daily lives. The other mitigating factor found in this study is that people will also accommodate permanent family members or authorities. This is consistent with Alderfer's contention that the order of needs can be different for segments of the population. As exhibited in Item ER1, people feel fairly safe that the Lower Manhattan business district will not be struck by terrorists again. So, this person can help his/her spouse. However, on the question about terrorists striking in Chicago, item EG1, this is something that could definitely happen, especially in the congested downtown area. Some people will say that it's hype and others will heed the government warnings. Also, item EG1 isn't asking someone to disrespect a close family member in order to ride a specific route.

3. People may be categorizing certain items differently from the researchers in this study. For example, on item ER2, in which the person could accommodate his/her mother or ride in comfort for the 40 minute ride, the person chose to accommodate the mother. However, comfort for 40 minutes could be considered something more of a convenience issue. Being comfortable and able to have space becomes more of an Existence issue over five hours of riding a long distance train, especially if you are elderly or have a health concern. Therefore, the next round of testing has to be careful about what is important when in categorizing characteristics, not just what the characteristic is.

The categorization of facilities and modes by LOS is based on the presumption that improvements to the non-highway modes (i.e., increasing LOS) will motivate more travelers to choose those options (i.e., if you improve it, they will come). The goal is to improve the functioning of the transportation system for all. Improving LOS for all modes should encourage more people to use these non-highway modes thus resulting in a reduction in the vehicle demand on the highway system (ignoring the changes due to population growth). This reduction can benefit communities by reducing delays, decreasing energy consumption and reducing emissions from mobile sources. Thus, the transportation community should seek to apply Alderfer's motivation as a means of improving LOS. Specifically, LOS systems should consider the wide range of needs to be satisfied.

As discussed in a previous section, Alderfer reduced the Maslow's number of levels to three when studies found that the middle levels of Maslow's hierarchy overlap (i.e., the "hierarchy" differs based on different circumstances and culture). This project focused on empirically testing Alderfer's Existence Relatedness Growth (ERG) theory of motivation 
to hypothetical mode choice decisions. The empirical results of this project support the ERG theory when operationalized for 30 paired travel scenarios. It supports the conclusion that more than one need may be motivational for choosing a particular mode. For example, the observed responses (expected verus actual) for each of the scenarios showed instances where a lower motivation (e.g., existence) may not be substantially satisfied in all cases before one moves onto higher level (e.g., relatedness). These differences may be due to cultural differences (e.g., higher priority on family or society than self).

Just as Alderfer refined Maslow's theory and its postulated definitive hierarchy of needs, transportation planners must recognize that a traveler has multiple needs to satisfy simultaneously. Furthermore, we must understand that under similar situations, the needs can follow a different priority order for different travelers depending on the circumstances. This broadening perspective of LOS measures implies that transportation planners should continue to reflect Existence needs such as safety and physiological requirements. However, LOS measures also should strive to reflect the Relatedness needs which stress the importance of interpersonal and social relationships. Finally, LOS measures should seek to consider the role that Growth needs such as the individual's intrinsic desire for personal development play in mode choice. For example, these growth needs could be reflected by the choice of alternative modes such as transit or biking or walking in order to protect the environment.

Improved understanding of motivational theory will have implications on how LOS is measured and how decisions are made based on those measures. Strategies to improve LOS that focus exclusively on addressing one need at a time will not effectively motivate change in travel behavior - a major purpose behind the multimodal LOS concept.

The expedient approach is to seek out variables to measure LOS where the data is readily available or easily obtainable. However, transportation professionals should take care when basing LOS measures solely on the such measures and concluding that improvements solely to those measures will improve LOS. Correlation does not mean causality. While we can conclude that bicycle LOS, for example, scores degrade as pavement width narrows, one can not claim that narrow pavement widths cause low LOS scores. The empirical results of this project show instances where higher level needs were sought to be satisfied prior to lower level needs. This demonstrates that there are other needs or variables that affect the results. While other measured variables can affect the results, it is possible the results could also be due to unmeasured variables. These unmeasured variables could be reflecting other needs such as meeting the normative expectations of individuals or groups important to him or her.

According to the ERG theory, focusing exclusively on one need at a time will not effectively motivate changes in behavior. In the workplace, for example, if growth opportunities such as providing specialized training are not provided to employees, they may regress to relatedness needs, and socialize more with co-workers. This situation is called frustration-regression principle. It also applies to the motivation to use alternatives to driving alone. If transportation planners do not consider how to satisfy the need for social interaction, for example, when assessing LOS then travelers might increase their demand for more security or better equipped transit vehicles. 
Transportation professionals must recognize that a traveler has multiple needs to satisfy simultaneously to motivate changes in travel behavior (i.e., increase the LOS). An individual's mode choice for a trip is presumably based on the level of service variables. How individuals respond to these variables depends on the observed and unobserved characteristics of a particular option for meeting their needs. Focusing on only one type of need (e.g., existence) and neglecting other factors could limit the effectiveness of improvements and miss the mark for tracking LOS in the first place.

LOS scales are based on generally on one level (e.g., Existence in the case of bicycle modes). This situation ignores the fact that motivating change will depend on relatedness factors as well. For example, in most situations driving an auto could be considered to be safer and quicker that biking. However, some people continue to bike. Growth needs may be superseding the lower level needs. Landis et al noted that participants in the initial Ride for Science study were asked to ignore aesthetics of the segment when, in fact, such needs may do much to influence their rating and ultimately their motivation to use the bike option.

Other means exist for improving the level of service that may fall outside of the typical improvements considered by transportation professionals. For example, if people thought that their mode choice would be accepted and approved by others important to them then they would have more of an intention to choose that mode. Thus, public information campaigns aimed at influencing attitudes and behavior could, in effect, improve LOS from a users' perspective without capital improvements. As a corollary, ignoring the role these other needs (e.g., relatedness and growth) can play in the mode choice decision may be directing improvements that are less effective in the ultimate goal of improving the perceived LOS among travelers.

Differences in how Level of Service is measured across all the modes pose a challenge of incorporating these findings. Level of Service is generally a measure of the volume to capacity ratio of motor vehicles and the roadways which they traverse. Bicycle and pedestrian LOS are based on comfort and safety measurements, and transit LOS measurements are based upon frequency of service and delay compared to single occupancy vehicle (SOV) service. The positives of pursuing multi-modal LOS systems are that it makes it easier for the general population to understand LOS ratings, provides consistency in ratings, it is more environmentally sensitive and balanced, and it should inform developers of how to design more livable communities. If a LOS system were developed that was multi-modal and reflective of the range of needs, it would be easier for non-professionals and regular travelers to understand how different modes are ranked.

This project demonstrated the importance for understanding the items motivating behavior beyond the traditional LOS measures of time and cost. These results imply that current LOS methods may provide incomplete or inaccurate assessments of policy actions aimed at motivating travelers to use transit, bike and walk options. An implication of this finding is the need to perform sensitivity analysis when modeling mode choice to reflect a range of responses expected from improvements to level-of-service variables.

In conclusion, this study provides adequate evidence that motivation theories apply to transportation mode choice (i.e., there is a Hierarchy of Transportation needs). Transportation planners should seek to supplement the variables currently used for 
determining LOS by incorporating factors that reflect the existence, relatedness, and growth needs for motivating mode choice decisions. This broader view will require rethinking of how level of service is measured and, therefore, how communities can respond. Further experimentation with better classification and crafted situations and simulation should provide stronger results in agreement with the results of this experiment. 


\section{Future Research}

In the current study, many of the problems with specific items resulted from apparent problems with categorization. The first item on the agenda for future research would be to test approximately 100 people of approximately the same sample composition as the current study and to ask them how they would categorize the specific items in each of the situations and why they would make those decisions. The problems with the current study do give a window to many of these situations, but further testing and analysis could clear up any misunderstandings from the current testing.

Many times, what people say they will do in a certain hypothetical situation and what they do in the real world in that same situation are two totally different things. The main goal for the continuation of this line of research will be to determine if stated preference in the hypothetical is real preference in the real world situation. There are many problems with comparing these two situations. One of them is that it is hard to perform a within-subjects analysis of all of the real world situations one could list in a stated preference questionnaire such as the one given to the participants in the current study. A study of real world behavior would suffer from issues such as attrition and problematic safety situations. There are many studies that claim people will change mode and travel behavior when working conditions/locations change or living locations or situations change (Seethaler \& Rose, 2003; Bamberg \& Schmidt, 1998, 2003; Bamberg et al., 2003). However, these experiments were all performed in Europe or Australia. This type of undertaking would be rather immense and would require cooperation between researchers and transportation providers on a rather intense level. And, there is the problem with that type of approach.

Simulation might offer the same benefits without the problems of trying to organize that type of large experiment. For simulation, each of the most highly believable and highly ranked items for each cluster would be presented with varied Existence, Relatedness, and Growth characteristics. For example, Question ER1 could be reworked as doing a favor for a friend, versus for an immediate family member. It seems plausible that there are varying levels of existence, relatedness, and growth and that those finer gradations could be parsed out through further study and simulation. 


\section{References}

1. Ajila, C. O. (1997). Maslow's Hierarchy of Needs theory: Applicability to the Nigerian industrial setting. Life Psychologia: An International Journal, 5(1) 162-174.

2. Ajzen, I. (1991). The theory of planned behavior. Organizational Behavior \& 11

3. Alderfer, C. P.(1972). Existence, relatedness, \& growth: Human needs in organizational settings. New York: Free Press.

4. Alderfer, C.P. (1985). An empirical test of new theory of human needs. Organizational Behavior and Human Performance, 4, 142 - 175.

5. Alderfer, C. P, Kaplan, R. E, Smith, K. K. (1974). The effect of variations in relatedness need satisfaction on relatedness desires. Administrative Science Quarterly, 19(4), 507-532.

6. Baber, J; Vlacic, L; Noel, T; Parent, M (2003). Personal rapid transportation in cities. Computing and Control Engineering Journal, 14(4), 20-21.

7. Baltes, M. (2003). The Importance Customers Place on Specific Service Elements of Bus Rapid Transit. Journal of Public Transportation, 6(4). 1-19.

8. Bamberg, S. \& Rolle, D. (2003). Determinants of People's Acceptability of Pricing Measures-Replication and Extension of a Causal Model in Acceptability of Transport Pricing Strategies. 235-248.

9. Bamberg, S.; Rolle, D.; \& Weber, C. (2003). Does Habitual Car Use Not Lead to More Resistance to Change of Travel Mode? Transportation, 30(1), 197-208.

10. Bamberg, S \& Schmidt, P. (2003) Automobile or Bicycle? Empirical test of a Utility-Theory Approach. Kolner Zeitschrift fur Soziologie und Sozialpsychologie.46(1), 80-102.

11. Barrett, S.D. (2004). How do the demands for airport services differ between fullservice carriers and low-cost carriers. Journal of Air Transport Management, 10(1), 33-39.

12. Cleland, F., \& Thompson, B.J. (2001). Restful Riding Rather Than Stressful Driving. A NCTR report for the Florida Department of Transportation.

13. Friedman, D. (2003). A new road: The technology and potential of hybrid vehicles. Union of Concerned Scientists: Cambridge, MA.

14. Guttenplan, M., Landis, B., Crider, L., \& McLeod, D. (2001). Multimodal LOS Analysis at Planning Level. Transportation Research Record, 1776, 151-158.

15. Guttenplan, M., Davis, Steiner, \& Miller (2003). Planning Level areawide multimodal LOS analysis: Performance Measure for Congestion Management. Transportation Research Record, 1858, 61-68.

16. Hagerty, M. R. (1999). Testing Maslow's hierarchy of needs: National quality-oflife across time. Social Indicators Research, 46(3), 249-271.

17. Jansson, J.O. (2003). A simple bus line model for optimization of service frequency and bus size in urban transport, Classics in Transport Analysis, 8, 139166.

18. Johansson, M.V., Heldt, T. and Johansson, P. (2004). Latent variables in a travel mode choice model: Attitudinal and behavioral indicator variables. Swedish National Road and Transport Research Institute. Linkoping: Sweden.

19. Landis, B., Vattikuti, V. \& Brannick, M. (1997). Real-time human perceptions toward a bicycle level of service. Transportation Research Record.

20. LeClerc, Schmidt \& Dube (1995). 
21. Li, (2003). Journal of Public Transportation, 6(4).

22. Lowson, M. (2003). New approach to effective and sustainable urban transport. Transportation Research Record, 1838, 42-49.

23. Maslow, A. (1943a). A theory of human motivation. Psychological Review, 50, 370-396.

24. Maslow, A.H. (1943b). Preface to motivation theory. Psychosomatic Medicine, 5, 85-92.

25. Maslow, A.H. (1948a). "Higher" and "lower" needs. Journal of Psychology, 25, 433-436.

26. Maslow, A.H. (1948b). Some theoretical consequences of basic needgratification. Journal of Personality, 16, 402-416.

27. Maslow, A.H. (1950). Self-actualizing people: a study of psychological health. Personality, Symposium No. 1, 11-34.

28. Maslow, A. (1954). Motivation and personality. New York: Harper.

29. Maslow, A.H. (1955). Deficiency motivation and growth motivation. In M.R. Jones (ed.), Nebraska Symposium on Motivation: 1-30. Lincoln, NB.: University of Nebraska Press.

30. Maslow, A.H. (1956). Defense and growth. Merrill-Palmer Quarterly, 3, 36-47.

31. Maslow, A.H. (1967b). A theory of metamotivation: the biological rooting of the value-life. Journal of Humanistic Psychology, 7(2), 93-127.

32. Moriarty, P. and Honnery, D. (2003). Alternative transport fuels: The long-term future. International Journal of Vehicle Design, 31(1), 11-21.

33. Perone, JS \& Tucker, L. (2003). An Exploration of Triangulation of Methodologies: Quantitative and Qualitative Methodology Fusion in An Investigation of Perceptions of Transit Safety. NCTR-416-08.1,; NCTR-41608.2,; FDOT BC 137-22

34. Peters, J. F. (1997). An empirical correlation of Maslow's hierarchy of human needs levels and team performance. Dissertation Abstracts International: Section B: The Sciences \& Engineering, 58(4-B), 2062.

35. Schneider, B., Alderfer, C. P. (1973). Three studies of measures of need satisfaction in organizations. Administrative Science Quarterly, 18(4), 489-505.

36. Seethaler, R. \& Rose, G. (2003). Application of Psychological Principles to Promote Travel Behavior Change. $26^{\text {th }}$ Australasian Transport Research Forum, Wellington, New Zealand.

37. Steiner, Landis, Vattikuti, Miller. (2002). Refinement of the Roadway Level of Service.

38. Thomas, G. (2003). When low fares are not enough: Airlines need to rethink their advertising and branding strategies. Air Transport World, 40(9), 61-62.

39. Ulleberg, P. (2004). Social influence from the back-seat: Factors related to adolescent passengers' willingness to address unsafe drivers. Transportation Research. Part F: Traffic Psychology \& Behaviour, 7(1), 17-30.

40. Vallancourt, C. (2003). Breathing easy: Hybrid vehicles and the future of TDM. TDM Review, 11(1), 11-14.

41. Vogel, M. \& Pettarini. J. (2002). Personal Safety and Transit: Paths, Environments, Stops, and Stations. Report C 02-05. 1-102.

42. Wilson, B. (2004). Teens and Transit: The next generation. Community Transportation. Special Edition, Summer 2004.

43. Winters, PL; Perez, RA; Perone, JS; and Joshi, A. (2005). Worksite Trip Reduction Model and Manual. A report for the Florida Department of Transportation and NCTR. NCTR-473-14; FDOT BC137-41. 1-139. 
44. Winters, PL; Cleland, F; Mierzejewski, E; Tucker, L. (2001). Assessing Level of Service Equally Across Modes. A report for the Florida Department of Transportation and NCTR. Contract BC353RPWO\#15. 1-53. 


\section{Appendix A: Final Questionnaire}

\section{ERG Survey}

Instructions: Please answer the following questions.

1. What is your age and gender?

2. How many children under 16 are living in your home?

3. What is your ethnicity

4. Are you currently employed?

5. Are you a student?

6. How many cars do you have available at your home?

7. Do you have a valid driver's license?

8. Do you currently take any form of transit? If yes, which form of public transit do you take?
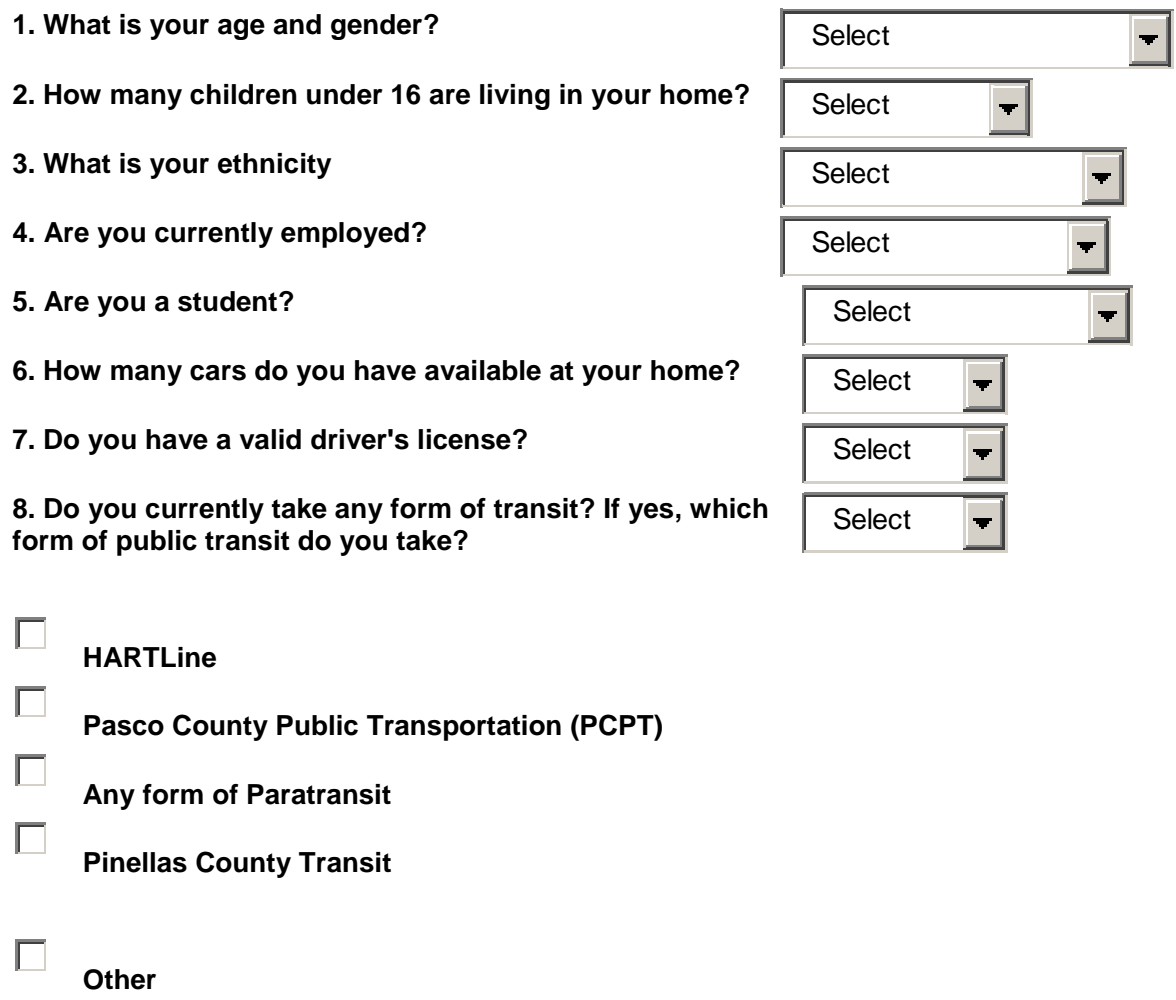

10. Currently, how often do you use the

\section{following modes of transportation?}

Select
Daily $=1$

Several times per week $=\mathbf{2}$

A few times a month $=3$

A few times a year $=4$

Never $=\mathbf{5}$
Drive alone

Carpool (i.e. ride with 2 to 6 persons in a car)

Vanpool (i.e. ride with 7 to 14 persons in a van)

Train

Bus

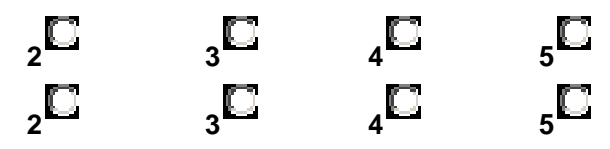




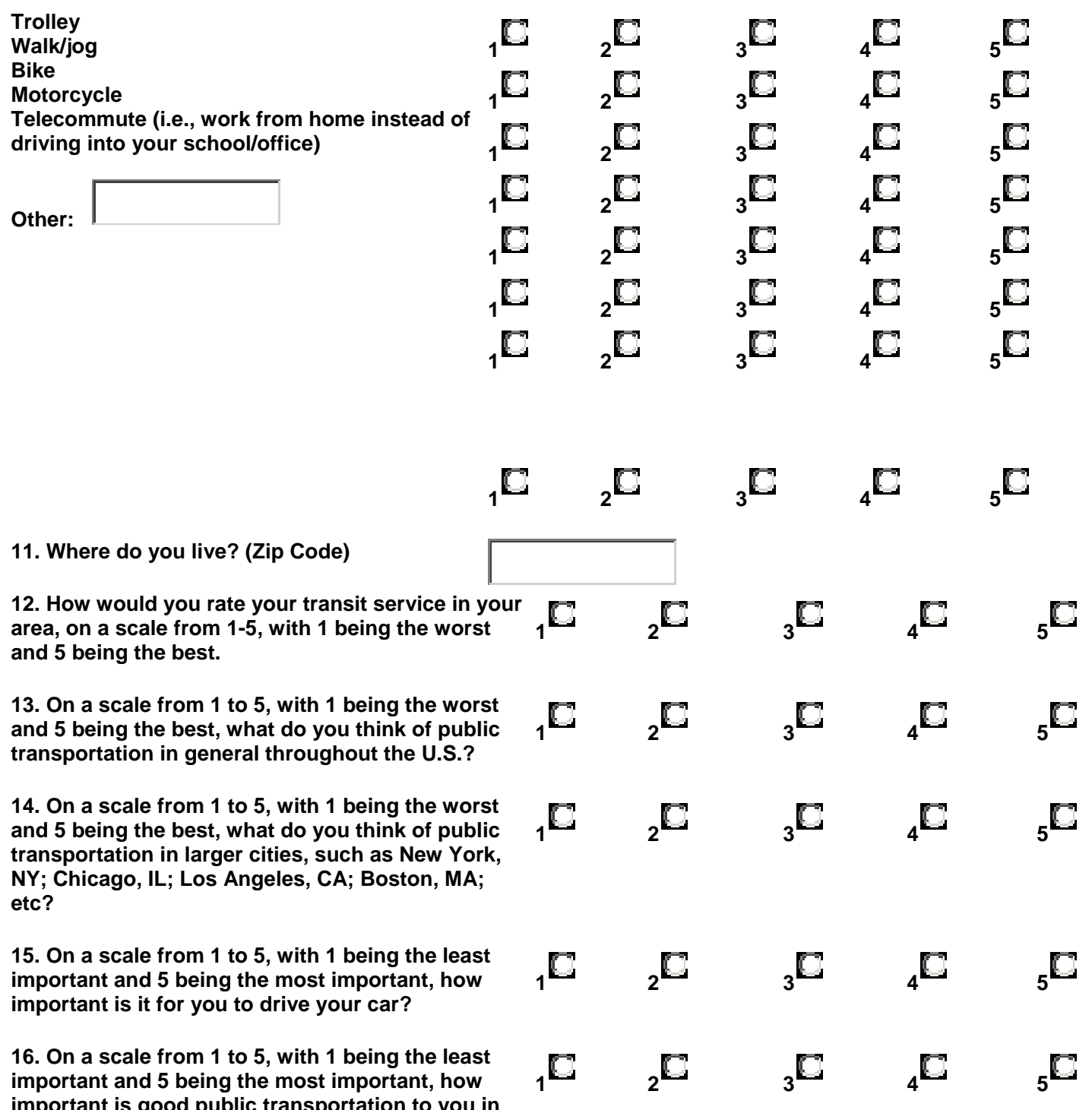

Instructions: As much as you possibly can, please imagine yourself and your actions within the situations listed below by selecting $A$ or $B$ for route, rating the attractiveness of each option, rating the importance of each characteristic, and rating the believability of each situation. Assume only the information given in the situations listed below. In each of the questions, you will be asked to selected between Route A or B and then asked to rank the attractiveness of each Route on a scale from 1 to 5 , with 1 being worst and 5 being best. In addition, there are three questions on the importance of certain attributes in the situation. Please rank the importance of each item on a scale from 1 to 5 , with 1 being least important and 5 being most important. Finally, we ask you to rank the believability of each scenario on a scale from 1 to 5 , with 1 being least believable and 5 being most believable. There are 30 questions on this survey.

1. Before the 9/11/2001 terrorist attacks, you took the subway from the PATH station in New Jersey into work in Lower Manhattan every day and it was very convenient. The PATH station in Lower Manhattan was damaged in the WTC terrorist bombings and had to be reconstructed. During this time, you used a longer route to access your workplace, which took you twice as long as your original commute. Due to your longer commute, the responsibility of picking up your children fell to your spouse. The reconstructed PATH line has opened up and you can now resume your commute on the PATH line. Your spouse wants you to take the new route because it would be easy for you to pick up the children on your way home if you took the reconstructed PATH line. Which do you choose? 


\section{C}

A: You resume your old commute and take the new PATH line. This allows you to pick up your kids, making your spouse very happy and also cutting your commute time in half.

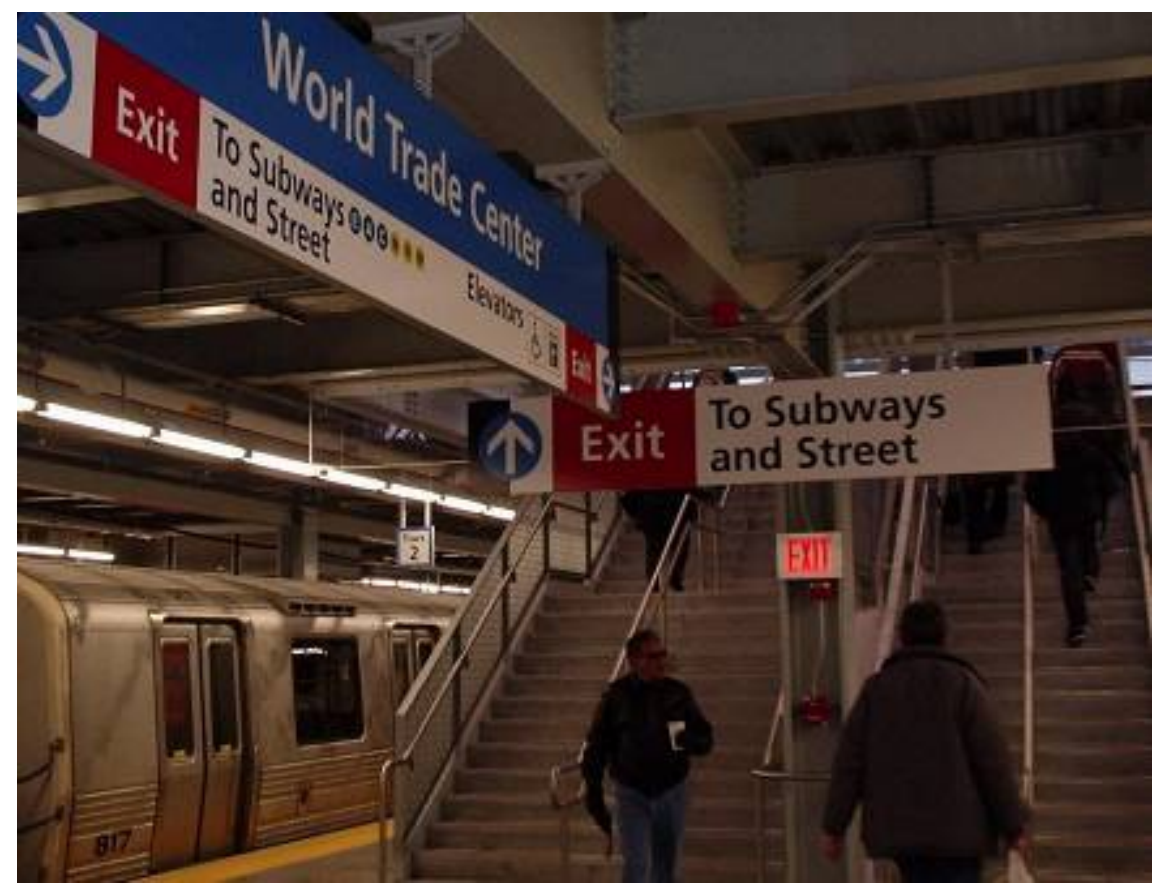

\section{E}

B: You continue to ride the longer route that you feel is safer, even though this means that you won't be able to help your spouse pick up the children before dinner time. You want to help your spouse, but the thought of returning to the PATH line terrifies you and you can't seem to get it out of your mind.

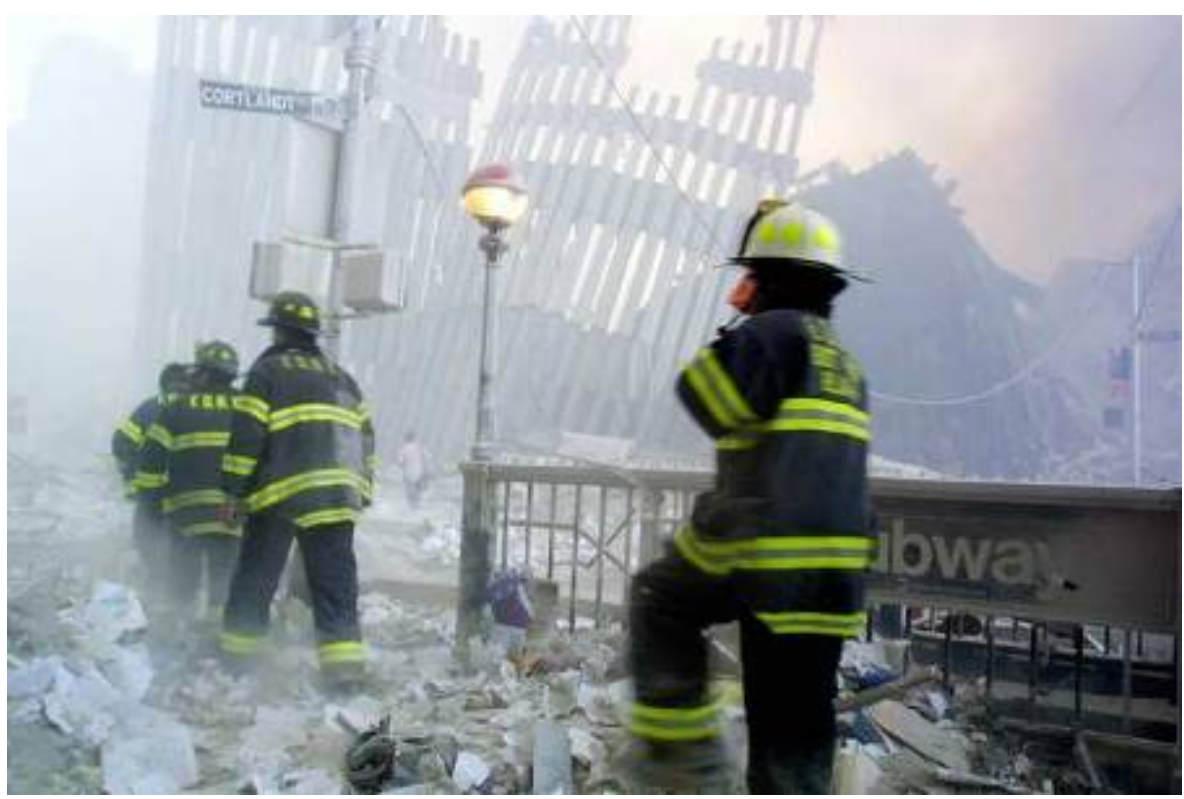


Directions: Please answer the following questions for this situation. For each of the following questions 1 is the lowest and 5 is the highest rating.

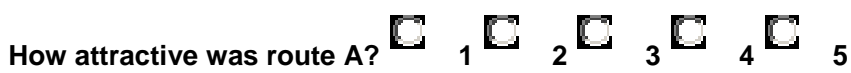

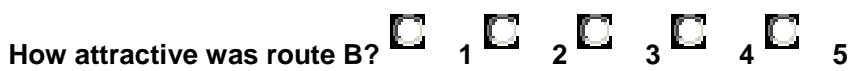

How important it is to feel safe during your work commute.

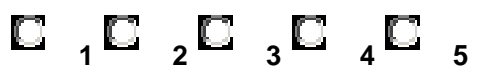

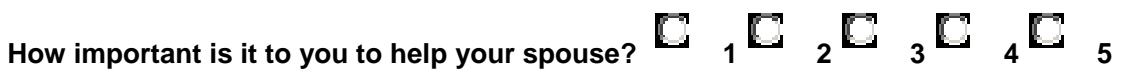

How important is the monetary cost of riding each route?

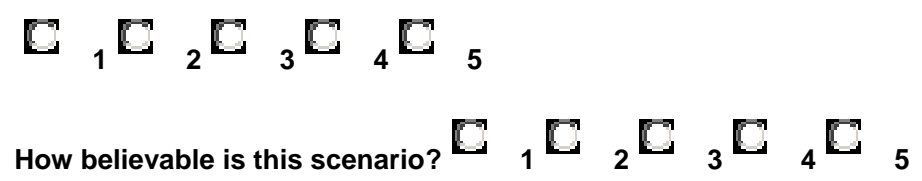

Question ER2

You will be taking a train this evening to eat dinner with your family. You have a choice of two trains, an express train that will get you to the stop at the same time your mother arrives to her park and ride lot at the train station and another train that will get you there $\mathbf{4 5}$ minutes later. You know that the later train will be a lot less crowded than the express train and you will have space to sit and be comfortable. Which do you choose?

A: You choose to ride the express train so that you can accommodate you mother's schedule, even though you are unable to find a seat and are very uncomfortable during the $\mathbf{4 0}$ minute train ride.

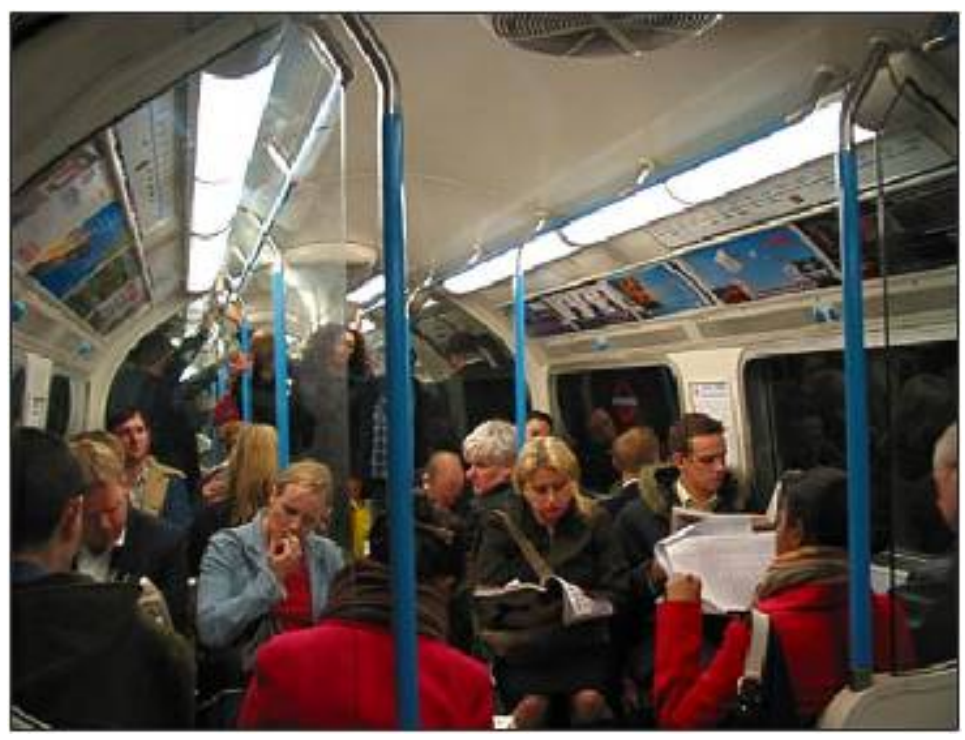


C

B: You choose to go against your parent's wishes and choose to ride on a train that has plenty of seats so that you can be comfortable on for the trip. Your mother is unhappy that she had to wait on you, but you were comfortable for the trip.

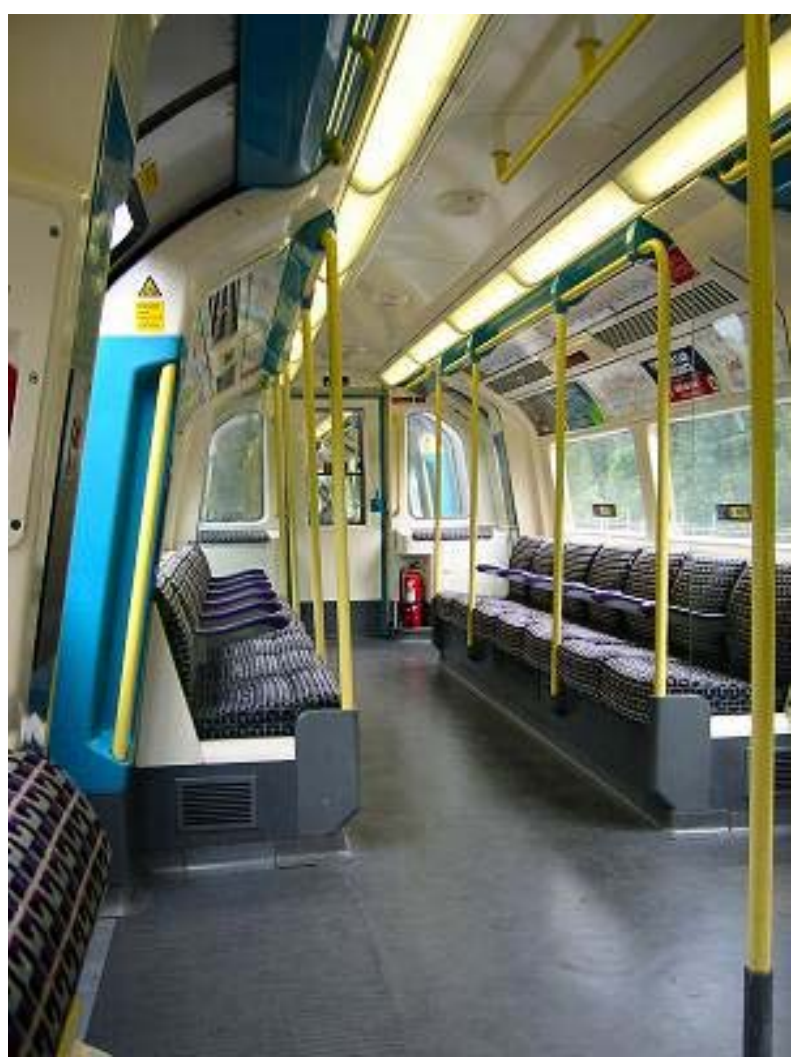

Directions: Please answer the following questions for this situation. For each of the following questions 1 is the lowest and 5 is the highest rating.

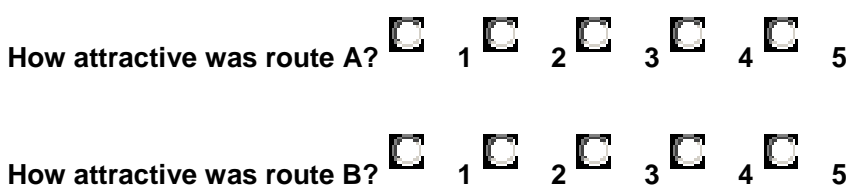

How important was it to be comfortable on your train ride?

\section{$\mathrm{C}_{1} \mathrm{C}_{2} \mathrm{C}_{3} \mathrm{C}_{4} \mathrm{C}_{5}$}

How important was it to accommodate your mother?

\section{$\mathbb{C}_{1} \mathrm{C}_{2} \mathrm{C}_{3} \mathrm{C}_{4} \mathrm{C}_{5}$}

How much each route cost to ride? $\mathrm{C}_{1} \mathrm{C}_{2} \mathrm{C}_{3} \mathrm{C}_{4} \mathrm{C}_{5}$
How believable is this scenario? $\mathrm{C}{ }_{1} \mathrm{C}{ }_{2} \mathrm{C}_{3} \mathrm{C}_{4} \mathrm{C}_{5}$




\section{Question ER3}

You are staying on a small island for the summer and you are going to go bike riding to your friend's house and the only route is a soft dirt road. You have a choice of two bikes to ride. The first bike makes it much easier to ride in the sand and the second makes it much harder to ride in the sand on the way to your friend's house. The sand bike, because of its light, large plastic wheels, is fairly easy to maneuver in the sand and will get you to your friend's house quickly and easily. However, your friend thinks that these sand bikes look ridiculous and will probably make fun of you if you ride the sand bike. Your friend likes the bike that you use on the paved roads around the island, but this bike will be very hard to ride in the sand. Which do you choose?

A: You choose the sand bike because you know that it will be easy to maneuver it in the loose sand on the way to your friend's house and you don't care if your friend thinks it looks silly, because you don't want to put yourself through trying to ride a bike that is not designed for use in the sand to impress your friend.

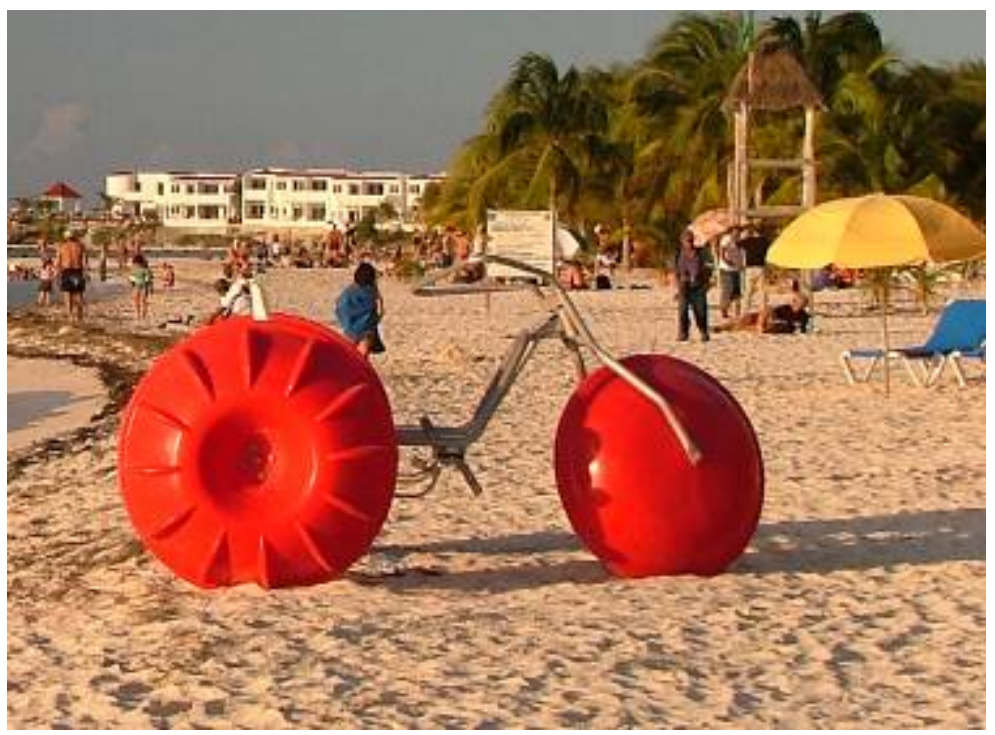

Ca

B: You choose the bike designed for use on pavement, even though you know you'll have a heck of a time trying to maneuver it through the loose sand. You want to impress your friend with the bike you know that he or she likes. 


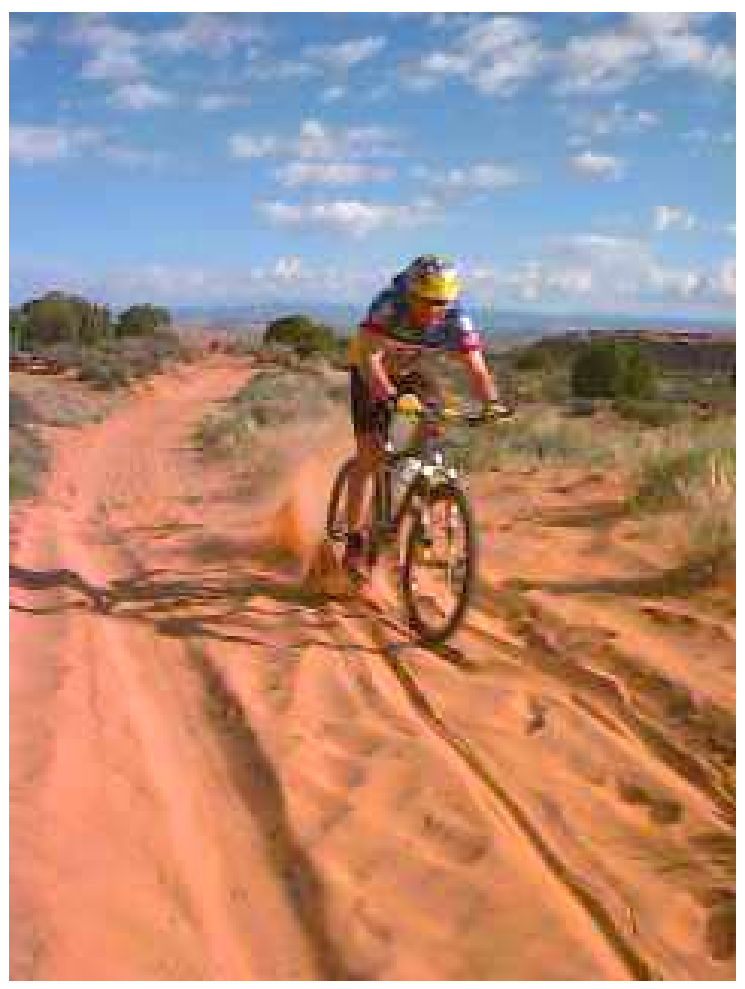

Directions: Please answer the following questions for this situation. For each of the following questions 1 is the lowest and 5 is the highest rating.

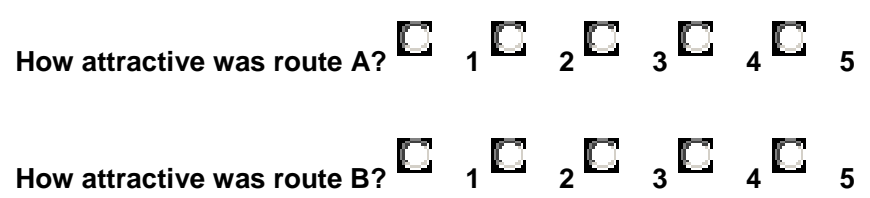

How important is it that you can safely maneuver your bike in the sand? ${ }_{1} C_{2} C_{3} C_{4} C_{5}$

How important is it for you to impress your friend?

$C_{1} C_{2} C_{3} C_{4} C_{5}$

How important is it to ride your bike to help the environment?

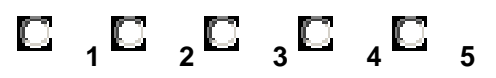

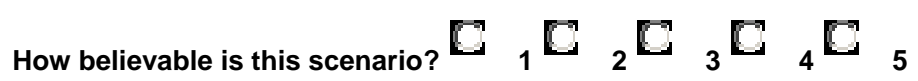

Question ER4

You need to use transit to get to a football game in a place with which you are not extremely familiar. You have a choice between two special event transit pick-up areas. However, the passengers who typically ride this bus line 
are opposing fans and they have hassled you the few times you have ridden this shuttle service in the past. You understand that there are two shuttle pick-up areas, one for the opposing team and one for the home team. You haven't yet been able to locate the opposing team pick-up area, because you have only ridden the shuttle bus from the home team pick-up area. Which do you choose?

C

A: You ride from the home team pick-up into the stadium, because you don't want to get lost looking for this visitor pick-up area. You can handle being harassed, but not being lost.

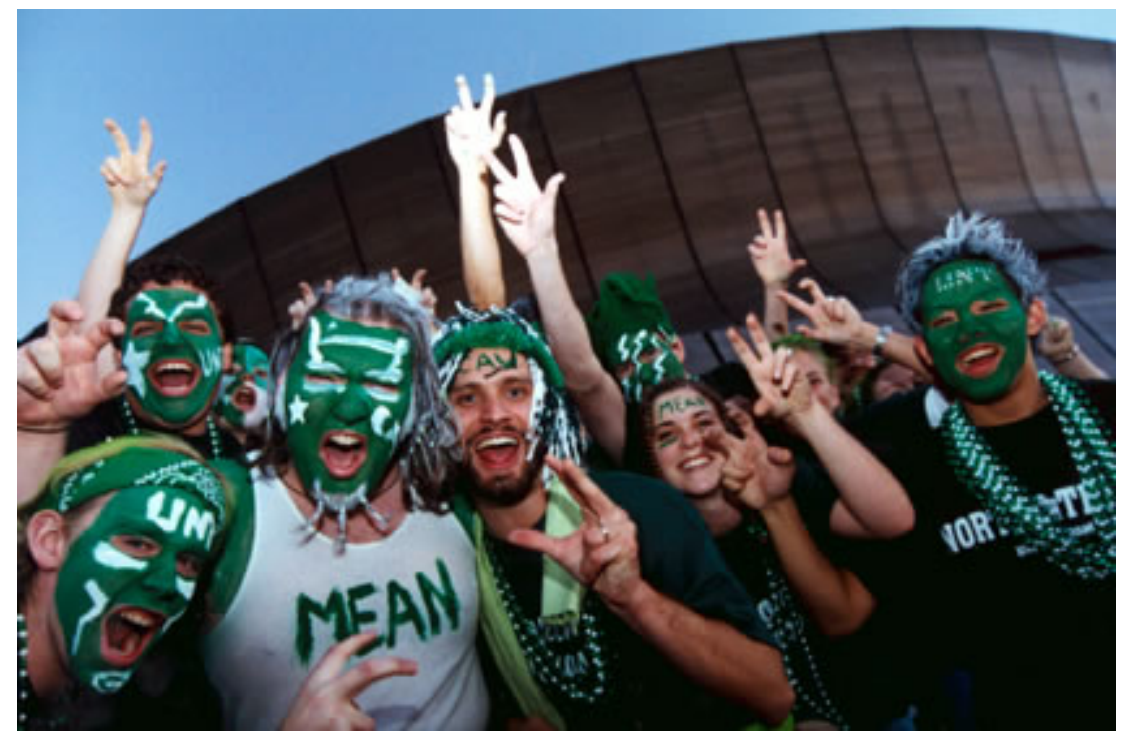

C

B: You go looking for visitor's pick-up point so that you don't have to be harassed on your way into the stadium. It took approximately 10 minutes to find this area, but you feel more comfortable riding into the game with the fans from your team and now you know you won't get lost again.

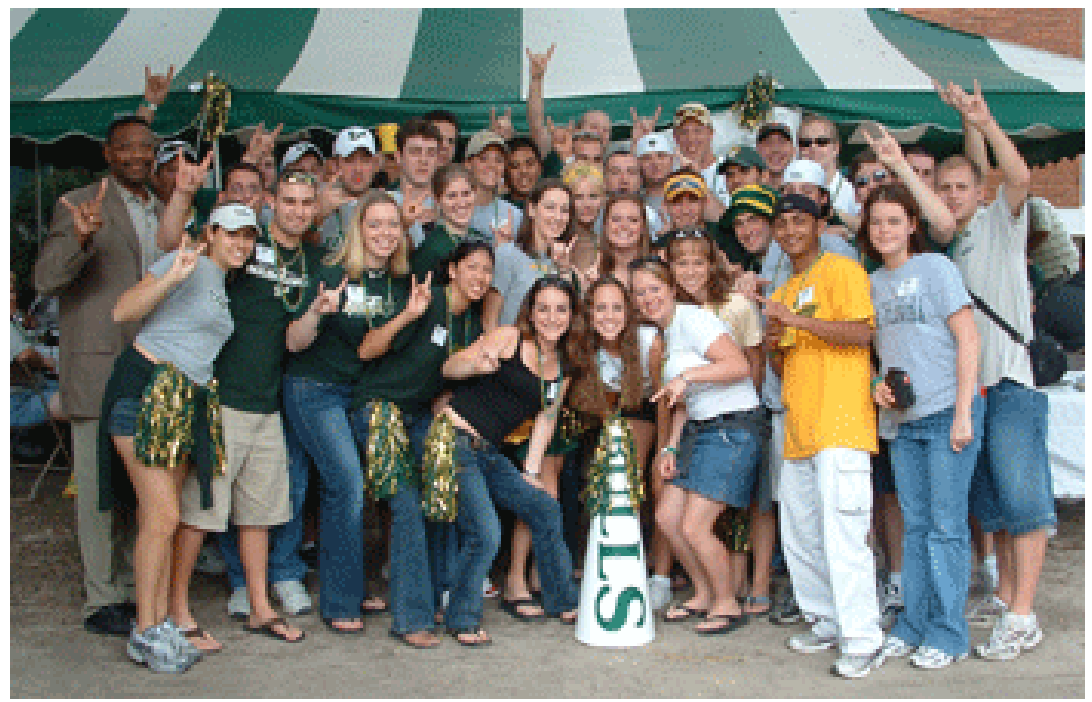

Directions: Please answer the following questions for this situation. For each of the following questions 1 is the lowest and 5 is the highest rating.

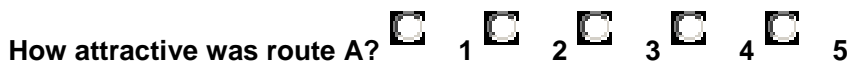




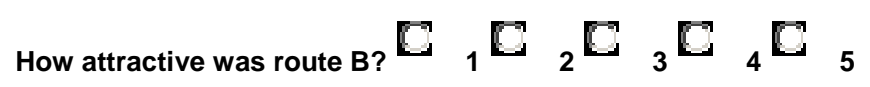

How important is it to not get lost on your way to the game?

\section{$\mathrm{C}_{1} \mathrm{C}_{2} \mathrm{C}_{3} \mathrm{C}_{4} \mathrm{C}_{5}$}

How important is it to not be harassed by opposing team fans?

\section{$\mathrm{C}_{1} \mathrm{C}_{2} \mathrm{C}_{3} \mathrm{C}_{4} \mathrm{C}_{5}$}

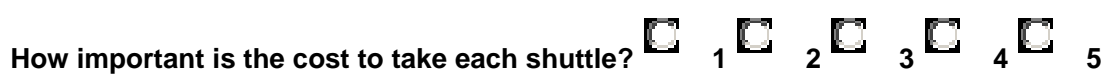

How believable is this scenario? ${ }_{1}{ }_{1}{ }_{2}{ }_{2}{ }_{3}{ }_{4}{ }_{4}{ }_{5}$

Question 5 ER

You and your spouse would like to drive a car 50 miles to Glacier National Forest for some hiking. There are two cars available for the drive, your 2004 H2 Hummer or your significant other's Toyota Prius, which needs some brake work. You want to take the Hummer because it is in perfect running condition, especially for the steep mountain twists and turns found in the park. Your significant other has never liked the Hummer because it is 'an ostentacious gas-guzzler.' Your significant other would rather take a more 'humble' car, even if it needs brake work, and claims that the Prius is fundamentally sound for mountainous travel. What do you choose?

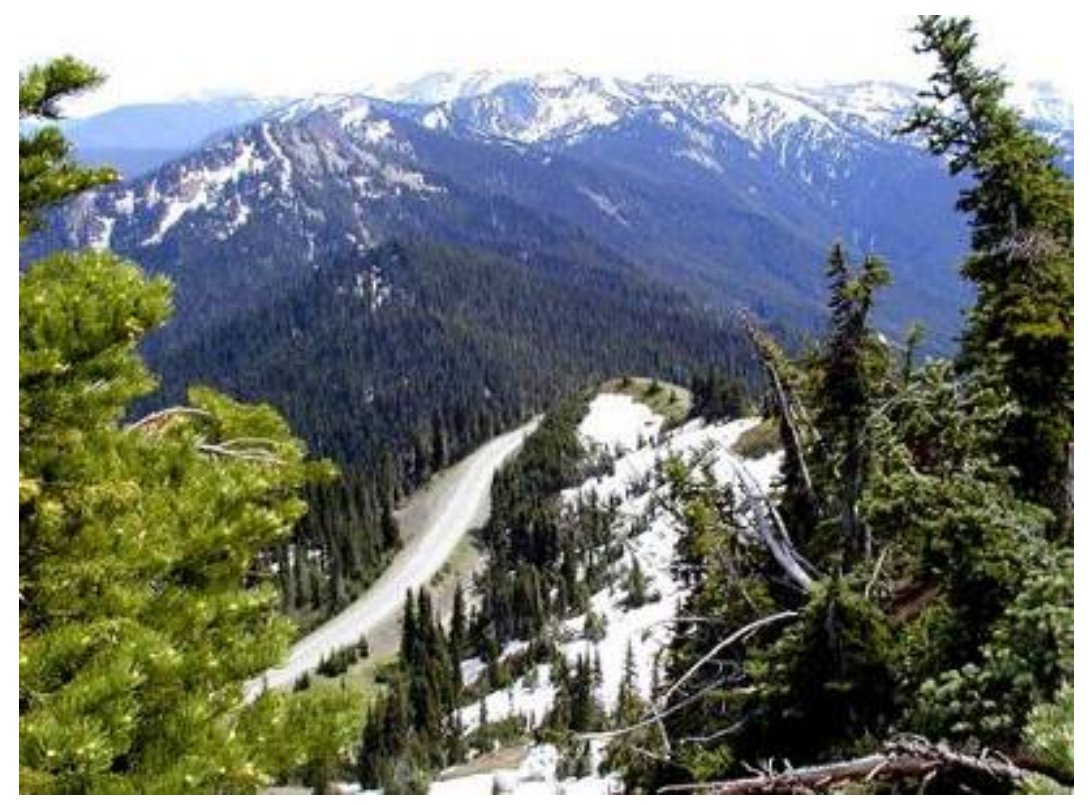

A. You honor the wishes of your significant other to NOT ride in your H2 Hummer and you take the Prius on the mountain ride, reasoning that their happiness is more important than little brake work. 


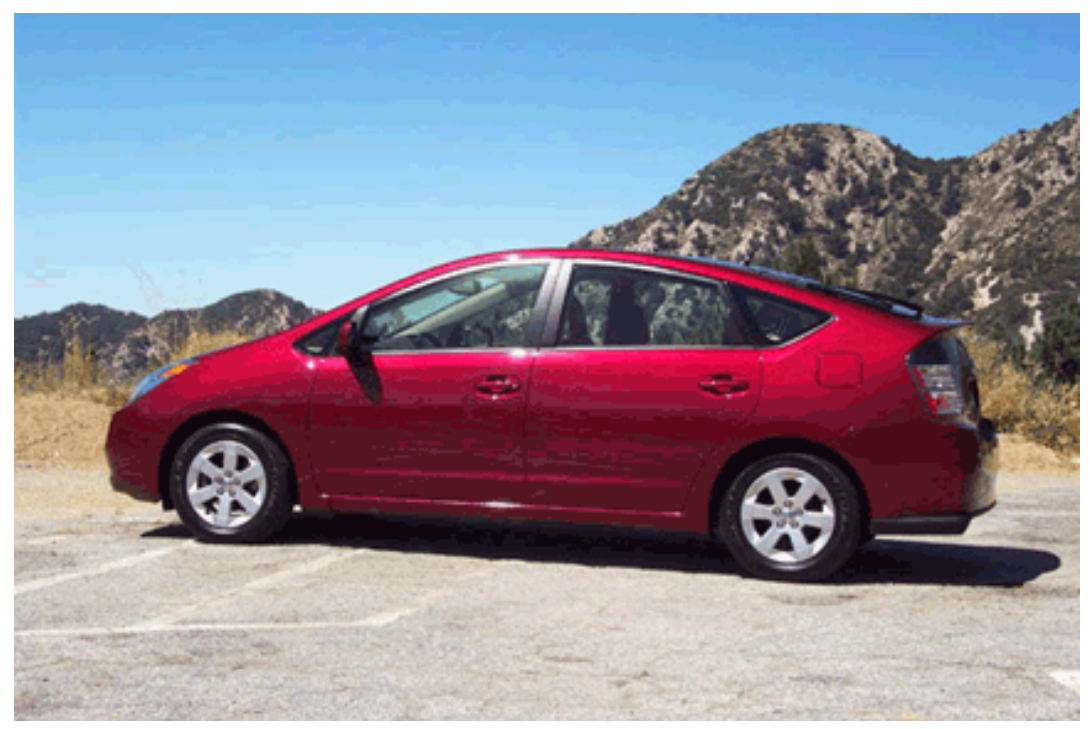

C

B. You're worried that the brakes on the Prius might not be safe enough for mountain climbing and so you insist on bringing the car which has the safer equipment, even though your significant other resents having to ride in the 'gas-guzzler.'

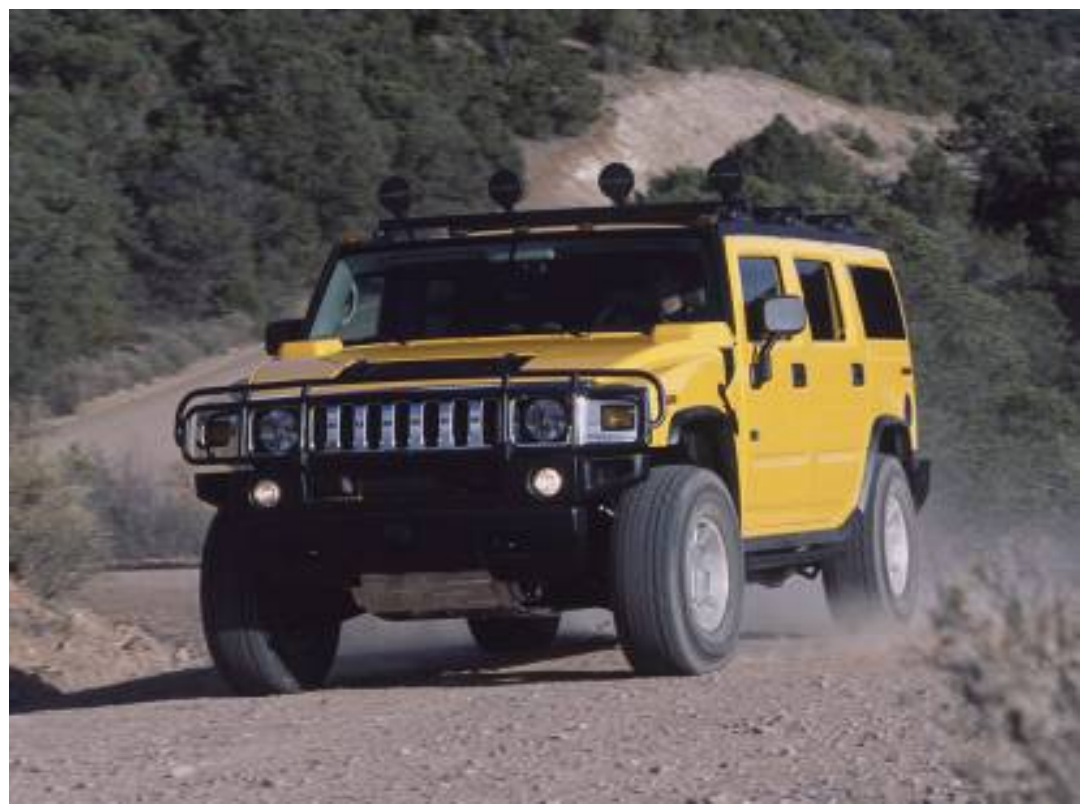

Directions: Please answer the following questions for this situation. For each of the following questions 1 is the lowest and 5 is the highest rating.

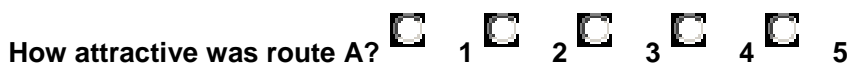

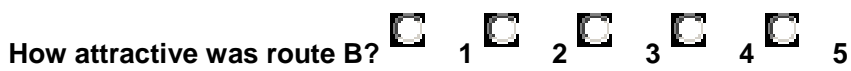

How important is it to have safe brakes in the mountains? 


\section{$\mathrm{C}_{1} \mathrm{C}_{2} \mathrm{C}_{3} \mathrm{C}_{4} \mathrm{C}_{5}$}

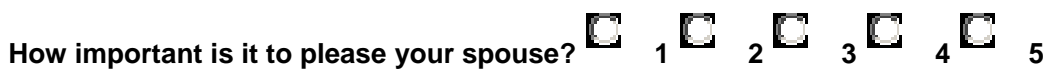

How important is it to try to reduce greenhouse emissions?

$\mathrm{C}_{1} \mathrm{C}_{2} \mathrm{C}_{3} \mathrm{C}_{4} \mathrm{C}_{5}$

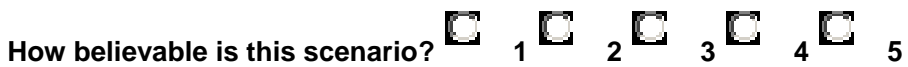

\section{Question ER6}

You take the train to work each morning. You usually wait 15 minutes for the train to arrive. You have the choice of riding one of two trains, which arrive 5 minutes apart at separate platforms, so that if you decided to take one train, you would not see the people from the other train. The one train arrives on platform $A$ and usually has some unusual types of people waiting to load and these people make you feel nervous about what they might do. However, one of the days when you were waiting on platform A, you noticed a very attractive person getting off the train as you were getting on. If you use the train at platform $B$, you probably will not see this possible love interest again soon, but you will be waiting with people who make you feel safer. What do you do?

A. You take the train at platform A, because you want to see that very attractive person again. You can handle the nervousness over the strange people if you can see this potential love interest again.

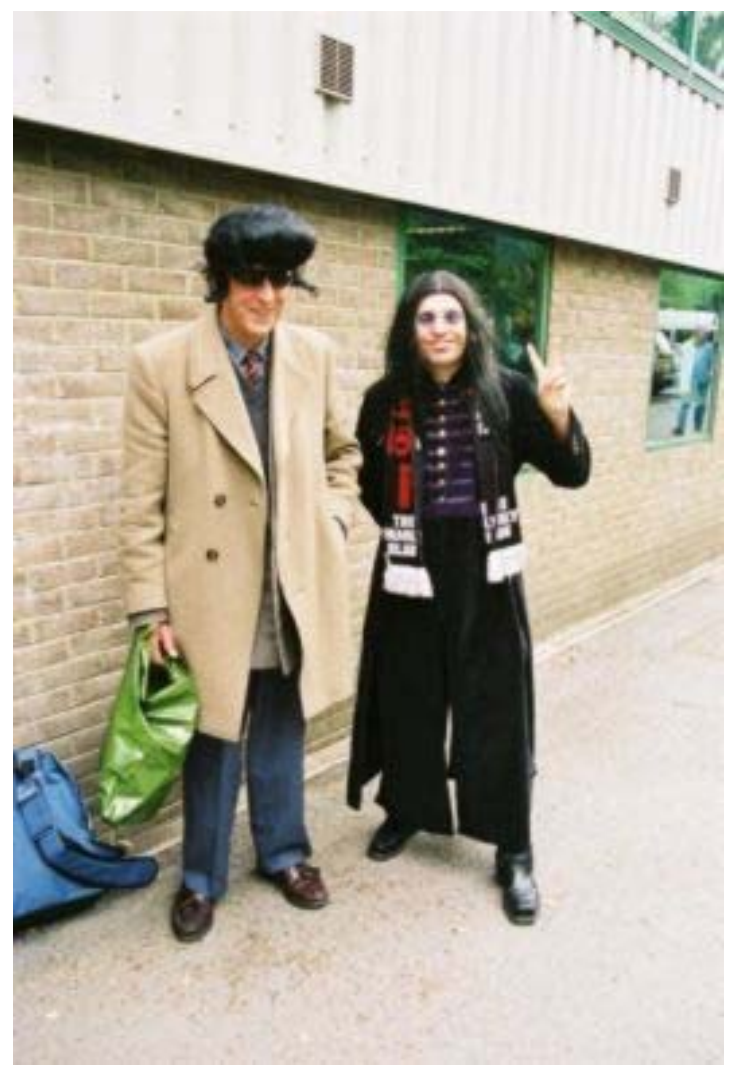


B

B. You take the train from platform B, because the unusual people just make you feel too unsafe and you want to wait with people who make you feel safer.

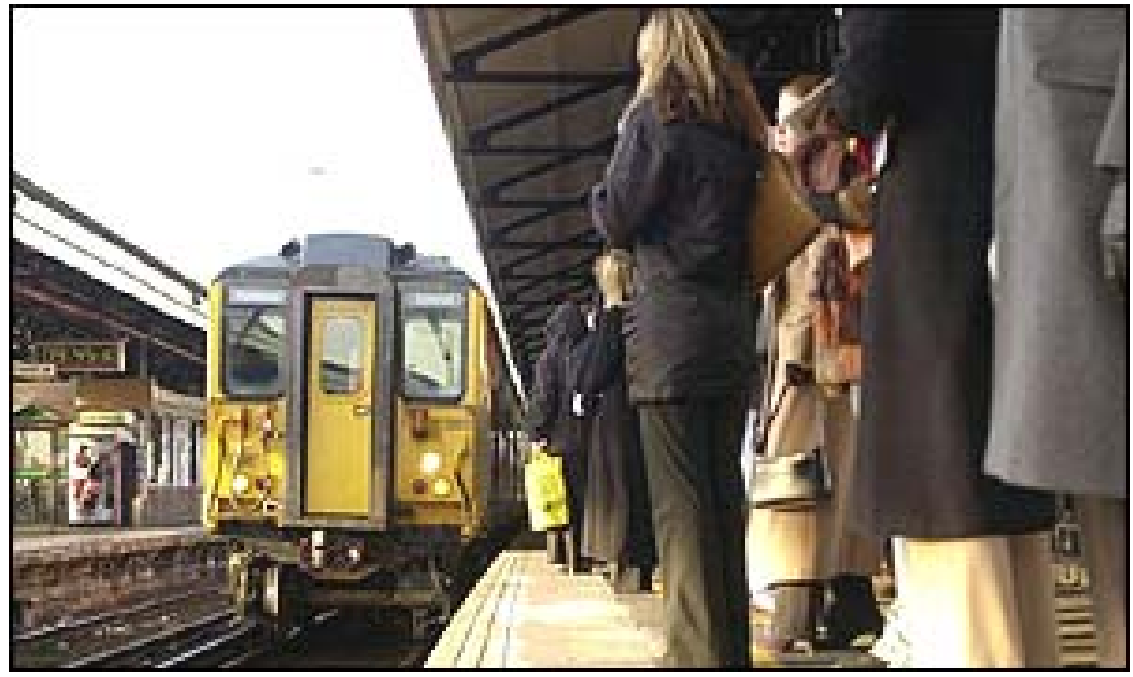

Directions: Please answer the following questions for this situation. For each of the following questions 1 is the lowest and $\mathbf{5}$ is the highest rating.

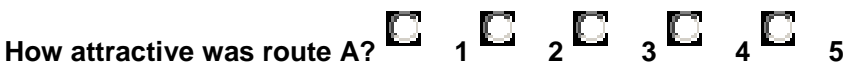

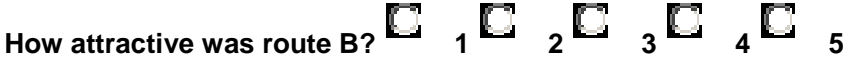

How important is it to feel comfortable in your transit waiting area?

$\sigma_{1}{ }_{2}{ }_{2}{ }_{3}{ }_{4}{ }_{5}$

How important is it to see your potential love interest again?

$\sigma_{1}{ }_{2}{ }_{2}{ }_{3}{ }_{4}{ }_{5}$

How important it is to help the environment by using transit?

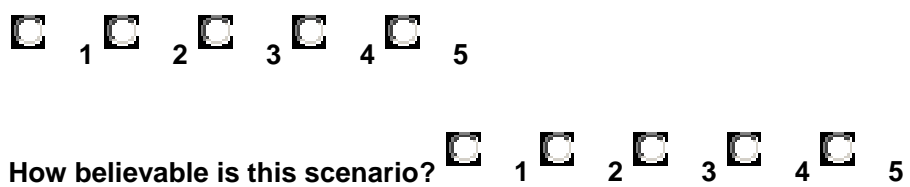

Question ER7

You are going to start riding your bike to work, a commute of 3-4 miles every day. A group of your friends also want to ride into work with you. However, you disagree on which route to take. Your friends want to take a shorter route, that is 3 miles long, that includes some very congested roads on which you don't feel safe. You want to take the 4 mile route which has less congestion and is safer. But, you also really would like to ride with your friends, because it will make the bike ride more fun. What do you choose? 


\section{C}

A. You choose to ride with your friends on the congested road, because you would rather ride a shorter route and be with your friends riding into work than alone.

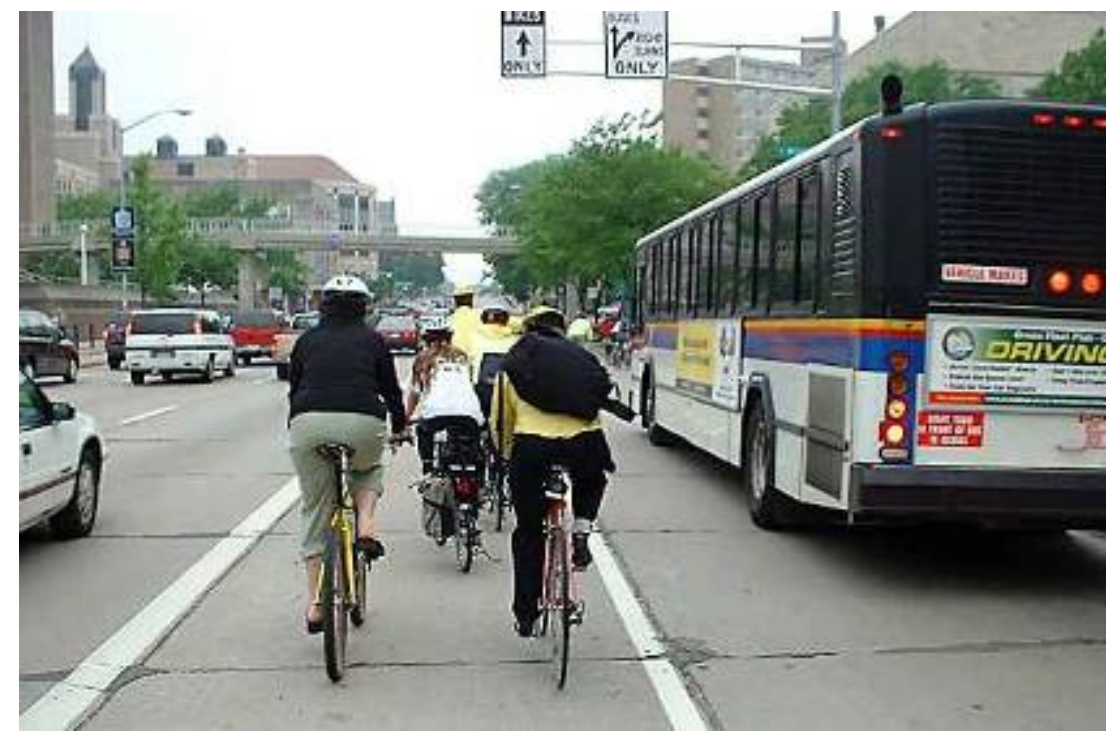

C

B. You choose to ride in the safer, less congested area, even though you have to ride a longer distance and you can't ride with your friends.

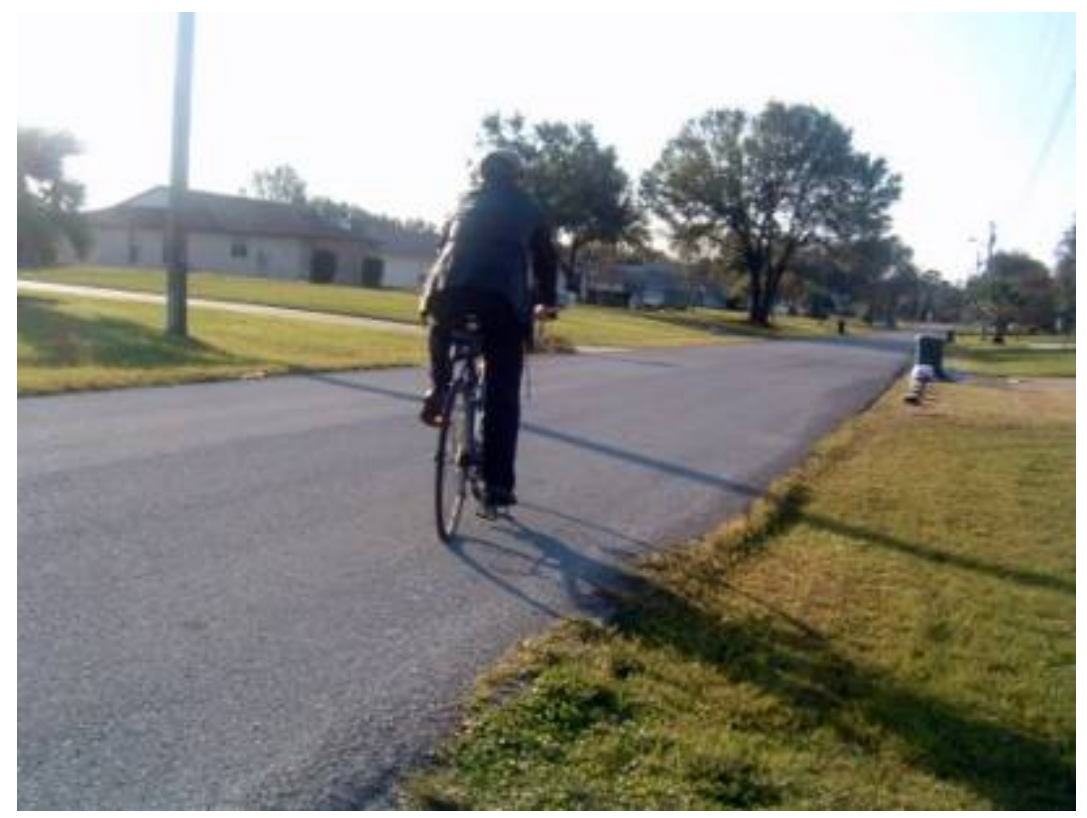

Directions: Please answer the following questions for this situation. For each of the following questions 1 is the lowest and 5 is the highest rating.
How attractive was route ${ }_{A}{ }^{C_{1}} \mathrm{C}_{2} \mathrm{C}_{3} \mathrm{C}_{4} \mathrm{C}_{5}$
How attractive was route $B ?{ }_{1} C_{2}{ }_{3}{ }_{3}{ }_{4}{ }_{5}$ 
How important is it to feel safe on your chosen bike route?

\section{$C_{1} C_{2} C_{3} C_{4} C_{5}$}

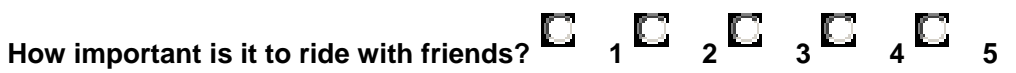

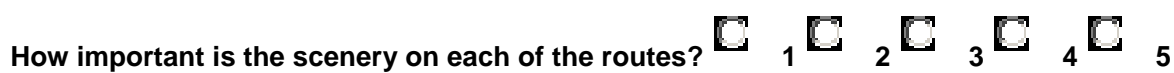

How believable is this scenario? ${ }_{1}{ }_{1}{ }_{2}{ }_{2}{ }_{3}{ }_{4}{ }_{4}{ }_{5}$

\section{Question ER8}

You are going to take the bus to the mall. You have the option of two different bus stops which are convenient to your house. The bus stop that is only 2 blocks from your house makes you feel a bit nervous, because there is no shelter or bench, it is very close to the oncoming flow fast traffic, and there is a large overhang from the building next to the bus stop that makes you feel a bit crowded. Most of your friends use this stop. The other stop is a really nice shelter, with plenty of bench space and protection from the elements, as well as protection from the oncoming traffic. This stop makes you feel much safer than the one that is so exposed to traffic. However, you have to walk 3 blocks to access this stop and your friends don't usually use this stop. But, you do like the fact that you have shelter and a place to sit. Which do you choose?

A: You choose to walk the extra block to access the safer stop because you like the safety that this stop affords you, as opposed to the corner stop. You don't mind if you don't get to wait with your friends.

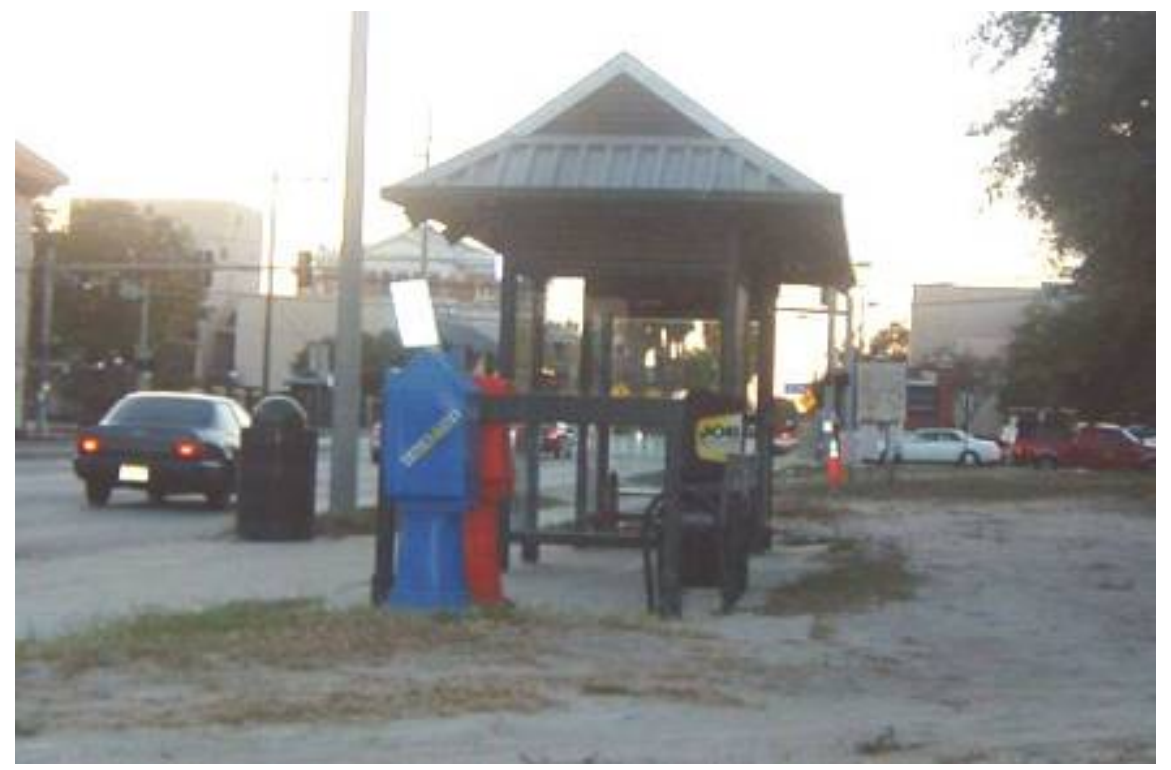

C

B. You choose the corner stop because it is more convenient and you can wait with your friends. You are not all that concerned about your safety being in such close proximity to traffic. 


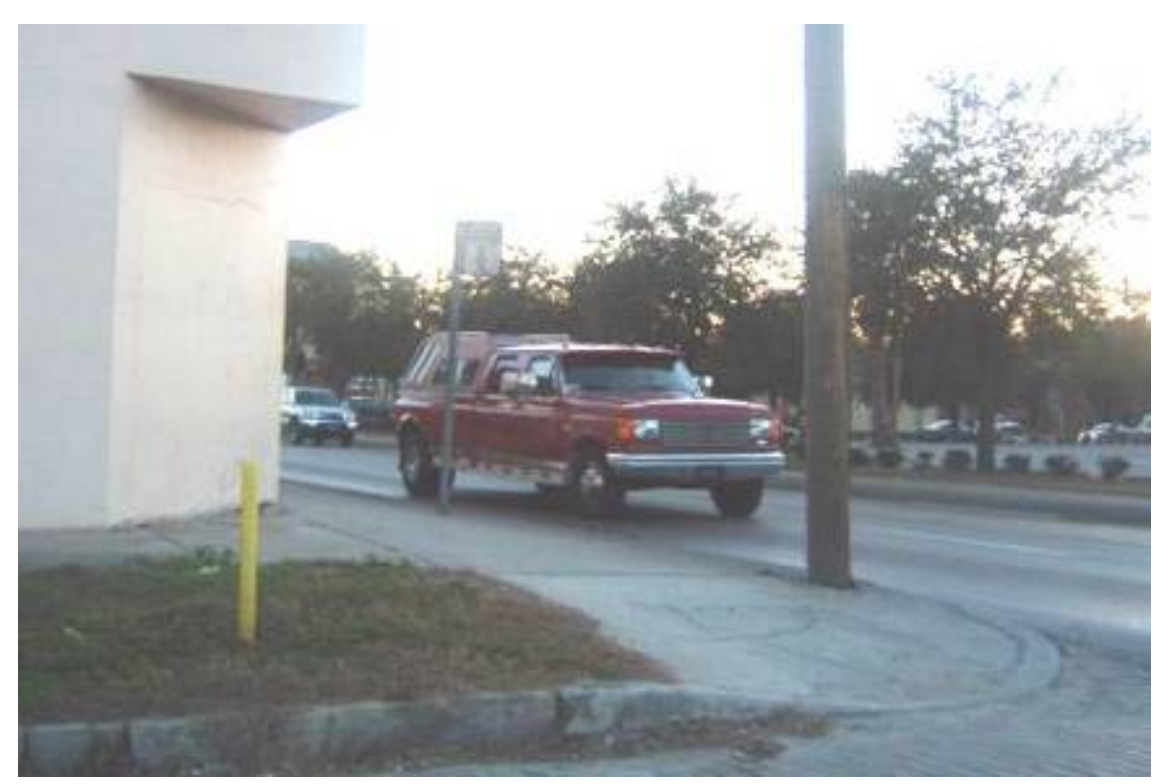

Directions: Please answer the following questions for this situation. For each of the following questions 1 is the lowest and 5 is the highest rating.

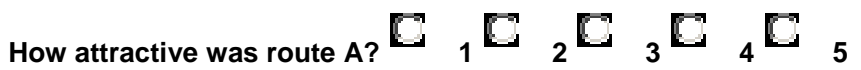

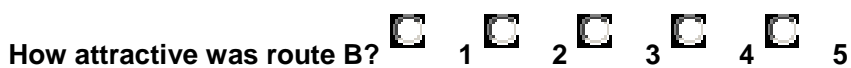

How important is it to wait in an area that is safe from oncoming traffic?

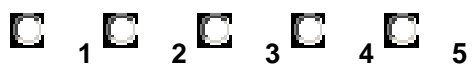

How important is it to wait with your friends at the bus stop?

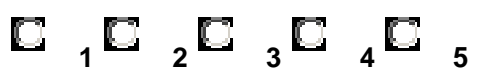

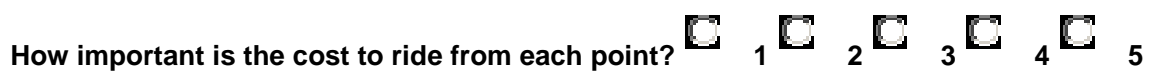

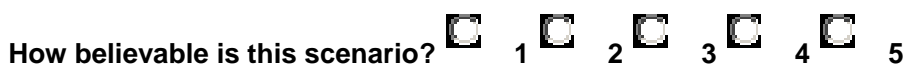

\section{Question ER9}

You are going to walk to the store and you have two paths to choose from. On one of the paths, you must cross a gas station in order to get to the store. This is the shortest and most convenient route and you are able to stop by your friend's Pizzeria on the way. Recently, there have been some gang members hanging out in this gas station lot and you feel afraid to cross by the gas station because of this reason. You used to like to stop by your friend's pizzeria to hang out and have a slice on the way back from the store. But, you have started taking the second route, even though it is longer and more complex and does NOT go by your friend's Pizzeria. You really want to stop by your friend's pizzeria on the way home from the store today. What do you do? 
C

A. You choose to take the route that takes you by the gas station, hoping that the gang members will not notice you crossing in front of 'their' gas station. You want to go hang out with your friend at the pizzeria and you don't want to let the hoodlums scare you off any longer.

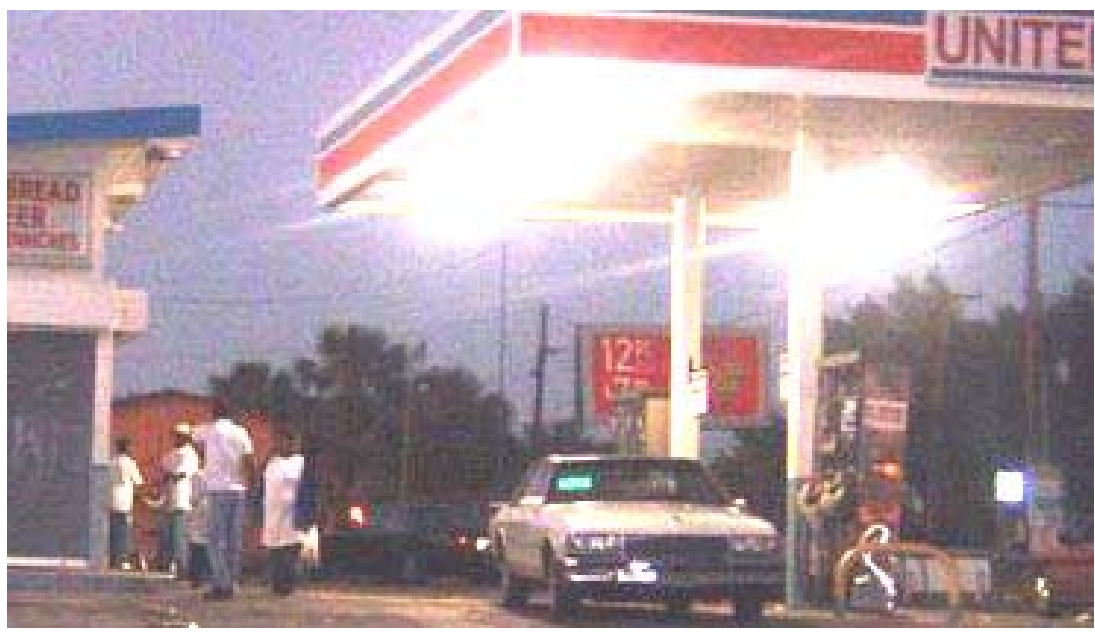

C

B. You choose the second route that is longer, but safe from the gang members. This doesn't allow you to see your friend, but you figure that you can call for carry out if you want some pizza and your friend can come and visit you in your home, where you feel safer.

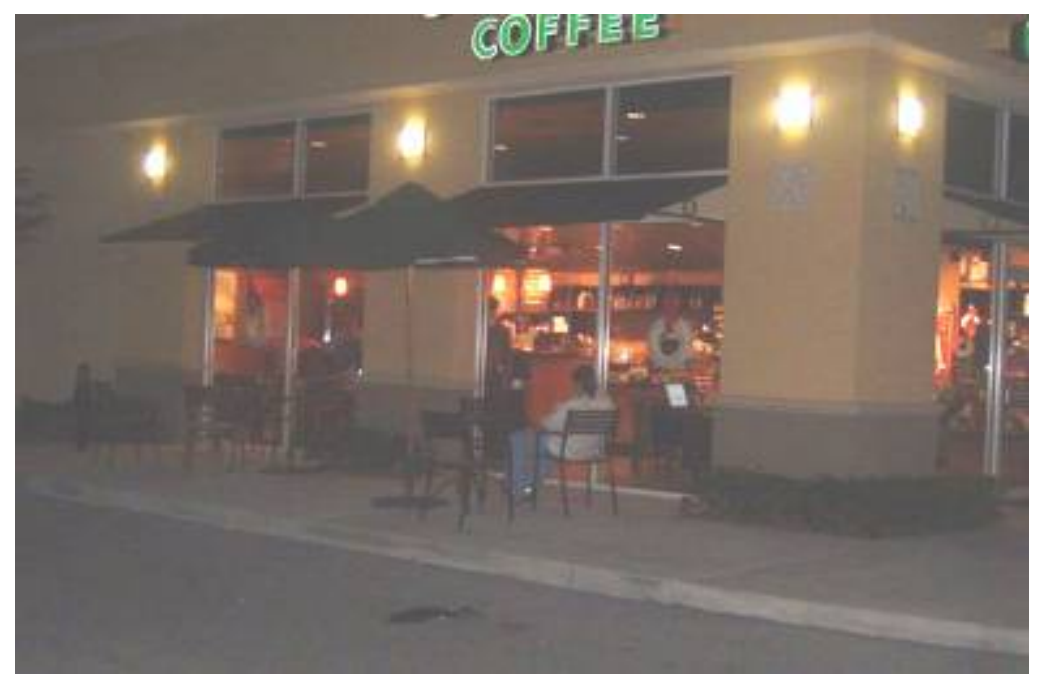

Directions: Please answer the following questions for this situation. For each of the following questions 1 is the lowest and 5 is the highest rating.

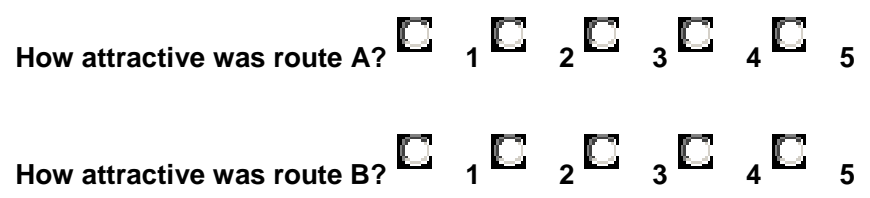

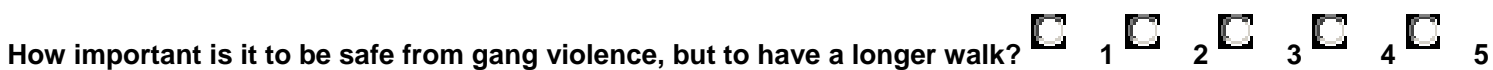




\section{$C_{1} C_{2} a_{3} a_{4} b_{5}$}

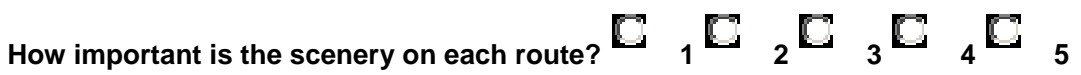

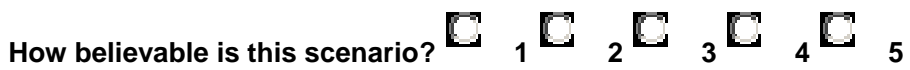

\section{Question 10 ER}

You are driving with your boylgirlfriend in a rural area on your way to a local College campus. Your girl/boyfriend thinks that you should take a route into campus that is rural and icy and slippery, because he/she wants to show you this place where you can go sledding this weekend. You feel nervous riding on icy roads, but you know that your boylgirlfriend will be angry if you choose not to go by the sledding site. You also know how terrified you were when you lost control of your car on this same slippery route a week ago. Which do you choose?

A. You choose the local maintained route for your own safety and, since he/she is riding with you, the safety of your boylgirlfriend. Your boylgirlfriend is very upset and unhappy that you won't drive by the sledding site and pouts all the way into campus, but you feel more comfortable on the maintained route.
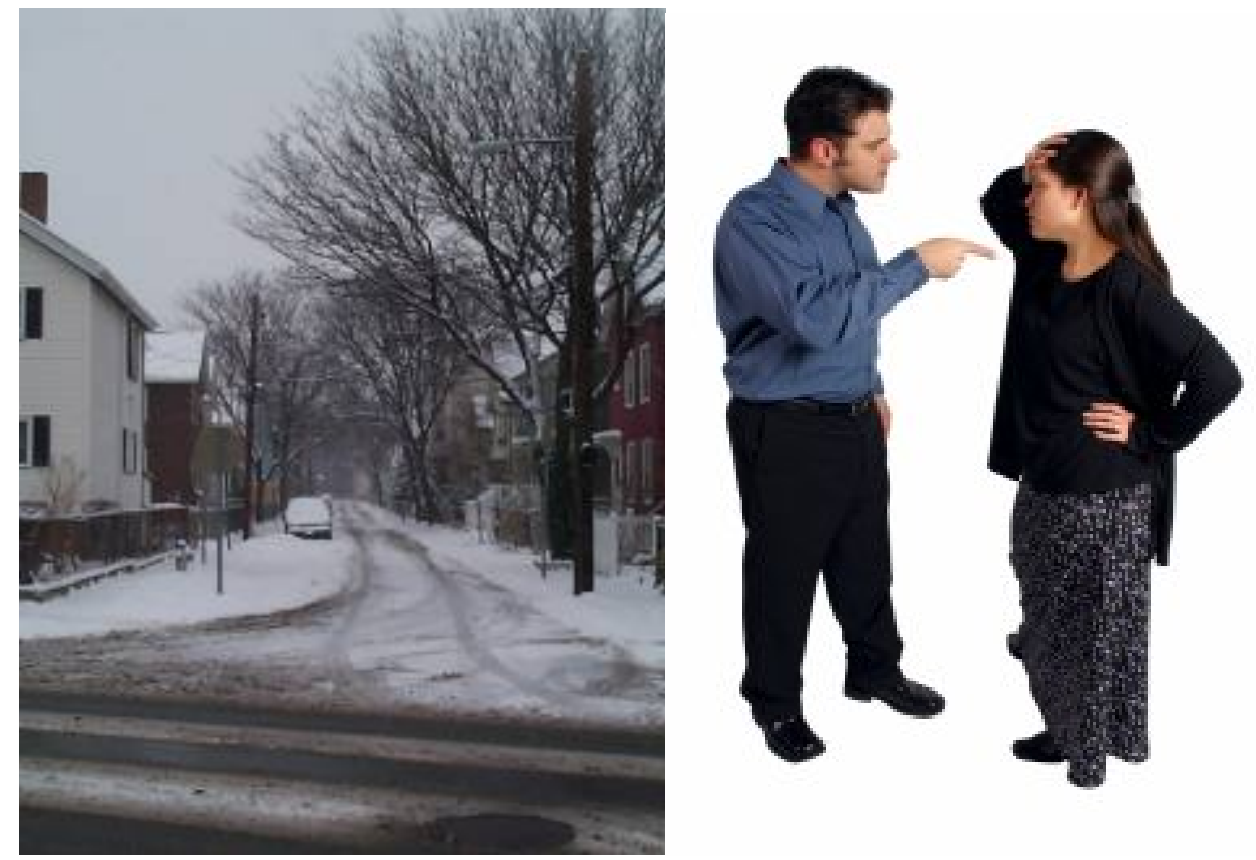

B. You choose to indulge your boy/girlfriend and drive by the sledding site on the way to campus, even though you don't feel safe driving on an unplowed icy road and you are afraid that you might have an accident. But, you are glad that you are making your boy/girlfriend happy. 


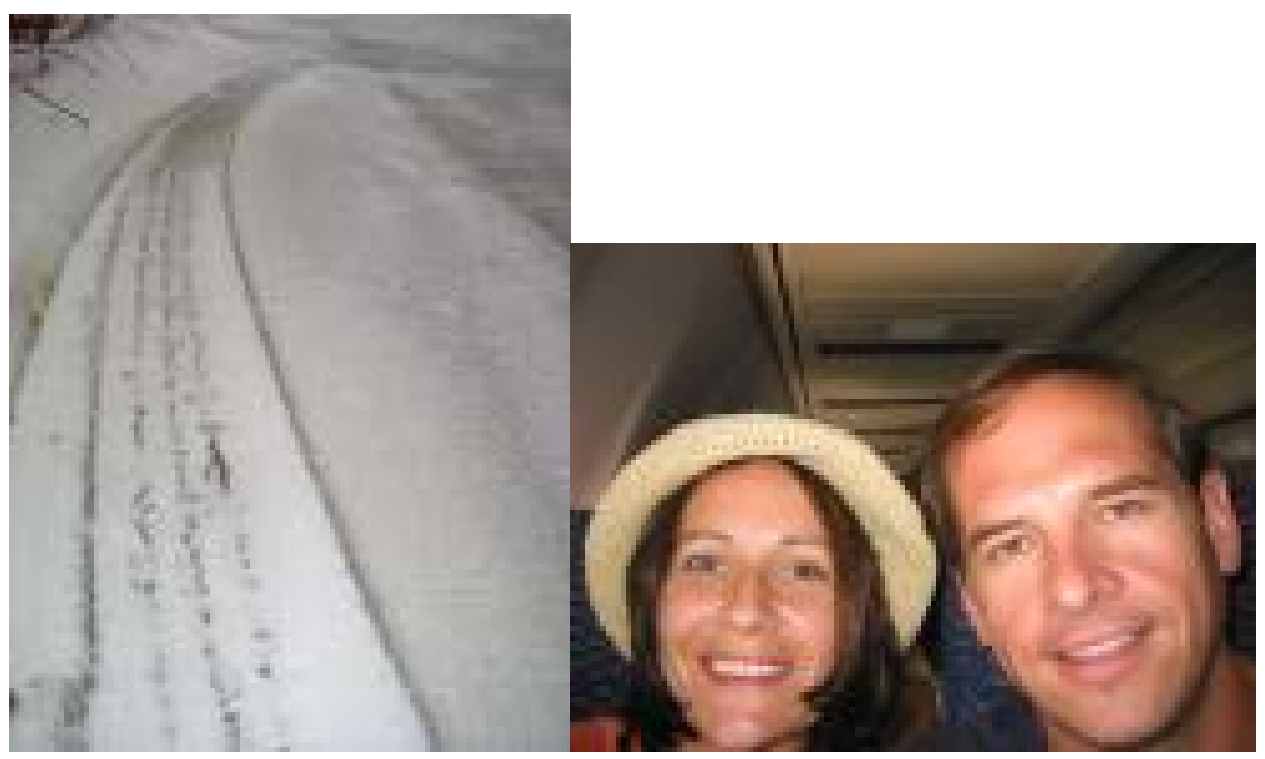

Directions: Please answer the following questions for this situation. For each of the following questions 1 is the lowest and 5 is the highest rating.

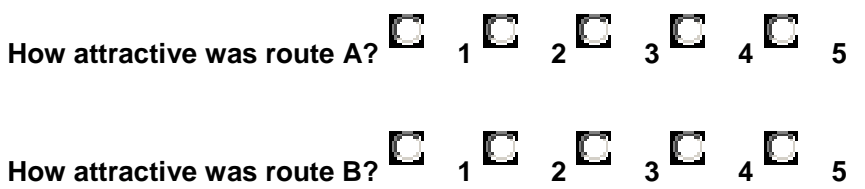

How important is it for you to be able to safely control your car on icy roads? ${ }_{1}{ }_{1}{ }_{2} \quad{ }_{3} C_{4} C_{5}$ How important is it for you to make your boy/girlfriend happy?

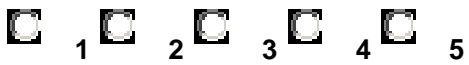

How important is it that you see nice scenery on the way?

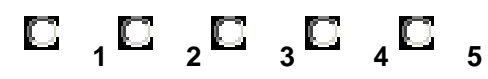

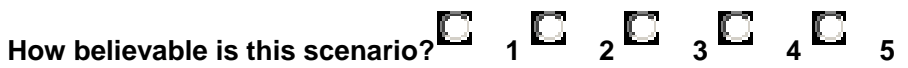

Question EG1

You usually ride the EL (elevated train) to work in Downtown Chicago. The Chicago Transit Authority has issued a terrorist warning about which routes may be susceptible because of their location in the city. The route that you usually take to work is on this list and there is another route that you can take to work that is not at risk, but you have to look at the backside of ugly row houses. What do you do?

A: You choose to ride on your normal route, reasoning that the U.S. State Department issues warnings all of the time about terrorist threats, with none of them happening. You enjoy your ride into work in the morning, and you're not altering your route because of State Department warning that something might happen. 


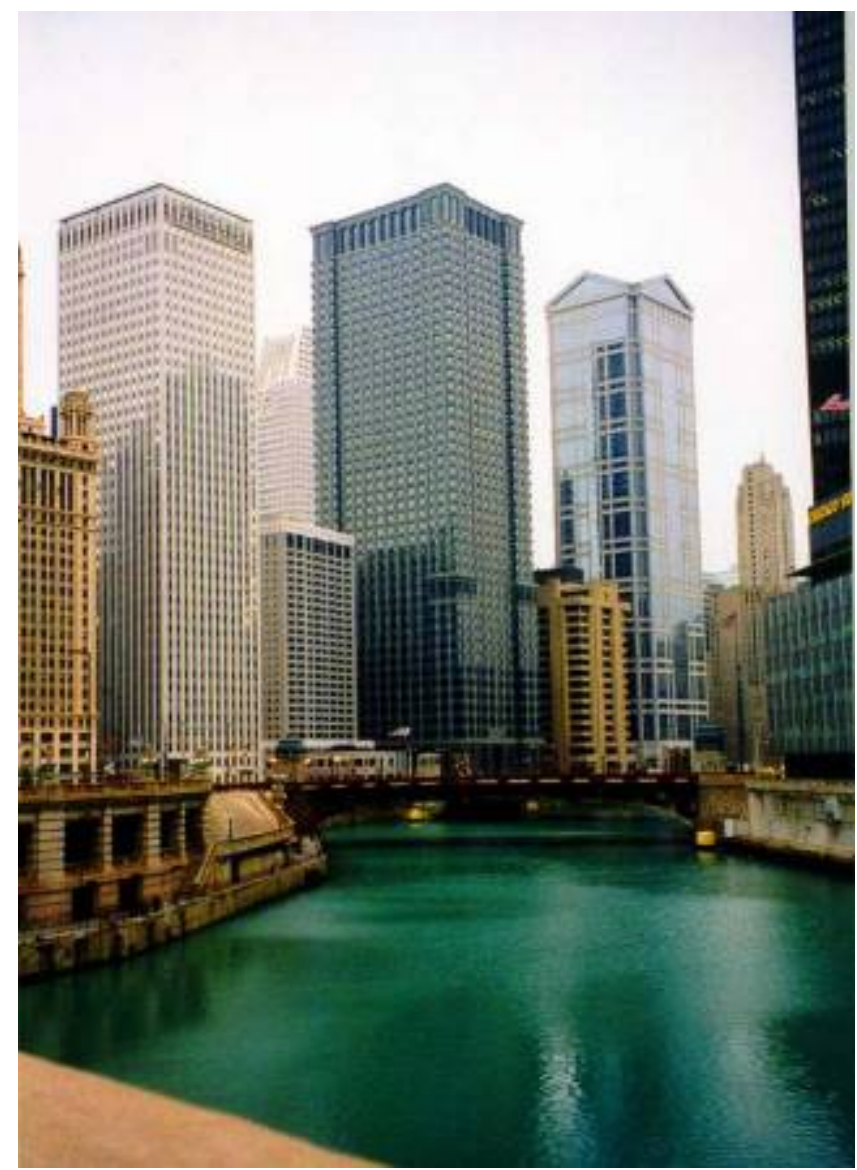

C

B: You are really afraid of another terrorist attack in a city such as Chicago, so you choose to alter your route and go the 'ugly' route, even though you miss your 'beautiful' route, in order to feel safer. 


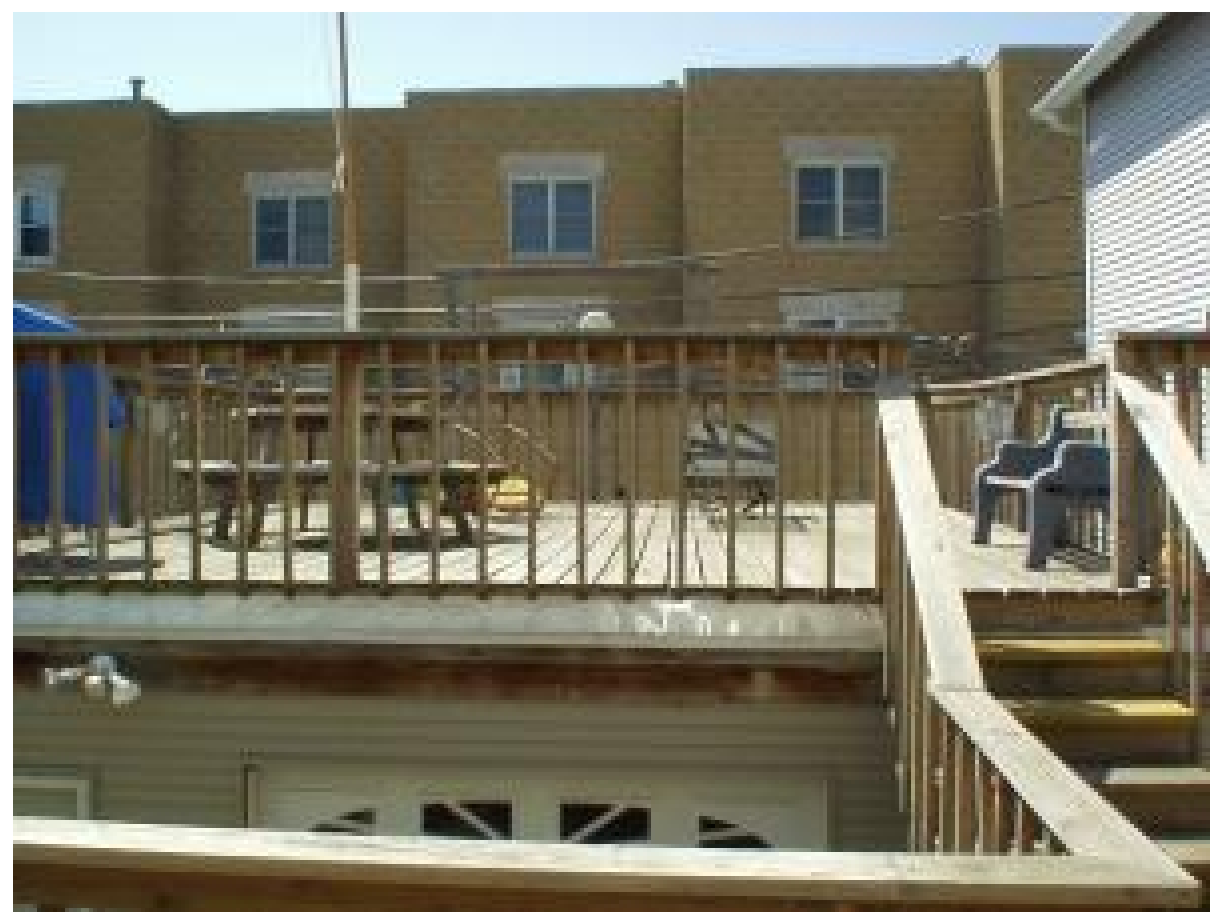

Directions: Please answer the following questions for this situation. For each of the following questions 1 is the lowest and 5 is the highest rating.

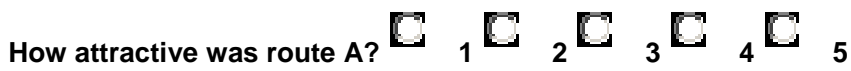

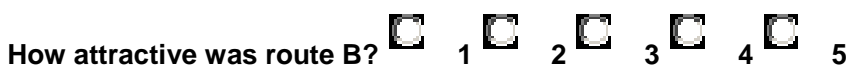

How important it is that your route is safe from terrorists?

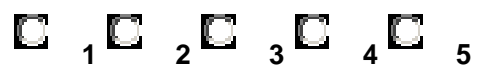

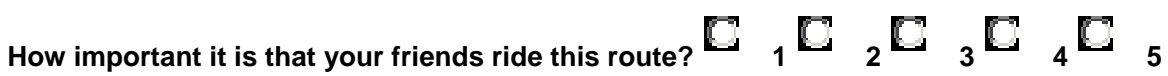

How important it is that you get to enjoy a scenic view on the way to work?

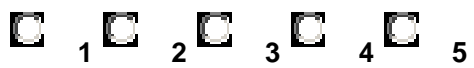

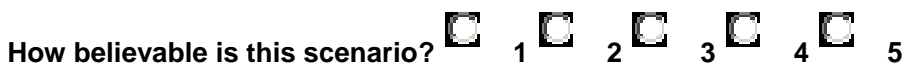

Question EG2

You are going to ride an Amtrak train to see your family. The train ride will last for $\mathbf{5}$ hours. You have a choice of two trains. The first one is a commuter special train that offers a bargain rate for commuters at certain hours of the day. You know that this train is often very crowded and when you have taken this train before, you've been very uncomfortable and hot from overcrowding. You are somewhat interested in taking this train because it is only \$36. But, you know that you could take another train that would not be so overcrowded and you would have room to relax or to sleep or work on the train. You like the idea of the extra comfort during your train ride, but the 
less crowded train is more than twice the price of the commuter special train at $\$ 75$. You want to save money, but you also want to be comfortable. What do you choose?

C

A: You choose to save money and ride the crowded train, figuring that you can stand several of hours of discomfort to save half of the fare.

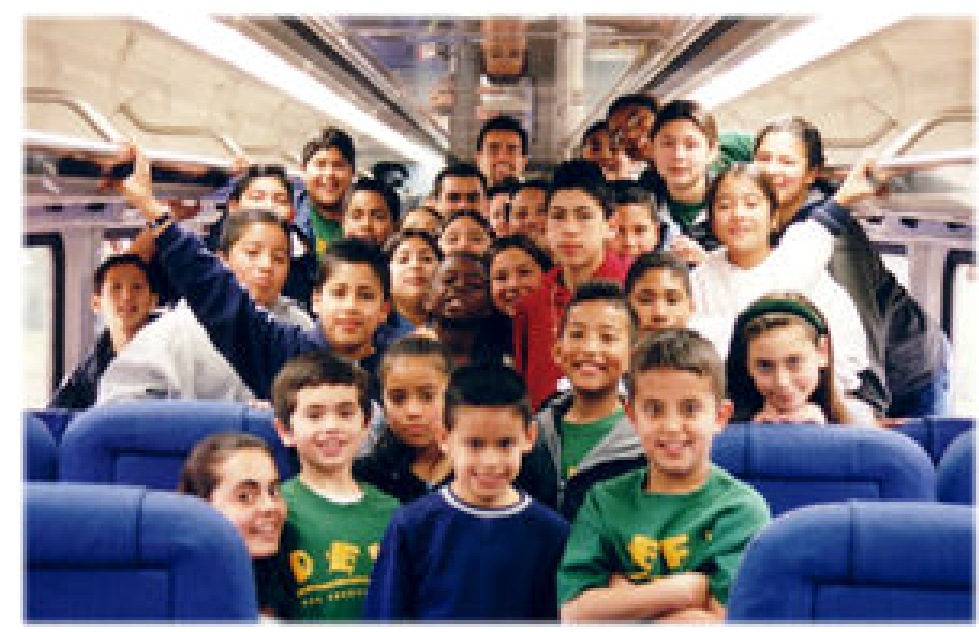

C B: You choose comfort over cost and choose to ride the more expensive, but more spacious train. Five hours is a long time to be packed into a small space.

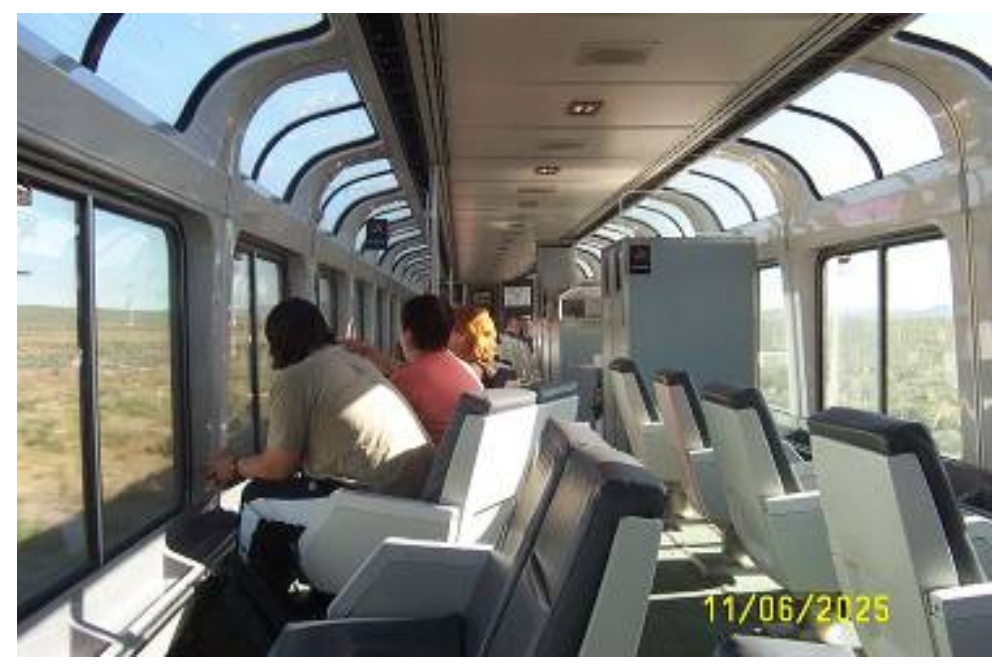

Directions: Please answer the following questions for this situation. For each of the following questions 1 is the lowest and 5 is the highest rating.

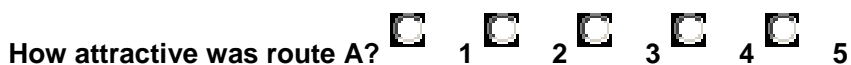

How attractive was route $\mathrm{B}$ ? ${ }_{1}{ }_{1}{ }_{2}{ }_{2}{ }_{3}{ }_{4}{ }_{5}$

How important is it for you to be comfortable on your long train ride? 


\section{$C_{1} C_{2} \square_{3} \square_{4} \square_{5}$}

How important is it for you to ride with your friends on your train ride?

\section{$\mathrm{C}_{1} \mathrm{C}_{2} \mathrm{C}_{3} \mathrm{C}_{4} \mathrm{C}_{5}$}

How important is it for you to save money on the train ride?

$\mathrm{C}_{1} \mathrm{C}_{2} \mathrm{C}_{3} \mathrm{C}_{4} \mathrm{C}_{5}$

How believable is this scenario? ${ }_{1}{ }_{1}{ }_{2} \overrightarrow{a_{3}}{ }_{3}{ }_{4}{ }_{5}$

\section{Question EG3}

You want to ride a bike to visit your friend to play a board game. Your friend lives $\mathbf{3}$ miles from you, down a soft dirt road. You can either use a regular bike that has a basket for a board game, which will be very hard to safely maneuver in soft dirt. Or, you can take the sand bike and the wide and light plastic tires will make riding in loose sand or dirt a breeze. But, the beach bike does not have a convenient basket for your board game, so you will have to figure out a way to carry it on the sand bike. Which do you choose?

E

A: You choose the sand bike. You know that if you try to ride the regular bike in the soft dirt, it will be extremely hard and inefficient, even though the regular bike has a carrying basket for your game. You think you can find another way to carry the game if the riding can be made easier.

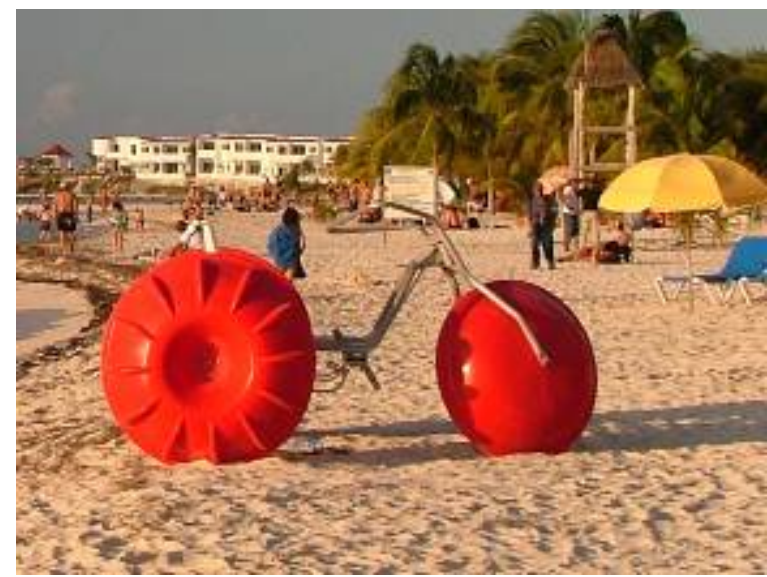

D

B: You can't figure out another way to get the board game to your friend's house, so you choose the bike with a basket. You know that it will be hard to ride the regular bike through loose dirt, but you can't figure out how else to carry the game to your friend's house. 


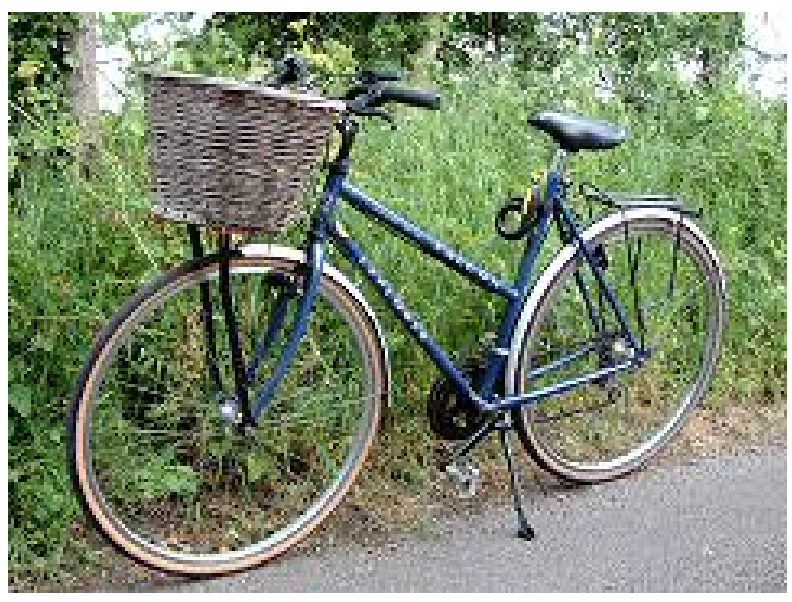

Directions: Please answer the following questions for this situation. For each of the following questions 1 is the lowest and 5 is the highest rating.

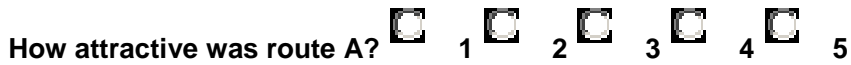

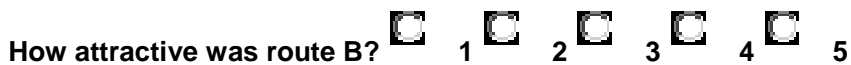

How important is it that you can easily control and maneuver your bike in sand? ${ }_{1}{ }_{2}{ }_{2}{ }_{3} C_{4}$ C. 5

How important is it that your friend doesn't make fun of the bike that you're riding?

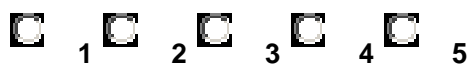

How important is that you have a basket in which to carry your board game?

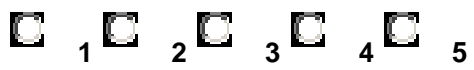

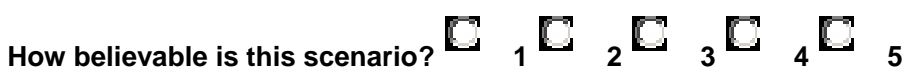

Question EG4

You are going to a concert in a somewhat unfamiliar city. You have a choice between two transit lines. The bus line has published extensive maps and other documentation that allow you to easily use the bus line. However, you will have to switch buses two times in order to reach your destination. There is also a trolley service that you noticed, but you are not sure of where this trolley goes or if it will take you to the concert. A stranger in the parking lot tells you that the trolley will take you to the concert. Do you choose to take the bus, because you are certain of where it goes, even though it might be inconvenient, or do you take the Trolley based on word of mouth information? Which do you choose?

A: You love this group and you don't want to miss the concert and you know for sure that the bus system will get you there and you have solid information about where it goes and what time it will get to the event center. So, you discount what the stranger in the parking lot said and go for the sure thing. 


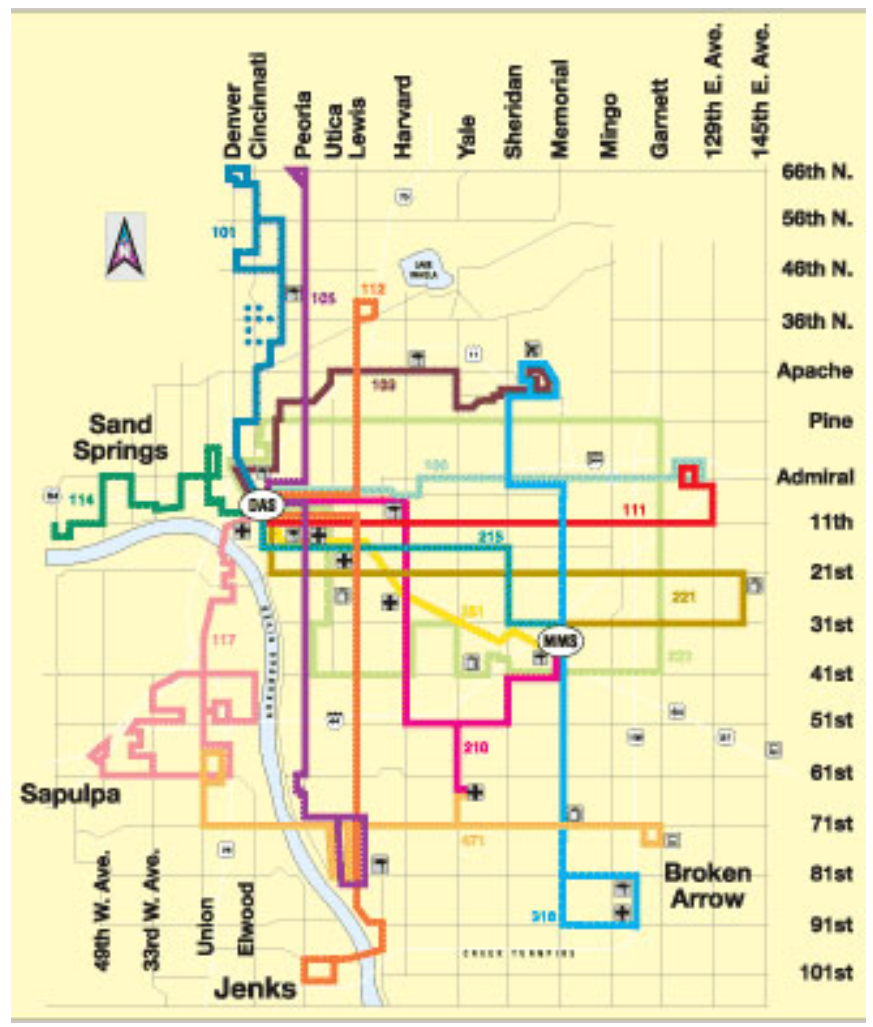

C

B: You decide to take the word of the stranger in the parking lot and you catch the Trolley to see where it goes. You figure that the stranger in the parking lot was trying to be helpful and save you some time. So, you jump aboard the Trolley, hoping that it will take you to the concert.

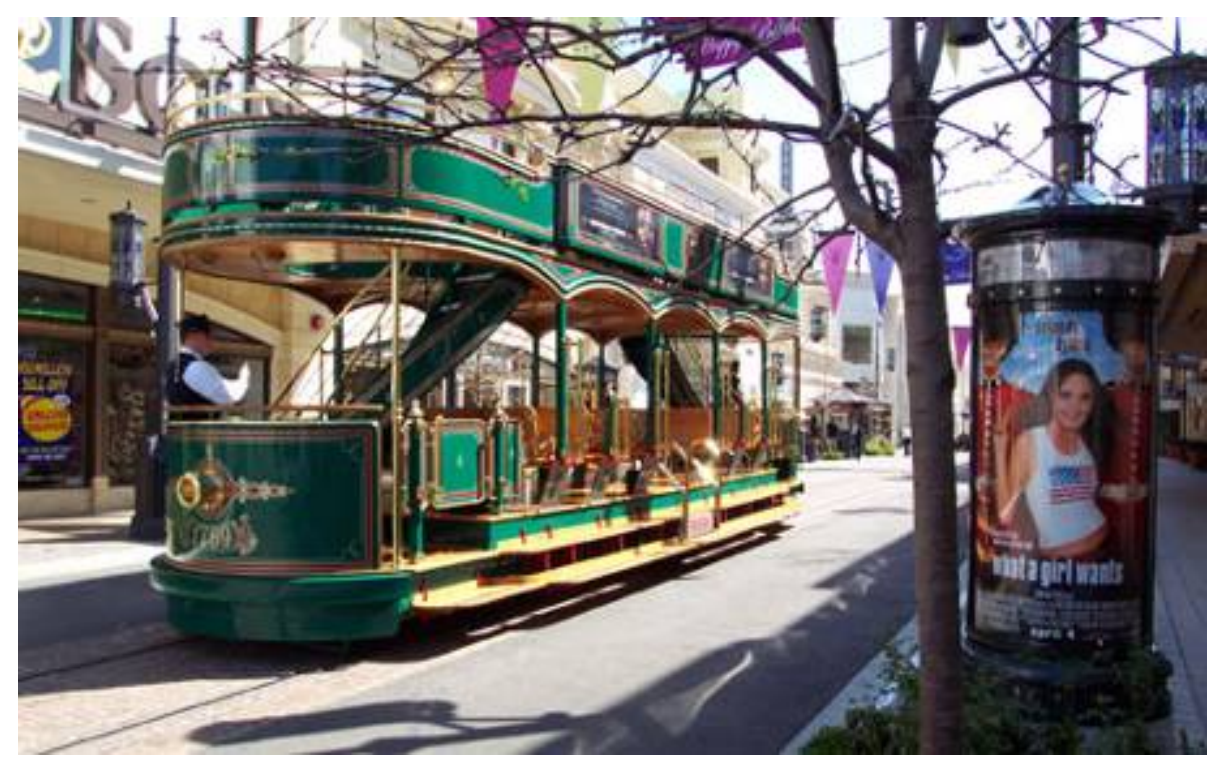

Directions: Please answer the following questions for this situation. For each of the following questions 1 is the lowest and 5 is the highest rating. 


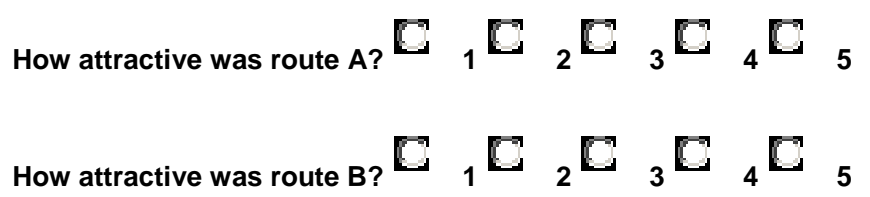

How important is it for you to know how to find your way on this transit system? ${ }_{1}{ }_{2}{ }_{3}{ }_{4}$ C. 5

How important is it for you to ride with your friends to the concert on the transit system?

\section{$C_{1}{ }_{2}{ }_{2}{ }_{3}{ }_{4}{ }_{5}$}

How important is it for you to be able to get to the concert in the least steps possible?

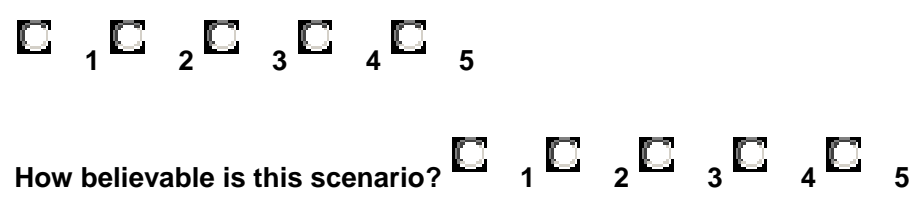

\section{Question EG5}

You are going to take a 200 mile trip with your family to go camping and hiking in a national forest this weekend. You have a choice of two cars. You have a Jeep Grand Cherokee and a Toyota Prius. In the past few days, the Jeep seems to be having some engine trouble and you really don't have time to take it into the shop prior to your trip. The Jeep has a lot more space for your passengers and hiking gear than the Prius, but you are afraid that the Jeep will have engine trouble up in the mountains. You know for sure that the Prius is in tip top shape because you just had it serviced by your mechanic two weeks ago. You're not sure of what to do, because the Prius really doesn't have a lot of passenger or cargo space and there are four of you. Which do you choose?

E

A. You decide that you want to have enough space for people and cargo. You believe that the Jeep can make the trip, even given the recent engine problems, so you go ahead and hope that don't break down 200 miles from home.

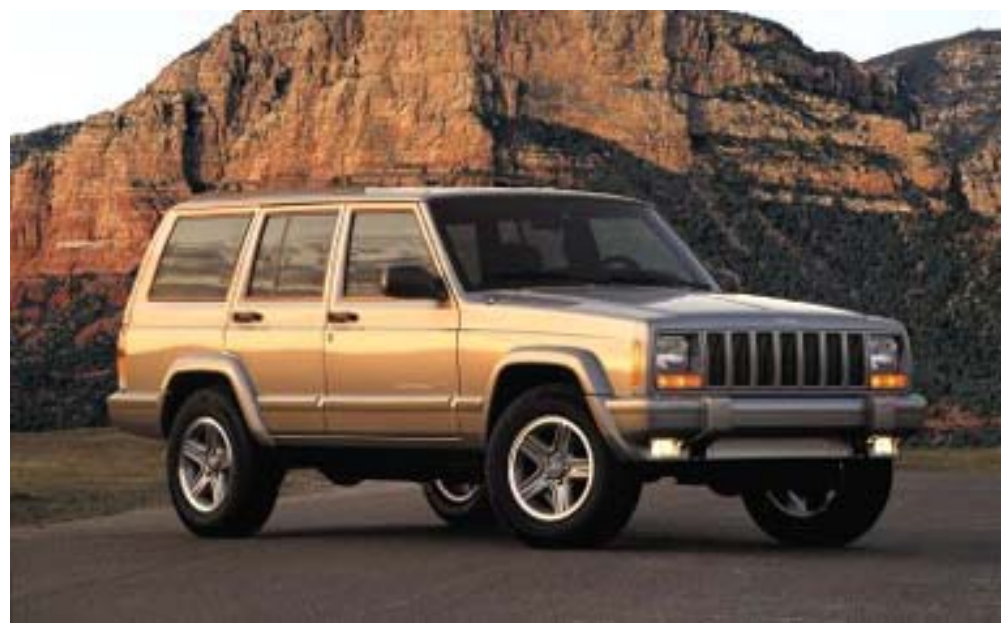


C

B. You decide that you don't want to chance having a major engine breakdown 200 miles from home. You decide to stuff 4 people and cargo in a smaller car that you know for sure will get you roundtrip on your camping trip.

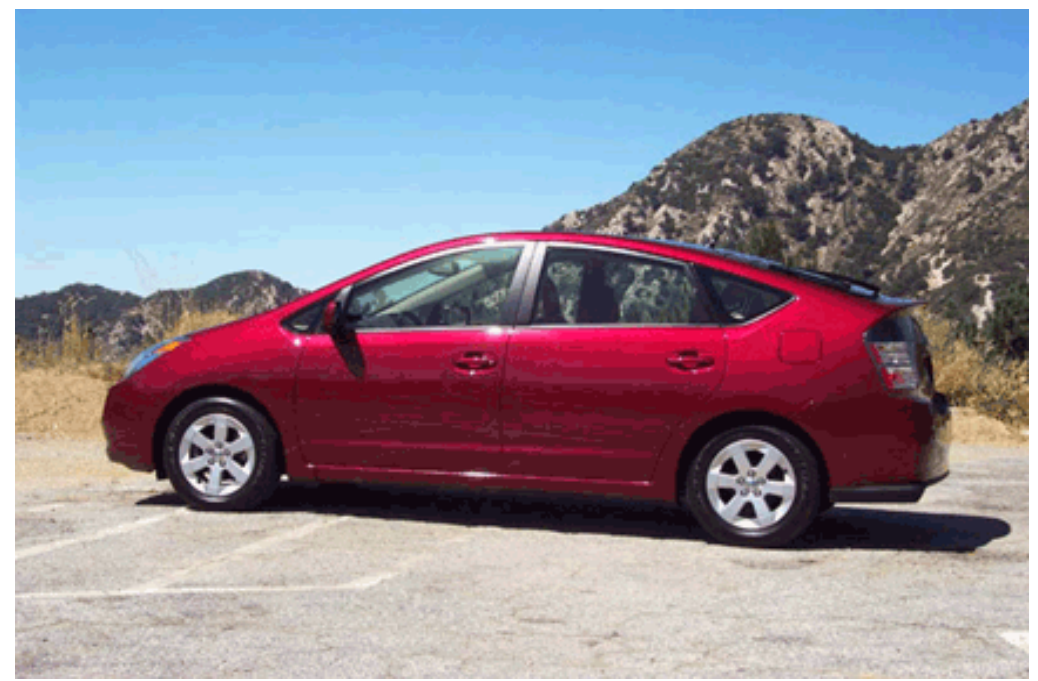

Directions: Please answer the following questions for this situation. For each of the following questions 1 is the lowest and 5 is the highest rating.

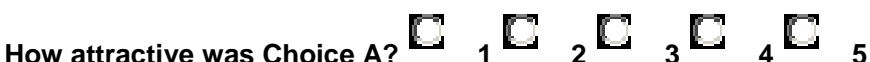

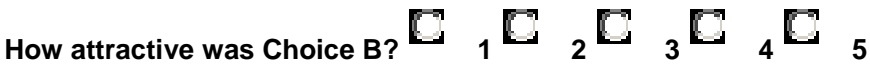

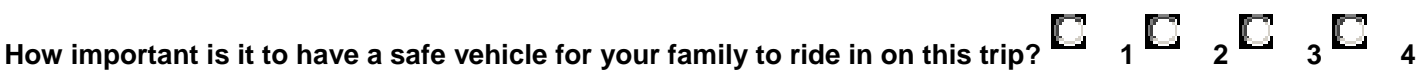
C

How important is it that your friends down the street approve of your vehicle for this trip?

$C_{1} C_{2} C_{3} C_{4} C_{5}$

How important is it to have more space for luggage and people on your trip?

$\sigma_{1} b_{2} b_{3} \mathbb{C}_{4}$

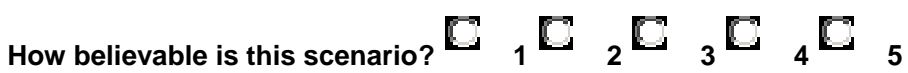

\section{Question EG6}

You take a train to work each morning and you usually wait approximately 15 minutes for your train to arrive each morning. You live equidistant between two train stations. At one train station, you can have amenities such as a coffee shop, a newsstand and a nice waiting area. Lately, you have noticed that there are some vagrants hanging out in the coffee shop and waiting area. They make you feel uncomfortable and a few have 
even approached you for money recently and you are worried that they may become violent. The other station only has vending machines and plastic chairs. You have complained to the management of the nicer station about the vagrants several times, but they have a hard time keeping them out, especially if they pay for a cup of coffee. What do you do?

C

A. You keep on taking the train from the nicer station. You don't want to let the vagrants keep you from enjoying the amenities of the nicer station.

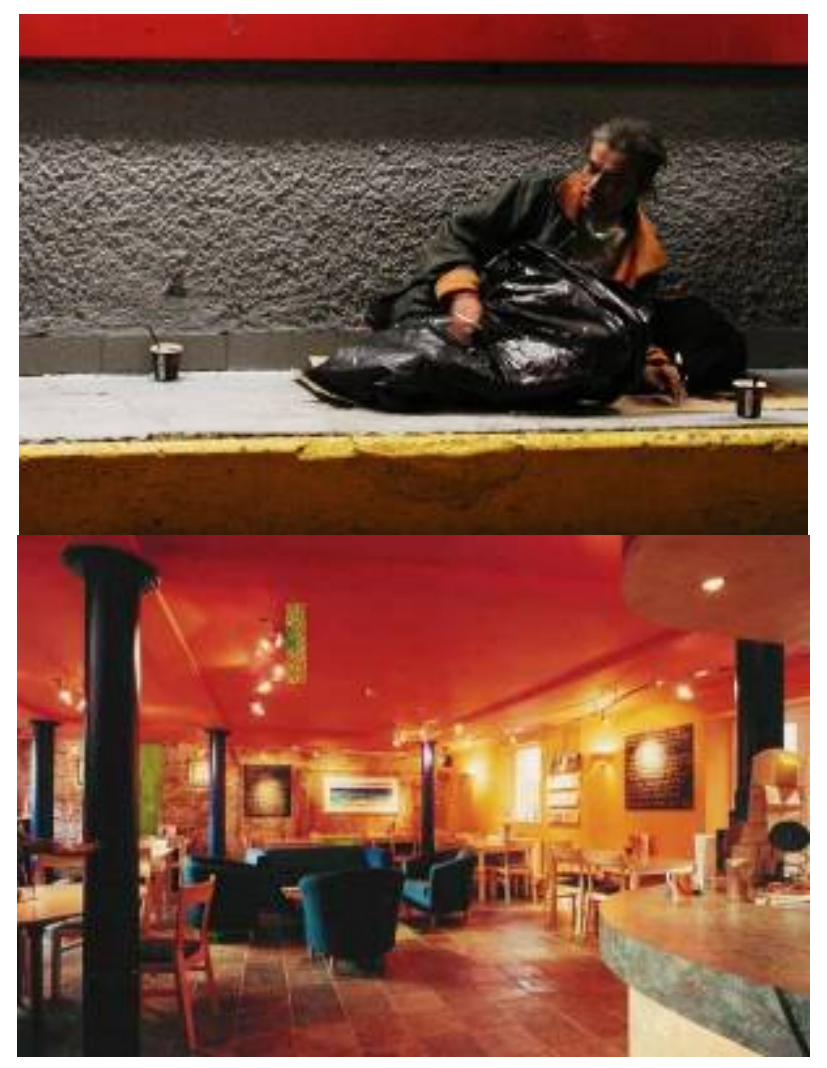

B. You go to the station with less amenities, because the vagrants at the nicer station make you feel too vulnerable and nervous during your wait. At lleast you can get coffee out of the vending machine. 

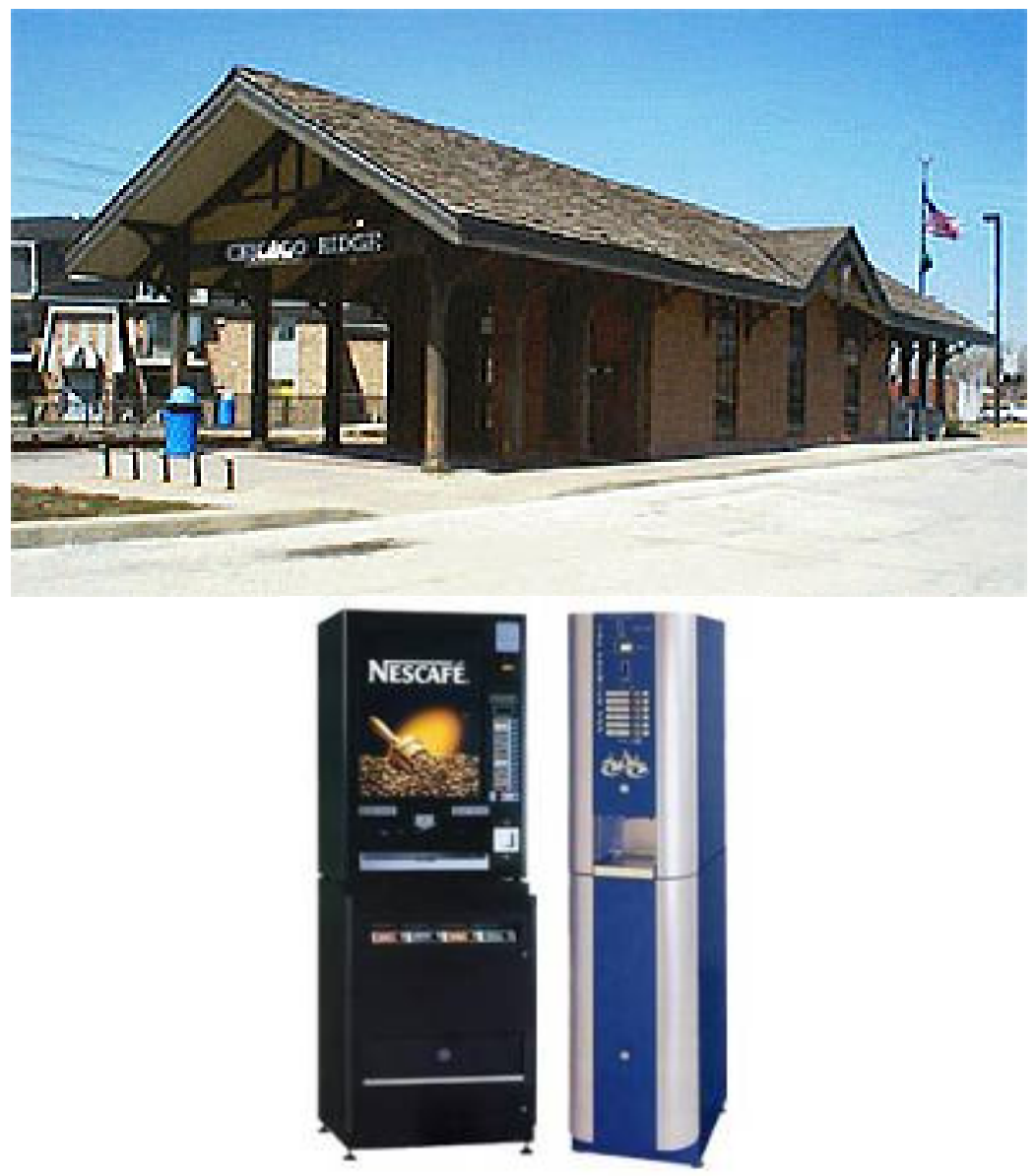

Directions: Please answer the following questions for this situation. For each of the following questions 1 is the lowest and $\mathbf{5}$ is the highest rating.

How attractive was route $A$ ? ${ }_{1} C_{2} C_{3} C_{4} C_{5}$

How attractive was route $B$ ? ${ }_{1}{ }_{1}{ }_{2} \square_{3} \square_{4} \square_{5}$

How important is it to feel safe from other people at your transit station?

$\square_{1} \square_{2} \square_{3} \square_{4} \square_{5}$

How important is it that you can meet your friends at this transit station?

$\mathrm{C}_{1} \mathrm{C}_{2} \mathrm{C}_{3} \mathrm{C}_{4} \mathrm{C}_{5}$

How important is it for you to have nicer amenities and a nicer place to wait?

$\square_{1} \square_{2} \square_{3} \square_{4} \square_{5}$ 
How believable is this scenario? ${ }_{1}{ }_{1}{ }_{2}{ }_{3}{ }_{3}{ }_{4}{ }_{5}$

Question EG7

You are going to start riding your bike to work, a commute of 3 miles every day. One of the routes is through a rural, unpopulated area, which runs by a cemetary, but there is nice scenery along the way. However, you have heard about some strange supernatural activities in that area in recent weeks that have everyone concerned (i.e., Blair Witch). The other route is also around 3 miles in length and runs through a very populated area, but it is not very scenic. Which do you choose?

C

A. You choose to ride where there are people, because you are afraid of riding alone in the rural, deserted area, especially by the cemetary.

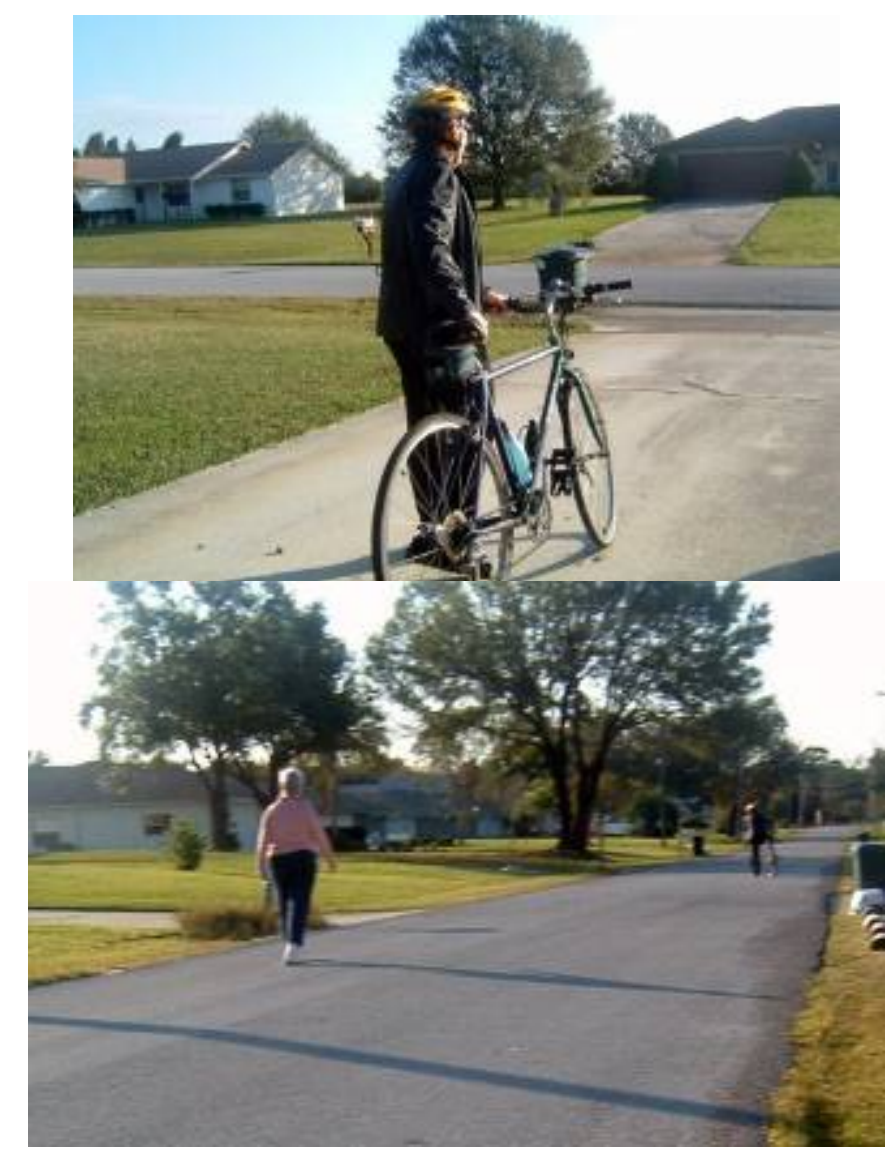

C

B. You choose to take the more scenic route and you think that the supernatural rumors are just to drum up tourist trade. It's a beautiful ride. 


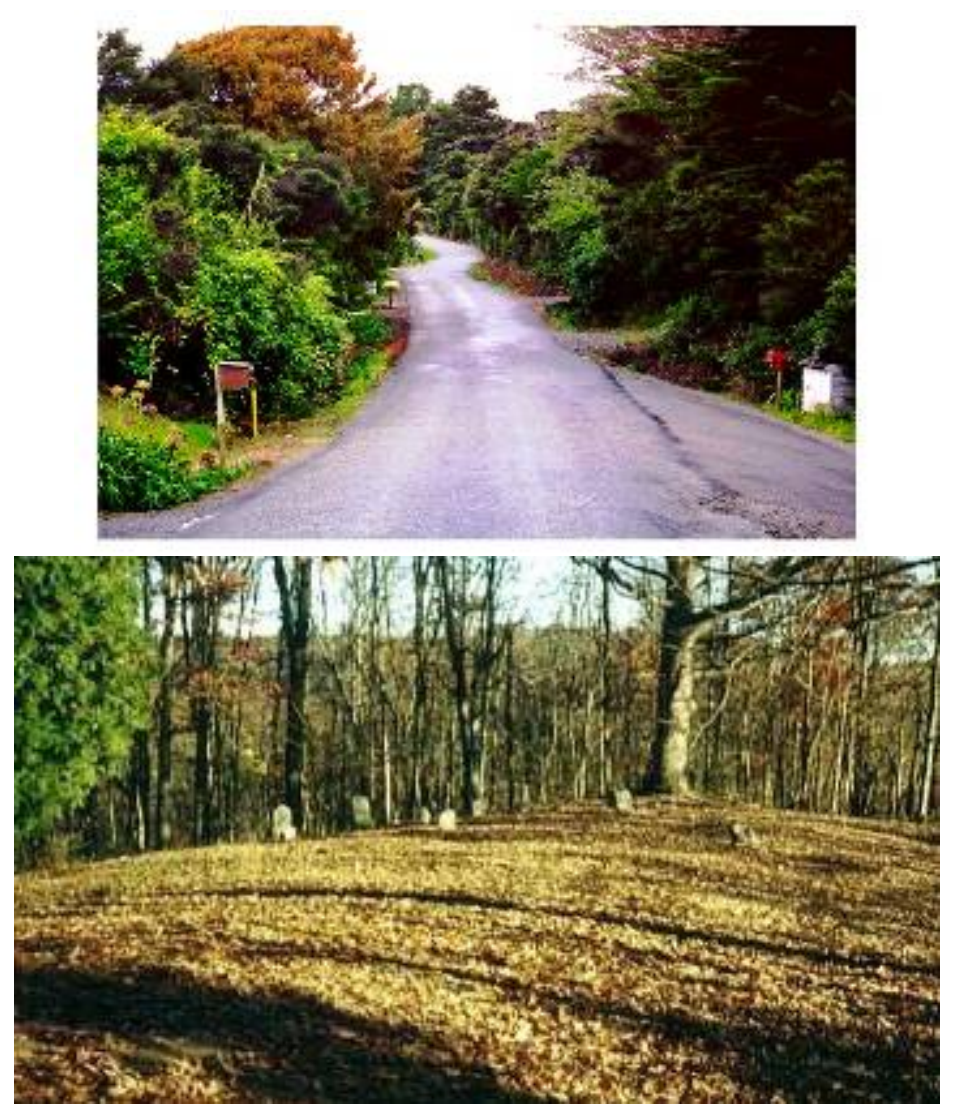

Directions: Please answer the following questions for this situation. For each of the following questions 1 is the lowest and $\mathbf{5}$ is the highest rating.

How attractive was route A? ${ }_{1} \mathrm{C}_{2} \mathrm{C}_{3} \mathrm{C}_{4} \mathrm{C}_{5}$
How attractive was route B?

How important is it to feel that there are safe people around you on your bike ride to work?

\section{$\mathrm{C}_{1} \mathrm{C}_{2} \mathrm{C}_{3} \mathrm{C}_{4} \mathrm{C}_{5}$}

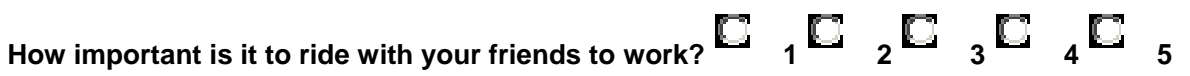

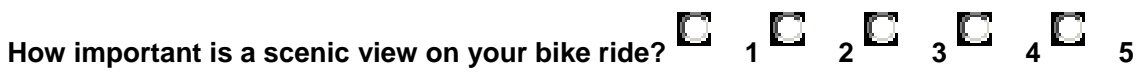

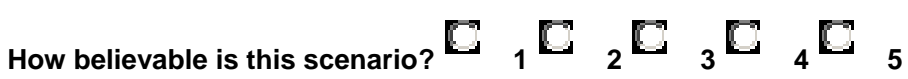

Question EG8 
You are going to meet a friend in Washington D.C. for a night out on the town. Your really want to go to a restaurant that is off of the transit stop in DuPont Circle, but you don't like the DuPont Circle station because there is a very steep escalator into and out of the station and you are afraid of both heights and escalators. You also heard that a person was seriously injured recently when their coat got caught in the escalator. Union Station does not have steep escalator entries or exits in the transit area, so you feel much safer there, but there are only chain restaurants in and around Union Station area. You really want to go to this restaurant which is off of the DuPont Circle Metra stop, but you're scared of the steep escalators and it will cost $\$ 10$ (versus a $\$ 2.50$ transit fare) to catch a taxi from Union Station to the restaurant at DuPont Circle. What do you choose?

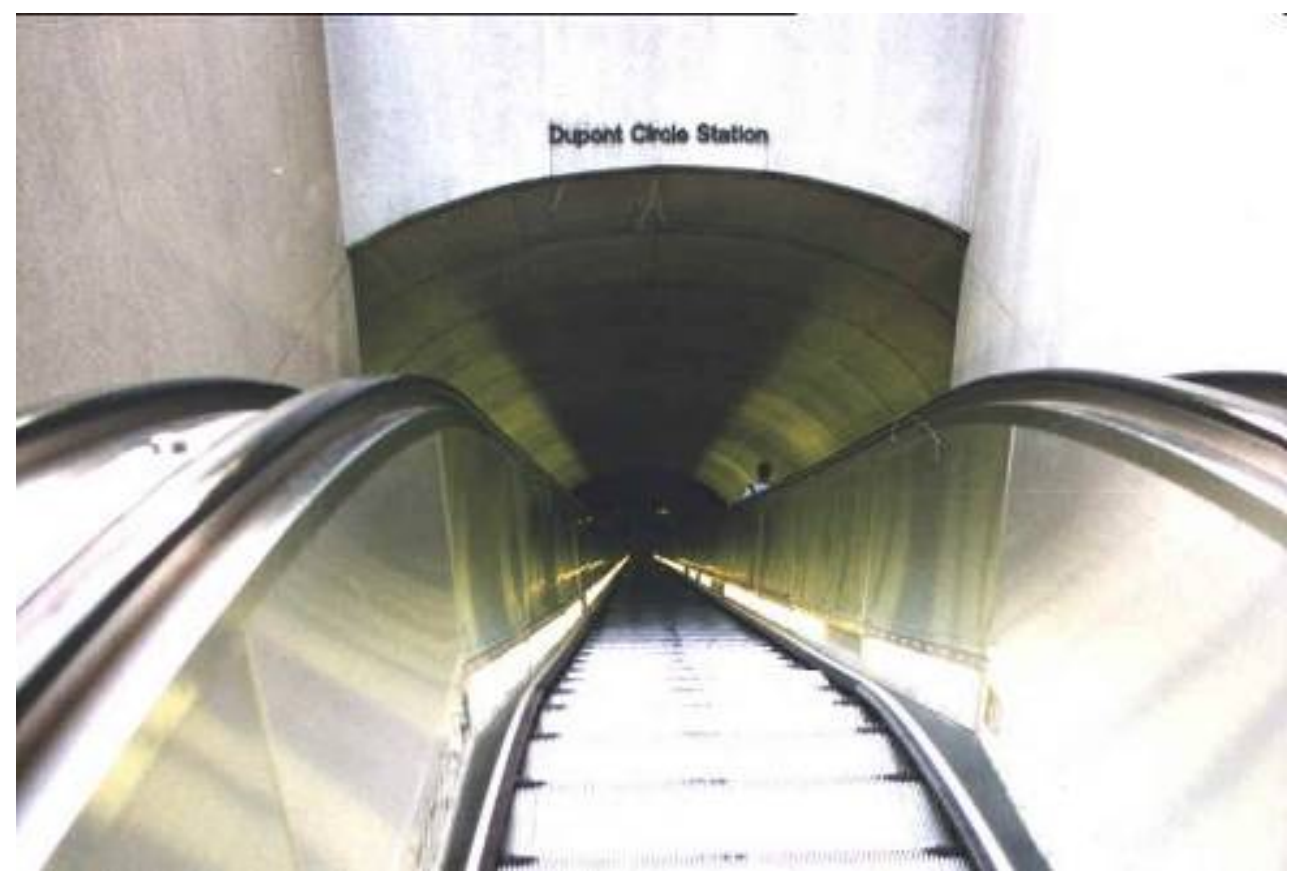

$B$

A: You decide to stay at Union Station to have dinner and to go to a movie later. You are very disappointed, because you wanted to try the new restaurant, but you know that you would have felt very panicked and unsafe entering/exiting the DuPont Circle Station.

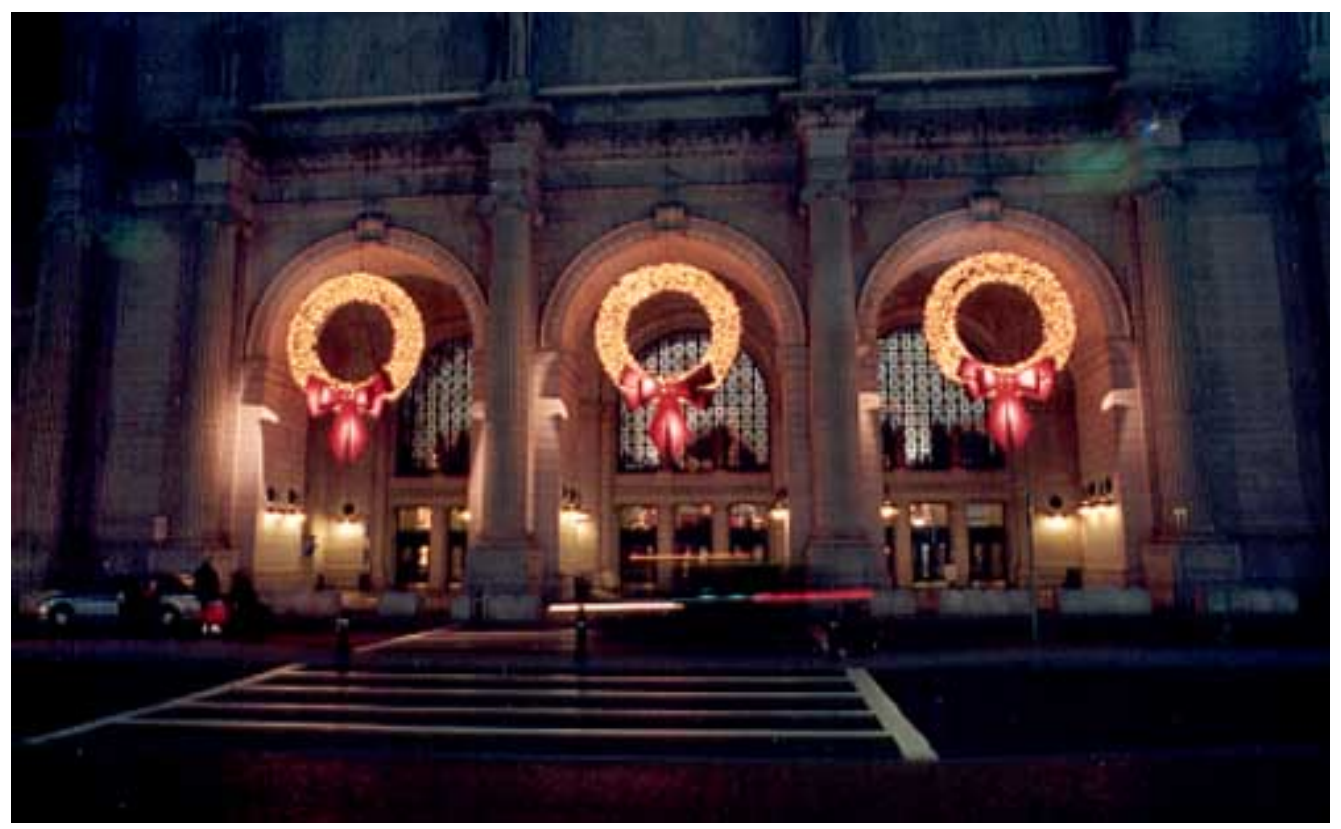


C

B. You decide to venture outside of the relative safety of Union Station and go to DuPont Circle to the new Asian/French fusion restaurant that you want to try. You decide to pay the $\$ 10$ to take a cab from Union Station to DuPont Circle area, instead of transit.

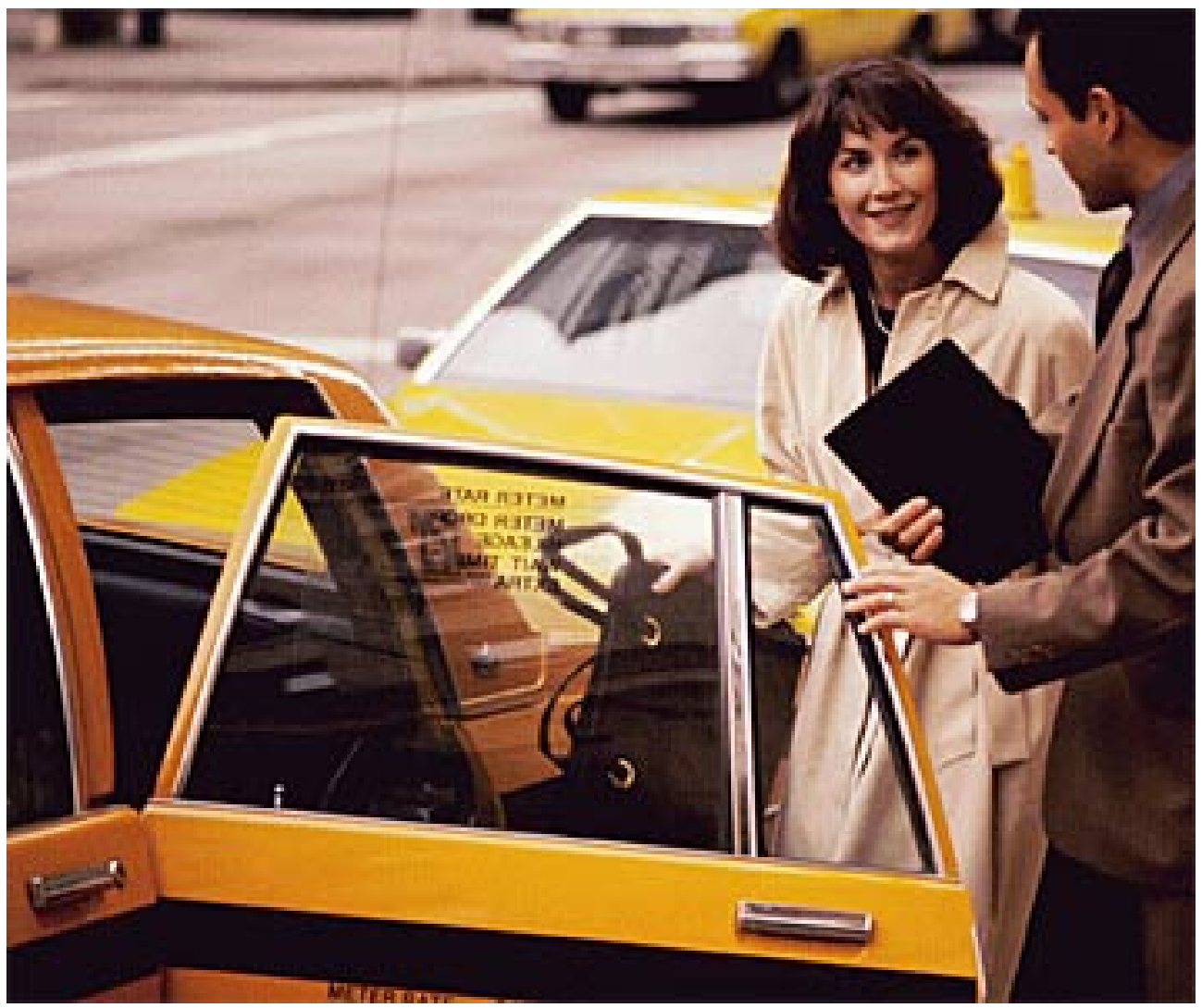

Directions: Please answer the following questions for this situation. For each of the following questions 1 is the lowest and $\mathbf{5}$ is the highest rating.

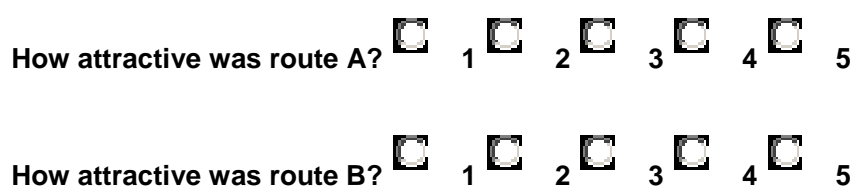

How important is it to feel safe entering and exiting the transit station? ${ }_{1} C_{2} C_{3} C_{4} C_{5}$

How important is it that people who you like and feel comfortable with are at the transit stations?

$$
\mathrm{C}_{1} \mathrm{C}_{2} \mathrm{C}_{3} \mathrm{C}_{4} \mathrm{C}_{5}
$$

How important is it to try a new restaurant? ${ }{ }_{1} C_{2} \square_{3} \square_{4} \square_{5}$

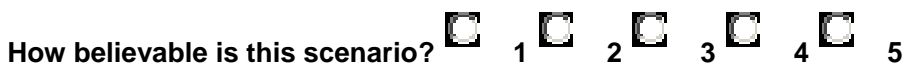




\section{Question EG9}

You are going on a walk down to Bayshore Boulevard. You have the choice of two routes. The one route is safer from traffic, but you also think it's a tremendously ugly, industrial part of town. The more scenic route has a lot of traffic on it and you have been nearly run down by cars crossing the street on this route. What do you do?

C

A. You choose the route that takes you into the more congested traffic route, because you prefer the more scenic route.

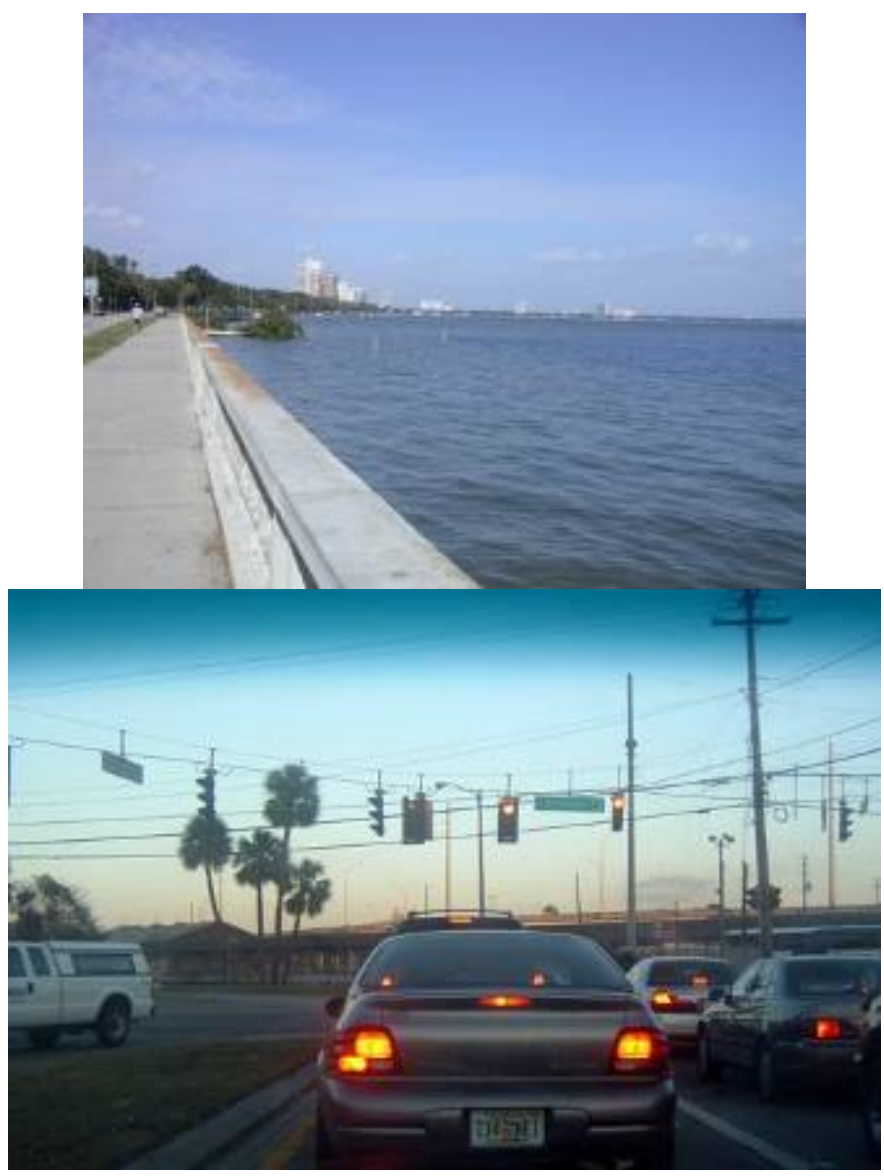

B. You choose the less congested, safer route, even though you don't like the scenery. 


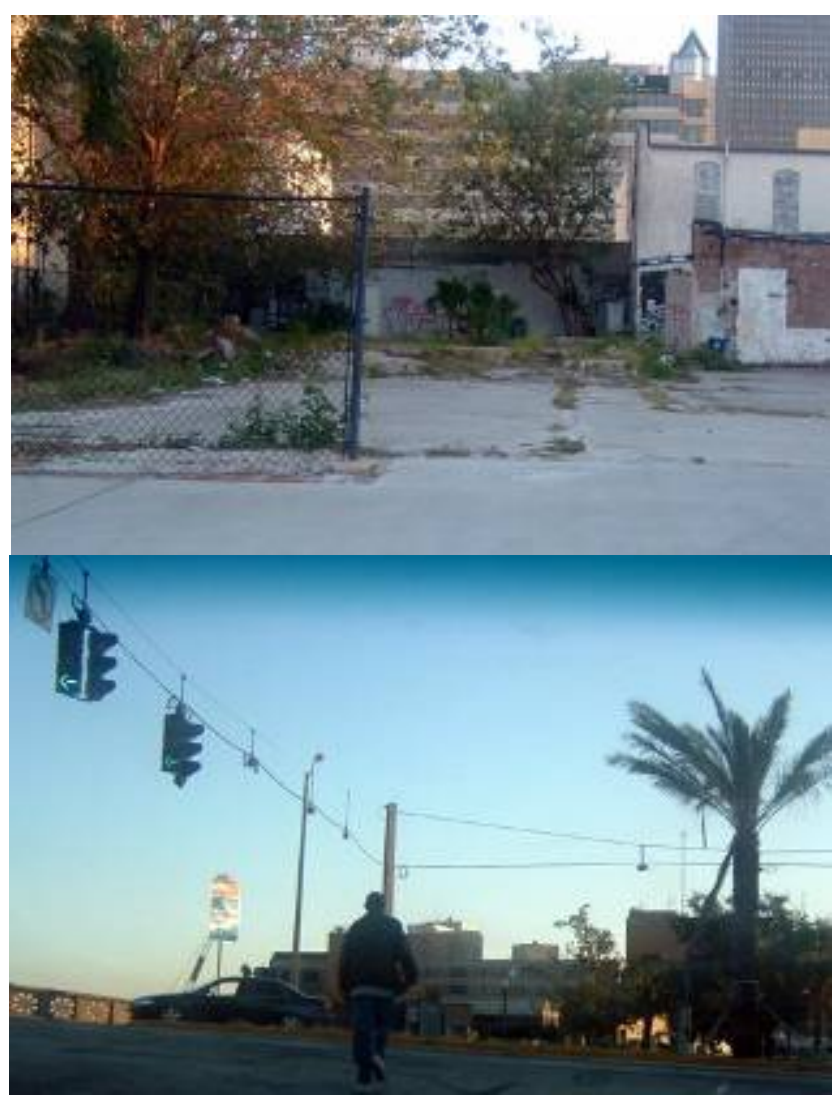

Directions: Please answer the following questions for this situation. For each of the following questions 1 is the lowest and 5 is the highest rating.

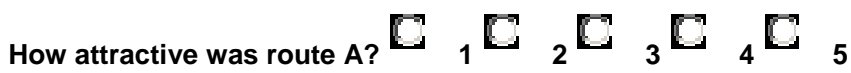

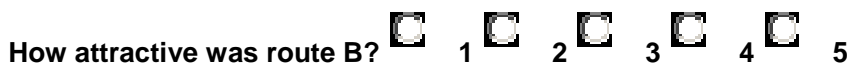

How important is it to be safe while walking to your destination?

\section{$\mathrm{C}_{1} \mathrm{C}_{2} \mathrm{C}_{3} \mathrm{C}_{4} \mathrm{C}_{5}$}

How important is it that your boy/girlfriend approves of your route?

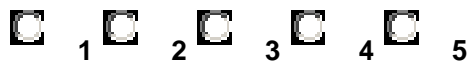

How important is it that you have a scenic walk on the way to your destination? ${ }_{1}{ }_{2}{ }_{2} C_{3}{ }_{4}$ E 5

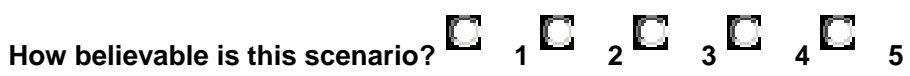

Question EG10 
You are driving in a rural area on your way to a local Campus. You need to take a route into campus that is rural and icy and slippery, because you want to see where you can go sledding on the weekend. You are not comfortable or experienced at driving in the snow, but you want to see the sledding site, so you will know how to get there this weekend. You lost control of your car in a similar rural area the week before and you are a bit apprehensive about driving on unmaintained, icy roads. Which do you choose?

A. You choose the local maintained route for your own safety and you tell yourself, that for safety's sake, you might not go out to the sledding site at all.

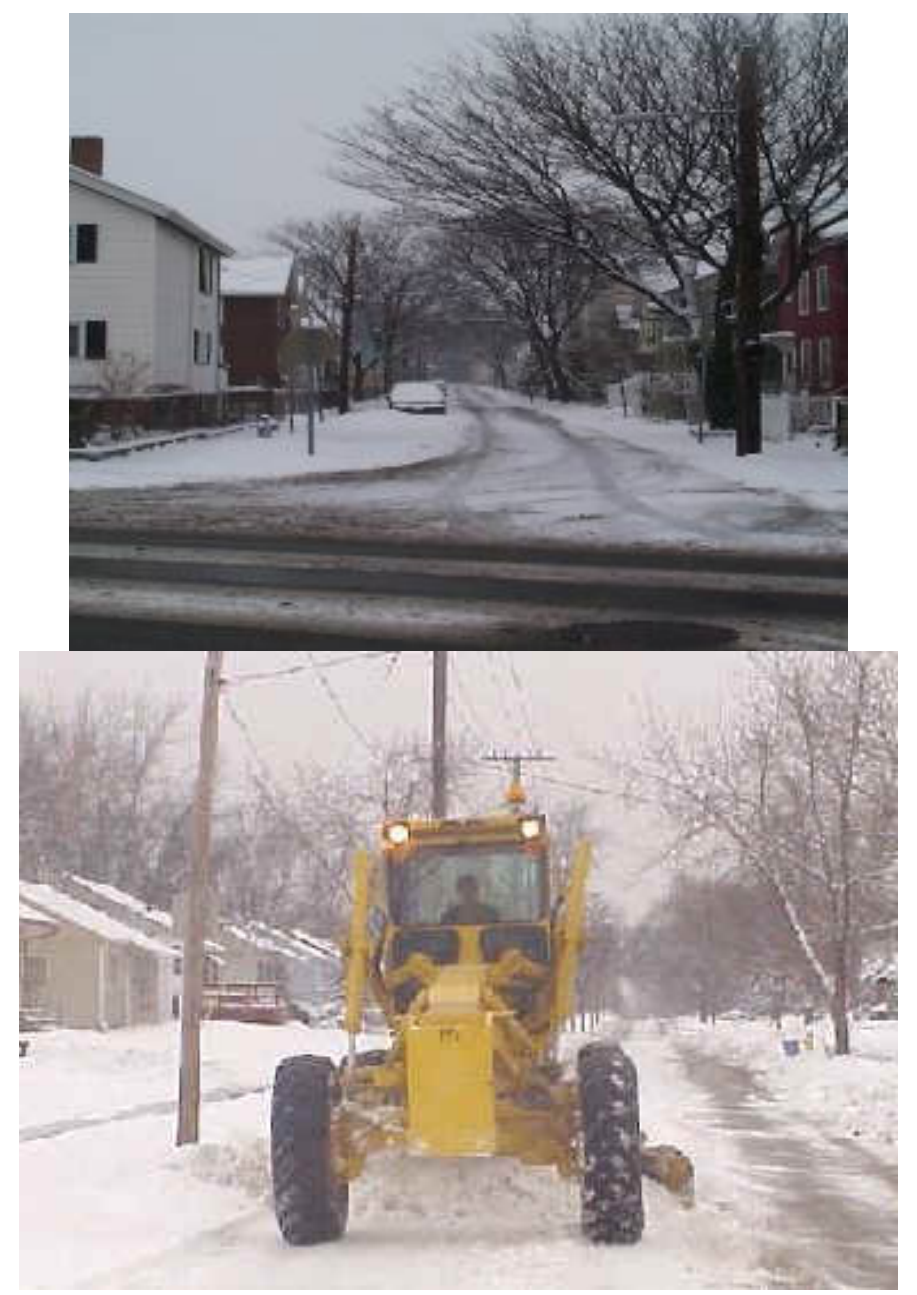

C

B. You choose to ride the unmaintained, rural route, so that you can see where to go sledding this weekend. You are nervous, but you think that the area will be very nice to sled around in. 


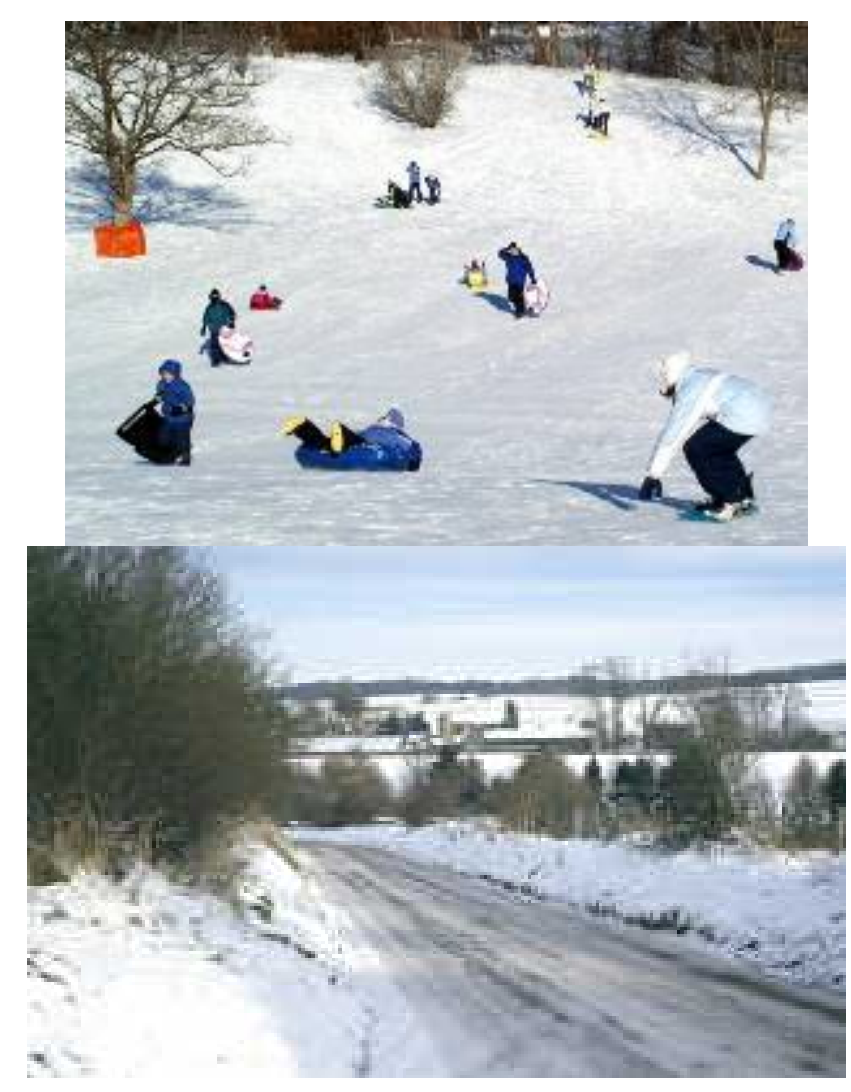

Directions: Please answer the following questions for this situation. For each of the following questions 1 is the lowest and 5 is the highest rating.

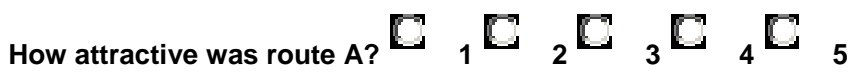

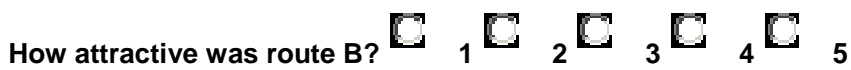

How important is it to maintain control of your car on icy roads?

\section{$\mathrm{C}_{1} \mathrm{C}_{2} \mathrm{C}_{3} \mathrm{C}_{4} \mathrm{C}_{5}$}

How important is it that your friends want you to take them sledding?

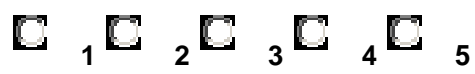

How important is it for you to find a site to go sledding?

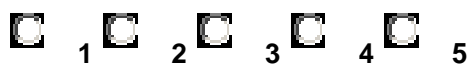

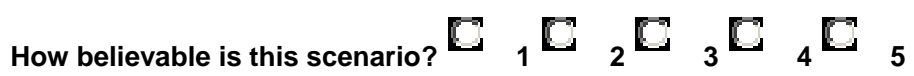

Question RG1 
You take the bus into work every day. You have a choice of two bus routes. On the one bus route, there are some people with whom you don't really like to ride the bus, mostly because many are vagrants and while not dangerous, offensive to your sense of smell. However, there is one reason why you enjoy riding this route, the fact that you can see the beach and the water as well as some very beautiful and historic buildings. It seems to make going to work more pleasant and worthwhile when you see the beach. The other route passes industrial areas and housing projects. However, the people on the less beautiful route are other working people like yourself. You really like to see the beach every morning, but you can hardly stand the smells of the people who ride the bus out to the beach every morning. Which route do you choose?

C

A: You decide that you need your 'beach fix' on the way to work in the morning, so you put up with the stinky vagrants. You figure that you can sit as far away as possible from those with the most offending odors and maybe you can ask the bus driver if you could crack open a window.

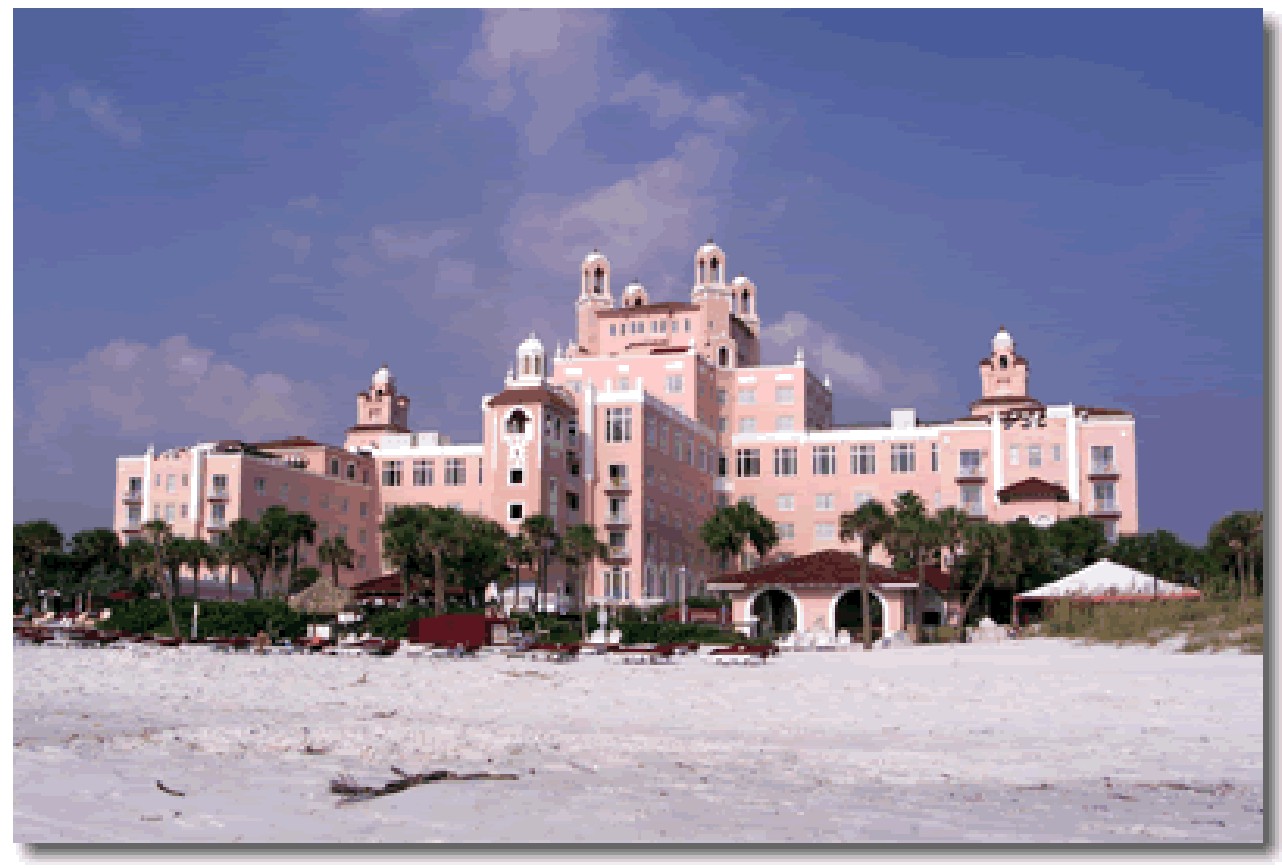

C

B: You decide that the vagrants make you so disgusted that you will have to forego your daily beach route and opt for the less beautiful route that passes housing projects. You can go to the beach and enjoy the sights on your days off. 


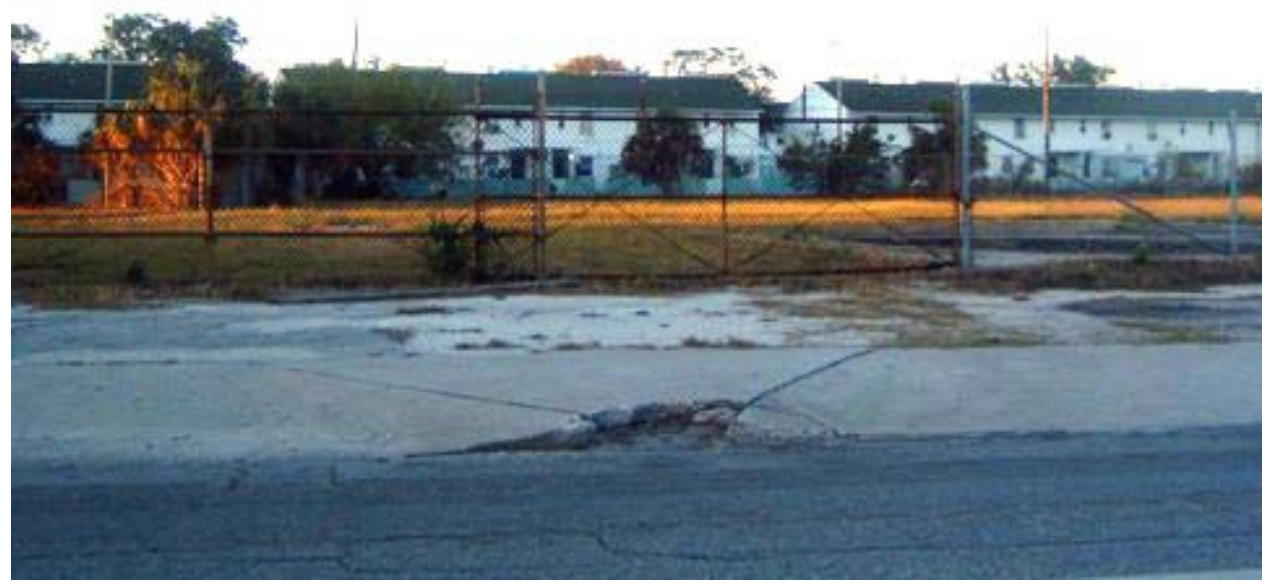

Directions: Please answer the following questions for this situation. For each of the following questions 1 is the lowest and 5 is the highest rating.

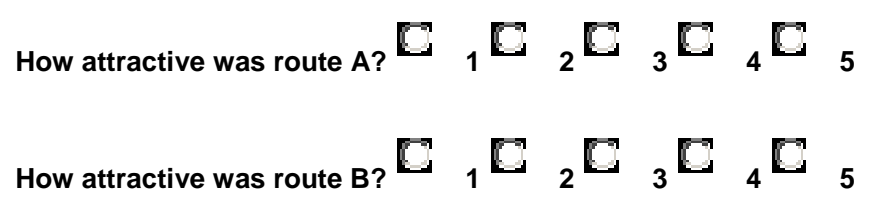

How important is feeling safe from harm by others on your ride to work?

\section{$C_{1} C_{2} C_{3} C_{4} C_{5}$}

How important is it that others on the bus are non-offensive with their personal appearance and odor?

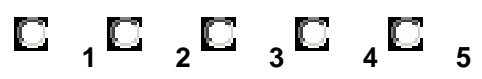

How important is it to be able to see pleasant scenery on the way to work?

$$
\sigma_{1} C_{2} b_{3} b_{4}{ }_{5}
$$

How believable is this scenario? ${ }_{1}{ }_{1}{ }_{2} \overrightarrow{a_{3}}{ }_{3}{ }_{4}{ }_{5}$ 
You want to ride a train visit your family for the weekend. Your family wants you to ride the express train, because it gets in at $7 \mathrm{pm}$ and it will be more convenient for them to pick you up at this time. However, you want to ride a later train that gets in at $10 \mathrm{pm}$ because this train is less expensive than the other train, $\$ 36$ versus $\$ 46$. You know that your family will be unhappy for most of your visit if you choose the later train. What do you do?

C

A: You choose to honor your family's wishes and to take the earlier and more expensive train, because you want to make your family happy.

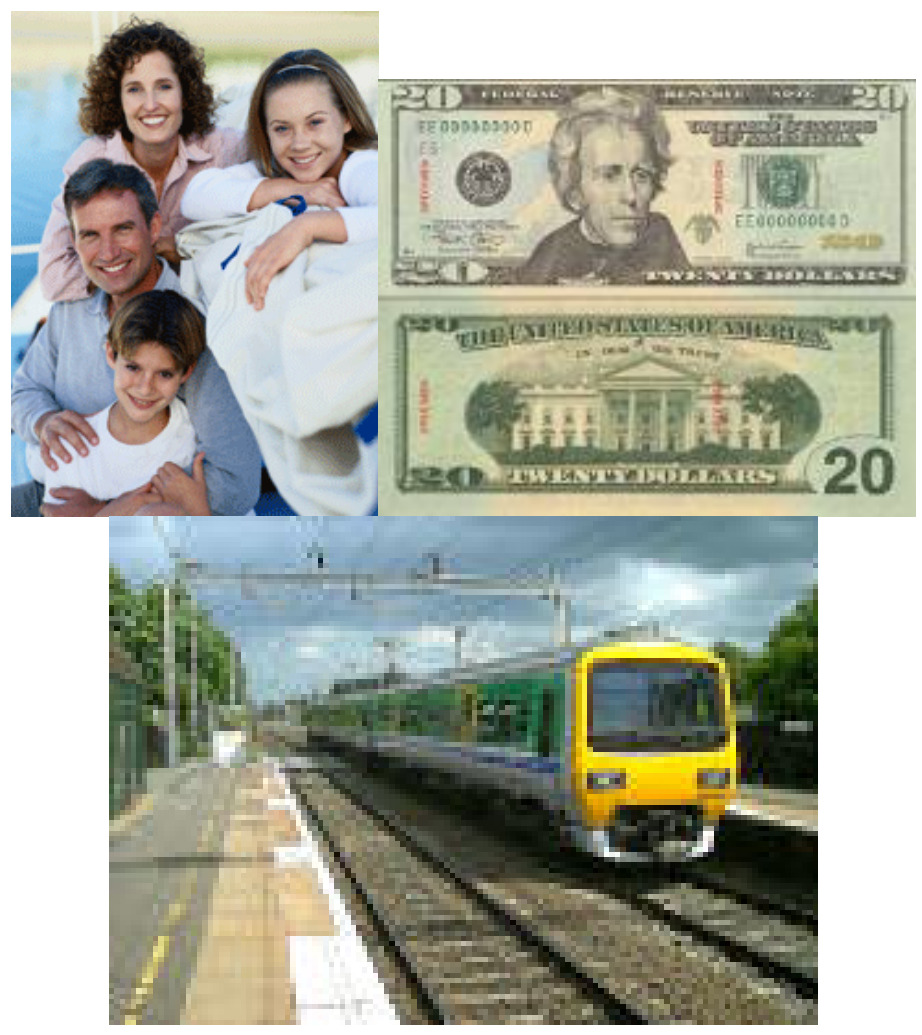

C

B: You choose to save yourself some money and ride the later train. Your family is very unhappy over this, but you saved money. 


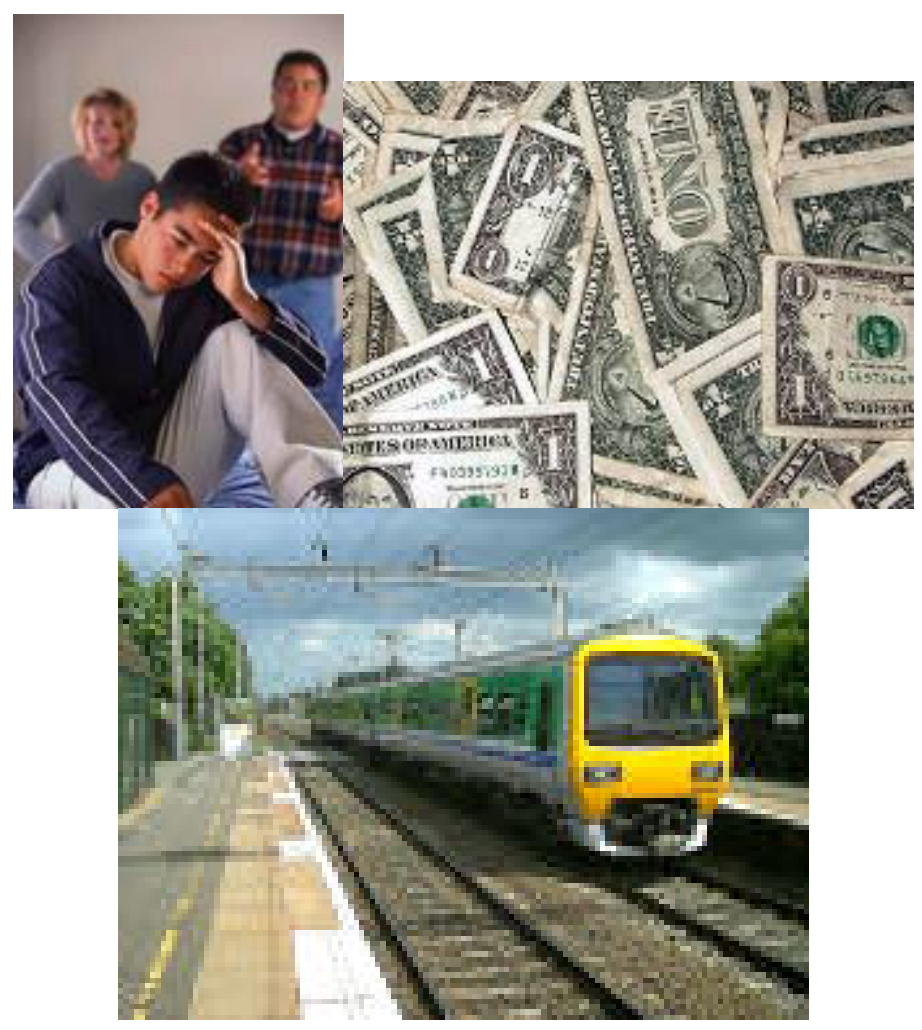

Directions: Please answer the following questions for this situation. For each of the following questions 1 is the lowest and 5 is the highest rating.

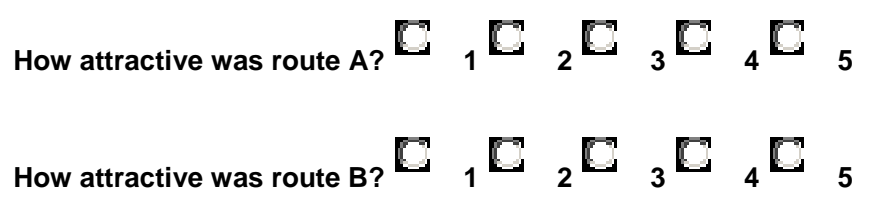

How important is it to ride on a train that is safe and secure?

$\mathrm{C}_{1} \mathrm{C}_{2} \mathrm{C}_{3} \mathrm{C}_{4} \mathrm{C}_{5}$

How important is it to make your family happy by riding the earlier train?

$$
\mathrm{C}_{1} \mathrm{C}_{2} \mathrm{C}_{3} \mathrm{C}_{4} \mathrm{C}_{5}
$$

How important is it for you to save $\$ 10$ by riding a later train?

$$
\mathrm{C}_{1} \mathrm{C}_{2} \mathrm{C}_{3} \mathrm{C}_{4} \mathrm{C}_{5}
$$

How believable is this scenario? ${ }_{1}{ }_{1}{ }_{2}{ }_{3}{ }_{3}{ }_{4}{ }_{5}$ 
You want to ride your bike 2 miles to visit your friend to play a board game. You have a choice of two bikes, one that your friend thinks is really cool and one that has a polka dotted basket on the front that your friend ridicules you about. However, the basket would help you to carry the board game. What do you choose?

C

A: You choose the bike that your friend thinks is cool, even though it's hard to manage riding the bike and carrying the board game without the basket on the other bike.

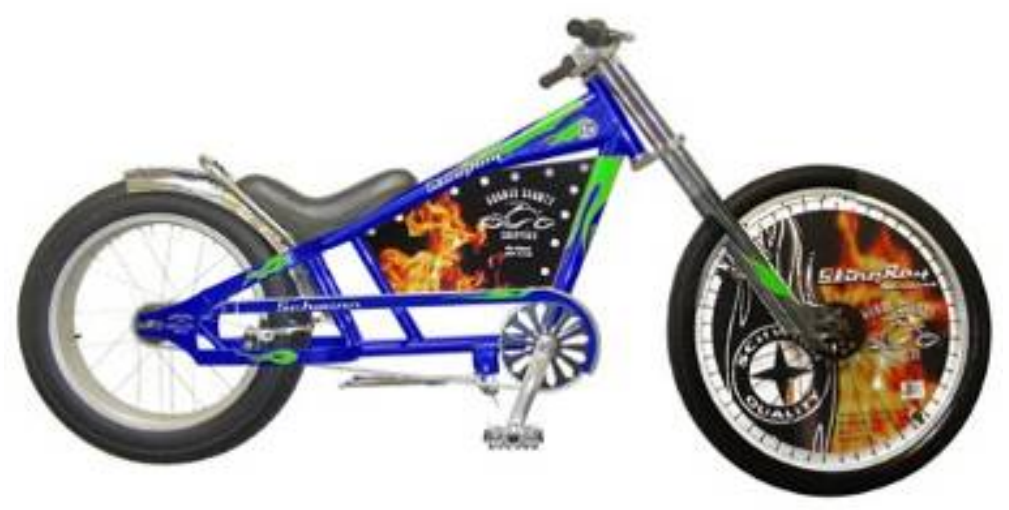

B: You choose the polka-dotted basket bike that your friend thinks is really silly-looking, because it is easier to carry the board game using this bike.

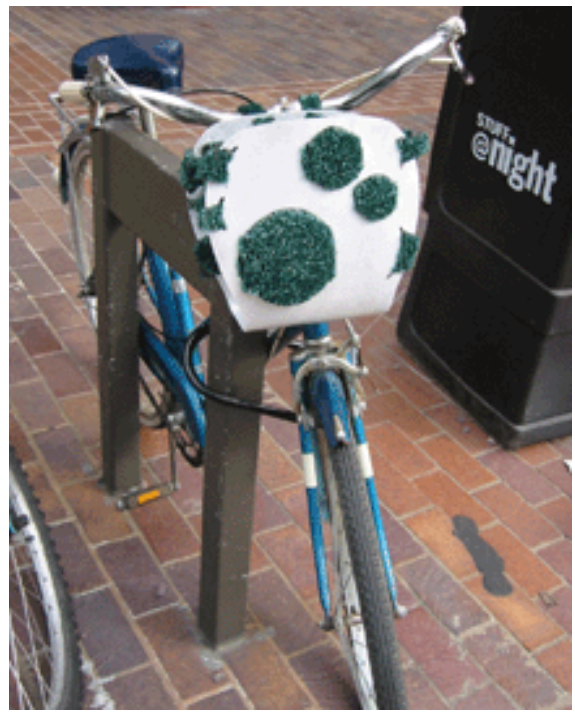

Directions: Please answer the following questions for this situation. For each of the following questions 1 is the lowest and 5 is the highest rating.

How attractive was route $A$ ? ${ }_{1}{ }_{2}{ }_{2}{ }_{3}{ }_{4}{ }_{5}$

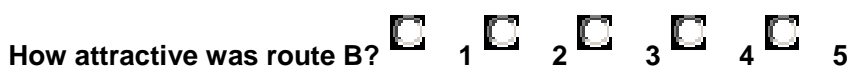

How important is it to be able to safely maneuver your bike? 


\section{$C_{1} C_{2} \square_{3} \square_{4} C_{5}$}

How important is it to impress your friend with your choice of bike?

$$
\mathrm{C}_{1} \mathrm{C}_{2} \mathrm{C}_{3} \mathrm{C}_{4} \mathrm{C}_{5}
$$

How important is it to be able to carry the board game more easily?

$$
\begin{aligned}
& \mathrm{C}_{1} \mathrm{C}_{2} \mathrm{C}_{3} \mathrm{C}_{4} \mathrm{C}_{5} \\
& \text { How believable is this scenario? }{ }^{\mathrm{C}}{ }_{1} \mathrm{C}_{2} \mathrm{C}_{3} \mathrm{C}_{4} \mathrm{C}_{5}
\end{aligned}
$$

Question RG4

You are going to take a bus to get to a concert taking place in a town that you are not super familiar with. You have a choice between two routes in the town. On one of the routes you will only have to make one transfer to get to the concert. However, you have taken this route before and the people on it were obnoxious and possibly intoxicated. You don't think that these people are dangerous, just annoying. The other route has more considerate and friendlier people, but you will have to make two transfers to get to your concert if you take this route. Which route do you choose?

C

A: You choose the route with the nicer people. You would rather be inconvenienced by the transfers than have to ride the bus with a bunch of obnoxious people.

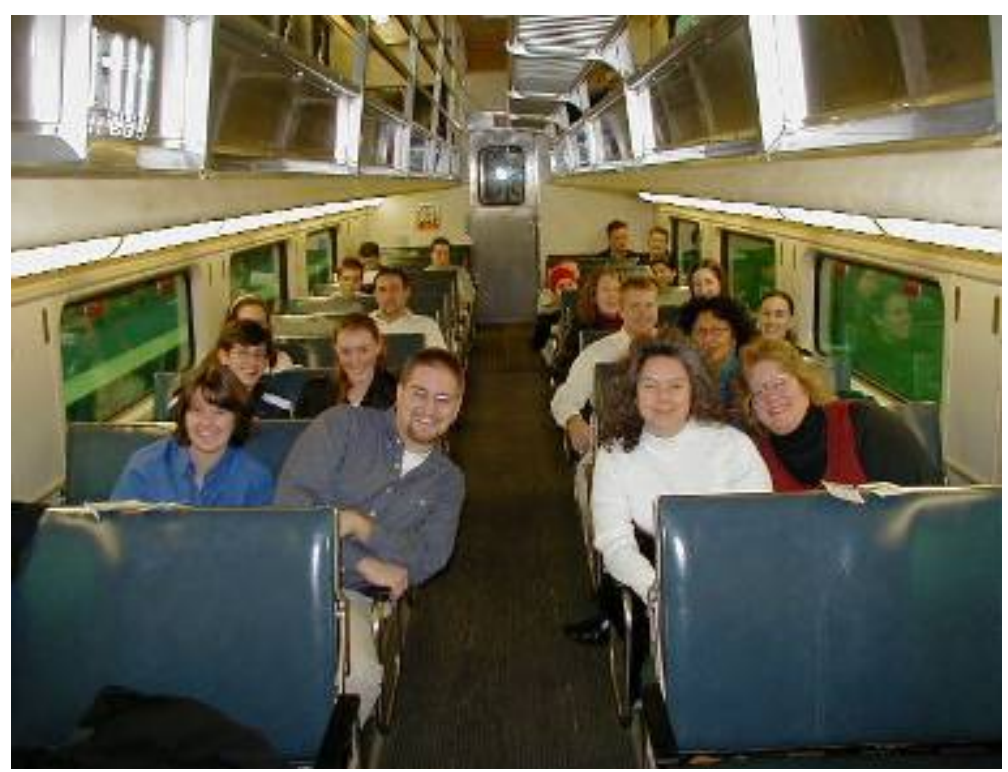

C

B: You choose the route with only one transfer, figuring that you can deal with the obnoxious people for the convenience of not having to transfer. 


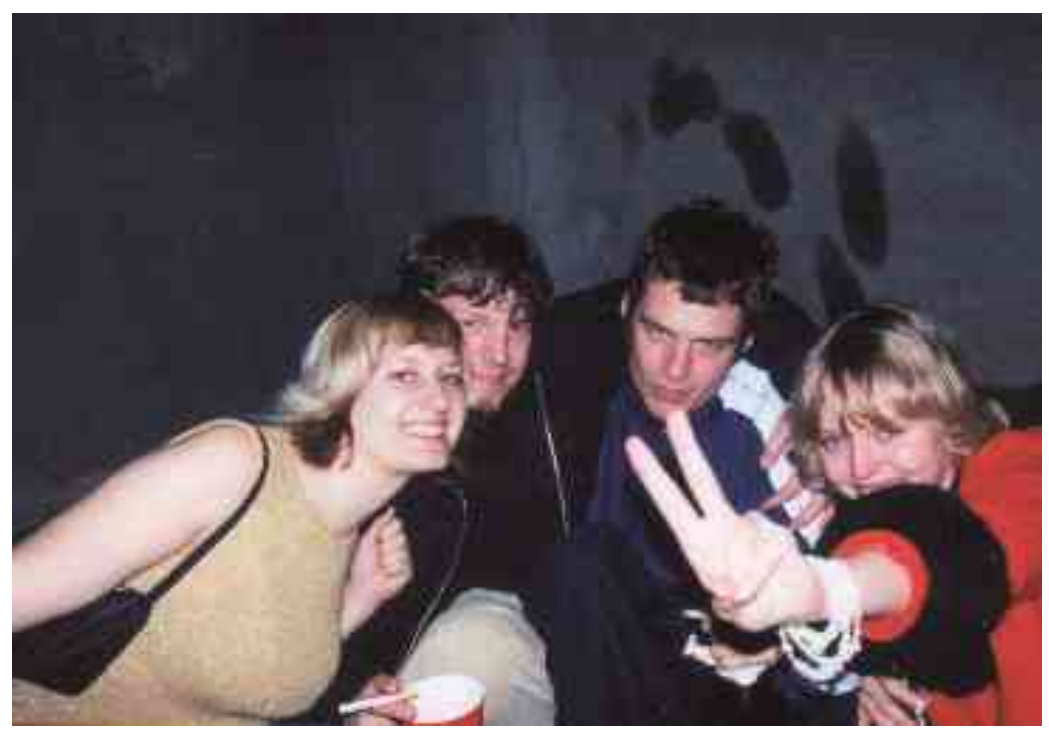

Directions: Please answer the following questions for this situation. For each of the following questions 1 is the lowest and 5 is the highest rating.

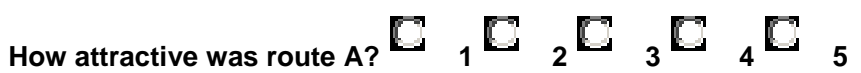

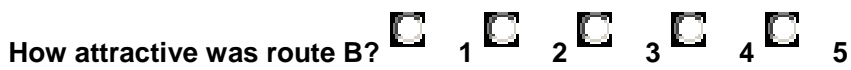

How important is it to be in a safe part of town when you catch this bus?

\section{$C_{1} C_{2} a_{3} b_{4} b_{5}$}

How important is it to be with people who you like on the bus ride?

$$
\vec{C}_{1} \mathrm{C}_{2} \mathrm{C}_{3} \mathrm{C}_{4} \mathrm{C}_{5}
$$

How important is it to have the convenience of not having to transfer to get to your destination?

$$
\mathbb{C}_{1} \mathrm{C}_{2} \mathrm{C}_{3} \mathrm{C}_{4} \mathrm{~b}_{5}
$$

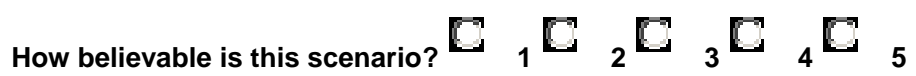

\section{Question RG5}

You are going to drive $\mathbf{2 0 0}$ miles to go hiking in a national forest. You have a choice of two different cars. Your significant other doesn't like your hybrid car that you want to take and wants to bring his/her Jeep. You think that the hybrid will do just as well and will be better for the environment. Which do you choose? 
C

A. You choose to bring the hybrid, even though your significant other doesn't really like it all that much. Helshe thinks that it's really uncool next to his/her Jeep and complains the whole time that he/she doesn't have enough space for the hiking gear.

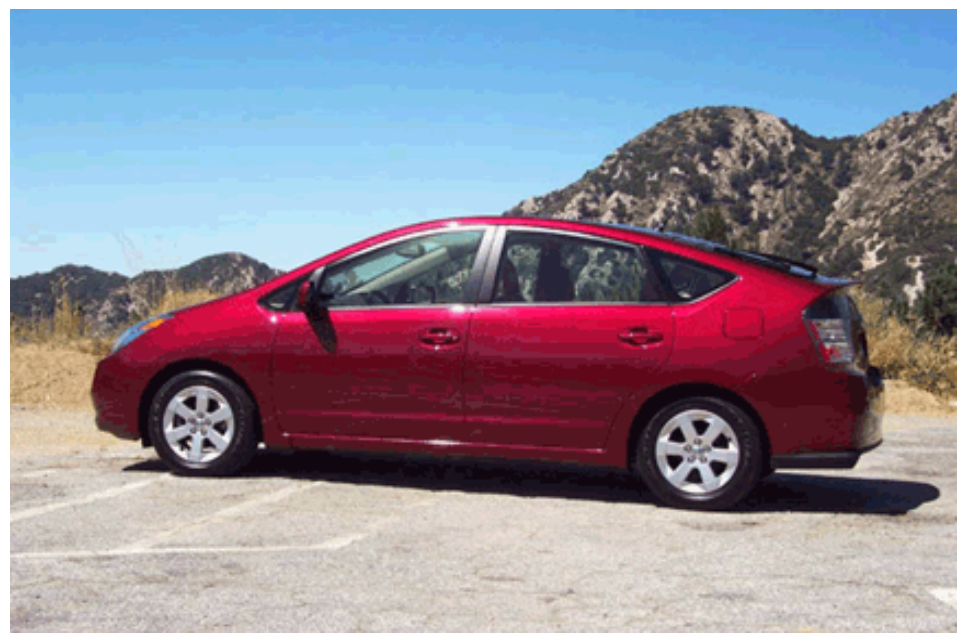

B. You choose to make your boylgirlfriend happy by bringing the Jeep, so that he/she will have enough space for his/her hiking gear, even though it will use a lot of gasoline and produce a lot of emissions.

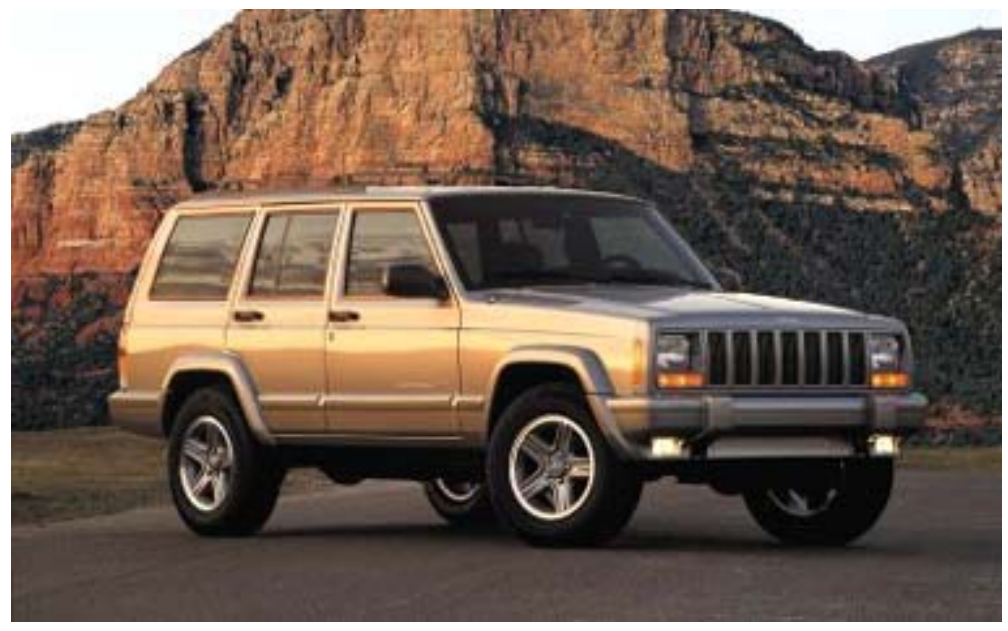

Directions: Please answer the following questions for this situation. For each of the following questions 1 is the lowest and 5 is the highest rating.

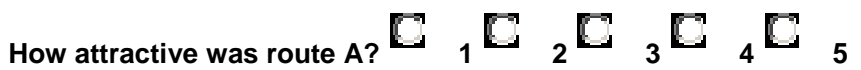

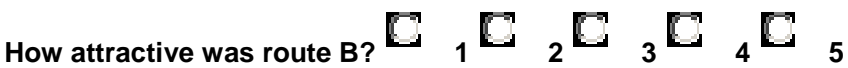

How important is it to have a safe, reliable car on your trip?

$\mathbb{C}_{1} \mathrm{C}_{2} \mathrm{C}_{3} \mathrm{C}_{4} \mathrm{C}_{5}$ 
How important is it to please your boy/girlfriend by taking the Jeep?

\section{$\mathrm{C}_{1} \mathrm{C}_{2} \mathrm{C}_{3} \mathrm{C}_{4} \mathrm{C}_{5}$}

How important is it to be more environmentally friendly by taking the hybrid car? ${ }_{1}{ }_{1}{ }_{2} \quad{ }_{3}{ }_{4}$ C 5

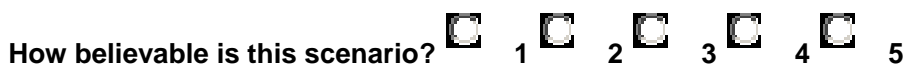

Question RG6

You take the train to work each morning. You usually wait 15 minutes for the train to arrive. You have the choice of two train stations, which are equal distance from your home. Train station $A$ is a hub and it has shopping and restaurants and nice waiting areas. Train station $B$ is nicely landscaped and attractive and offers shelter from the elements, but does not have all of the shops, restaurants, and other amenities that Train station A has. However, while waiting for train B, you noticed and had a nice interaction with a very attractive person, who you would like to get to know better. Which do you choose?

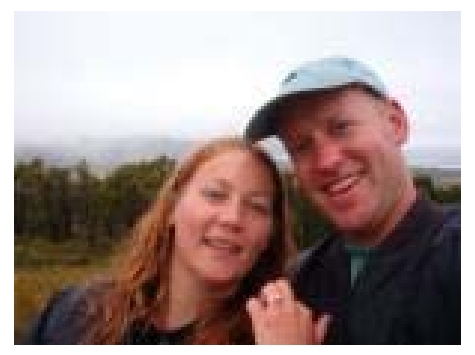

A. You choose train B, because you want to use your 15 minutes of waiting time to get to know this person better. 


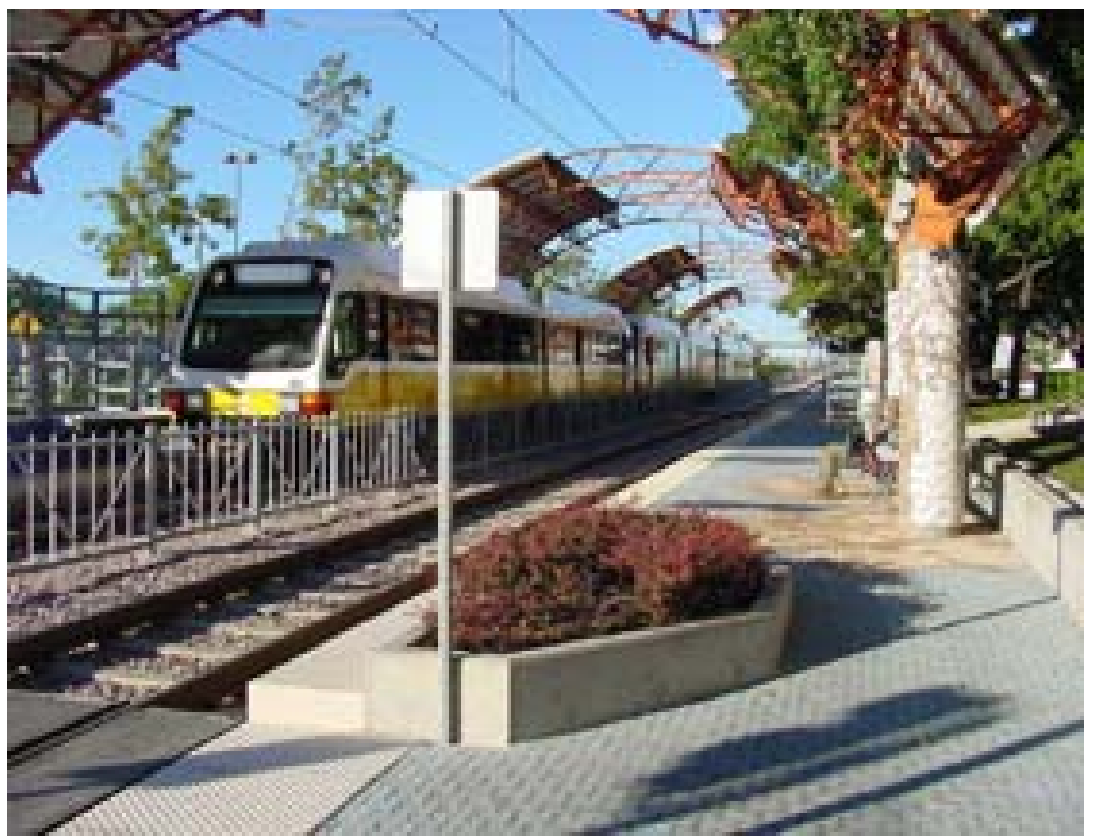

C

B. You choose train A, because you like having all of the amenities and you hope that you will find another attractive person at this stop.

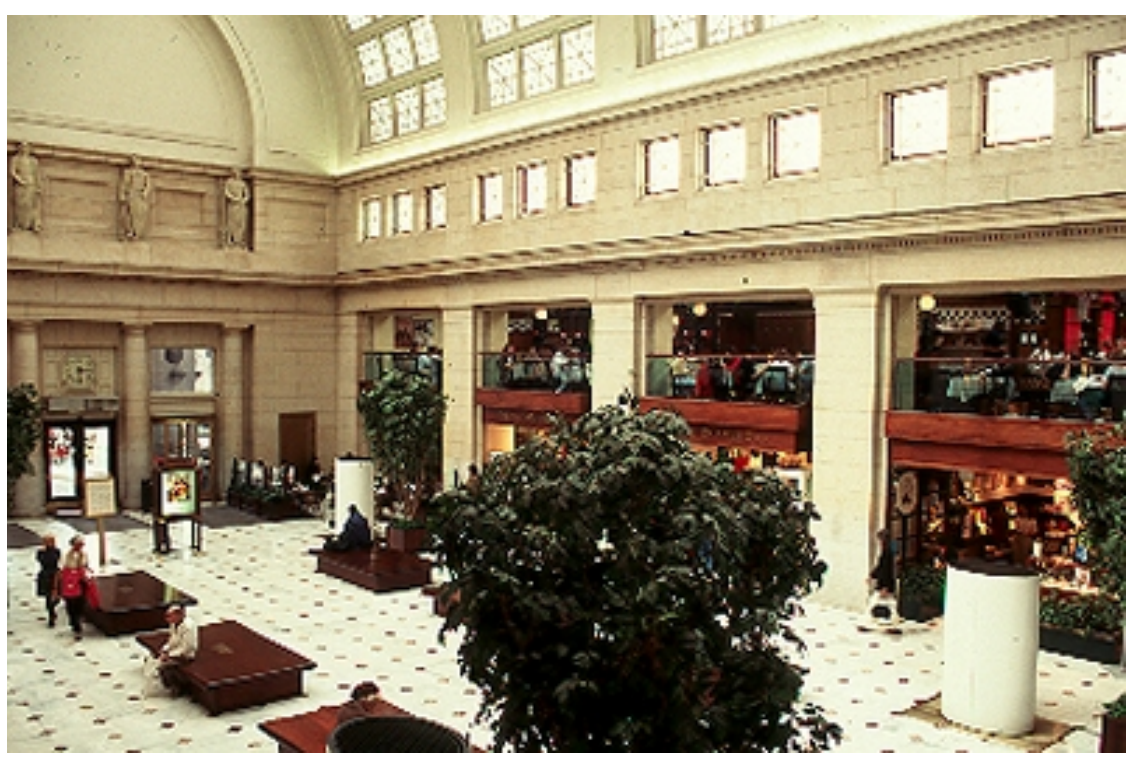

Directions: Please answer the following questions for this situation. For each of the following questions 1 is the lowest and $\mathbf{5}$ is the highest rating.

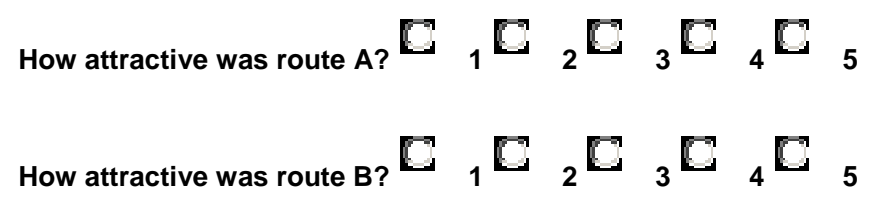

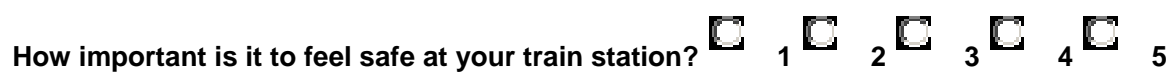


How important is it to see your possible love interest again? ${ }_{1}{ }_{1} C_{2} C_{3} C_{4} C_{5}$

How important is it to have amenities such as restaurants, shops, and seating areas?

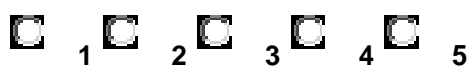

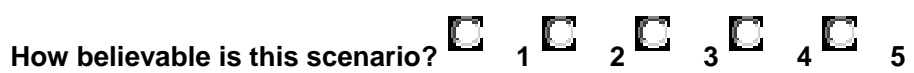

\section{Question RG7}

You are getting ready for a 5-day bike trip to the Grand Tetons. You and your spouse are avid cyclists and enjoy these types of trips. You are trying to decide between two different paths. You want to bike in the Grand Tetons and it's a very mountainous area. But, you like this one route that is full of natural potholes and your spouse likes the route that will be easier to ride on. You tell your spouse that it will be a fun adventure and that the scenery will be much better on the more strenuous route, especially the wildlife. Your spouse is an avid cyclist, too, and does enjoy a good ride, but feels that the difficulty of the route isn't worth the tradeoff for scenery. According to your guide, both routes are equally safe, it's just that one is much more strenuous than another. The guide agrees with you that the more strenuous route is also slightly more scenic than the less strenuous route, mainly that you get to be closer to wildlife such as moose and bison. What do you choose?

A. You choose the more strenuous route, because you want the better scenery and vistas, even though your spouse is a bit resentful that you didn't take his/her feelings into consideration. You figure that your spouse is in really good physical shape and they can handle the harder route. You think they'll thank you later for choosing the better scenery.
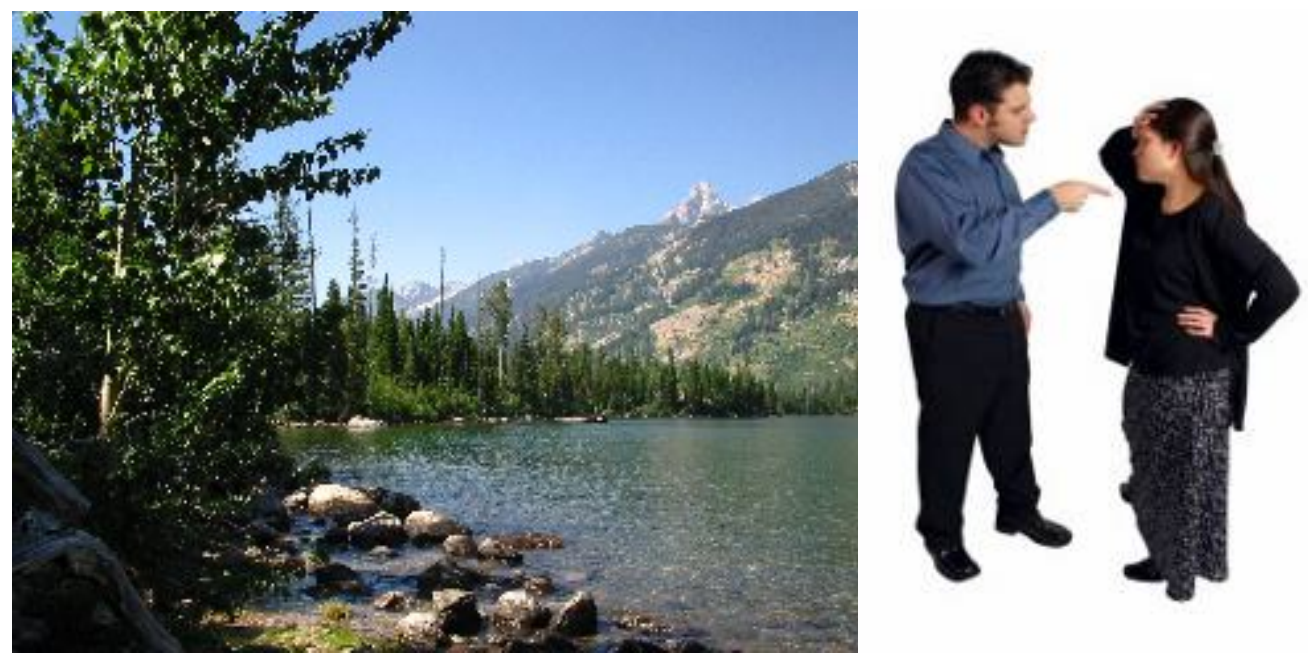

C

B. You choose the less strenuous ride, because you know that 5-days is a long time to be with an unhappy spouse and you want for him or her to enjoy the ride just as much as you do. In the Grand Tetons, the scenery never disappoints and maybe if your spouse has a good time on this bike trip he or she will agree to the harder one next time. 


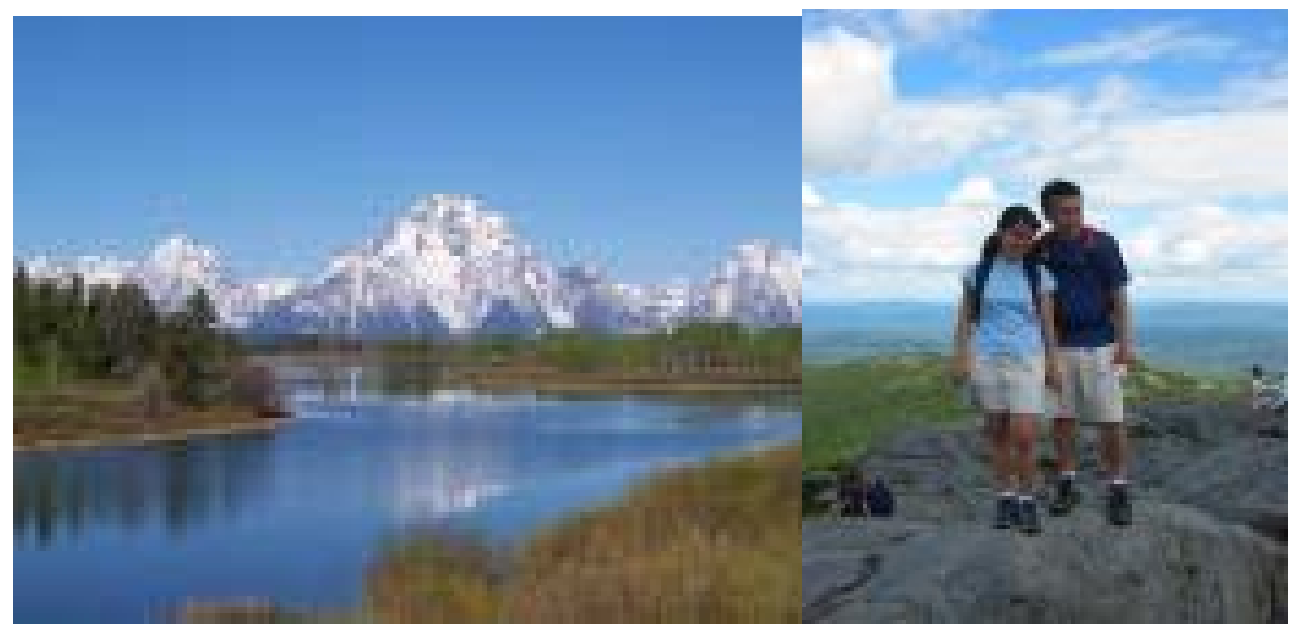

Directions: Please answer the following questions for this situation. For each of the following questions 1 is the lowest and 5 is the highest rating.

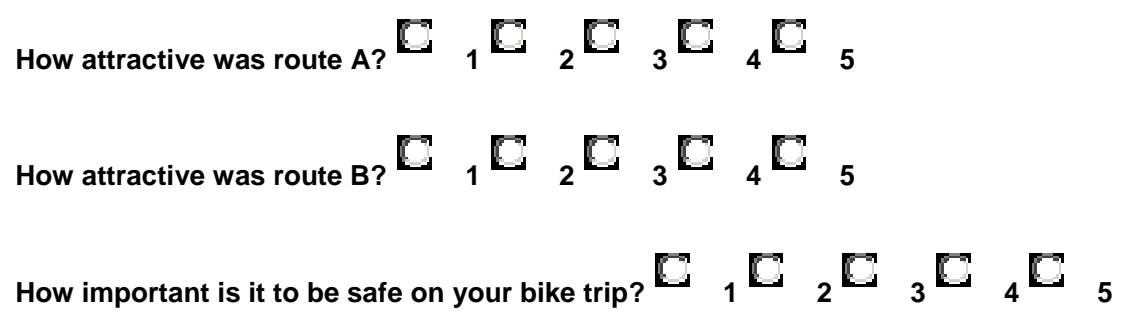

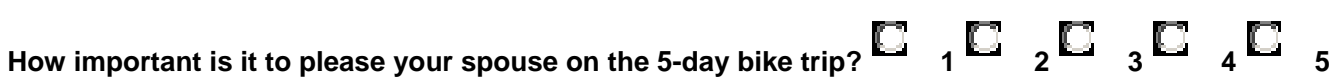

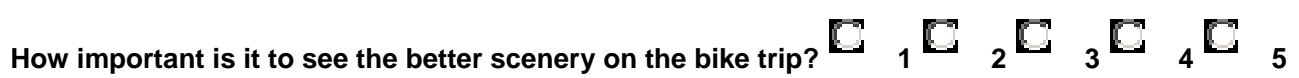

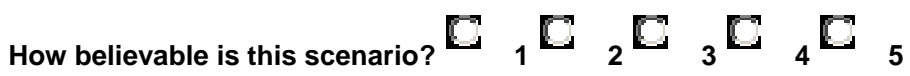

Question RG8

You are going to meet a friend in Washington D.C. for a night out on the town. Your friend wants to meet at a transit stop in DuPont Circle and you want to meet at Union Station. DuPont Circle is just a concrete hole in the ground that you take an escalator into and out of. It is not nearly as nice as you think Union Station is. But, your friend is very insistent on going to DuPont Circle to their favorite restaurant. You're not sure if you want to leave Union Station, which is also surrounded by beautiful and historical buildings to go to a local neighborhood that may not be as lovely. You are also only in town for the one night and it is your tradition to go to Union Station and people watch and enjoy the atmosphere and shopping and restaurants. But, you also only see your friend a few times a year when you're in D.C. on business and you want to make him or her happy as well. What do you choose?

E

A: You tell your friend that you don't live in D.C., so you get to decide where you go and you want to visit Union Station on your only night there. You know that your friend will be disappointed, but you really enjoying seeing the surrounding areas of Union Station. 


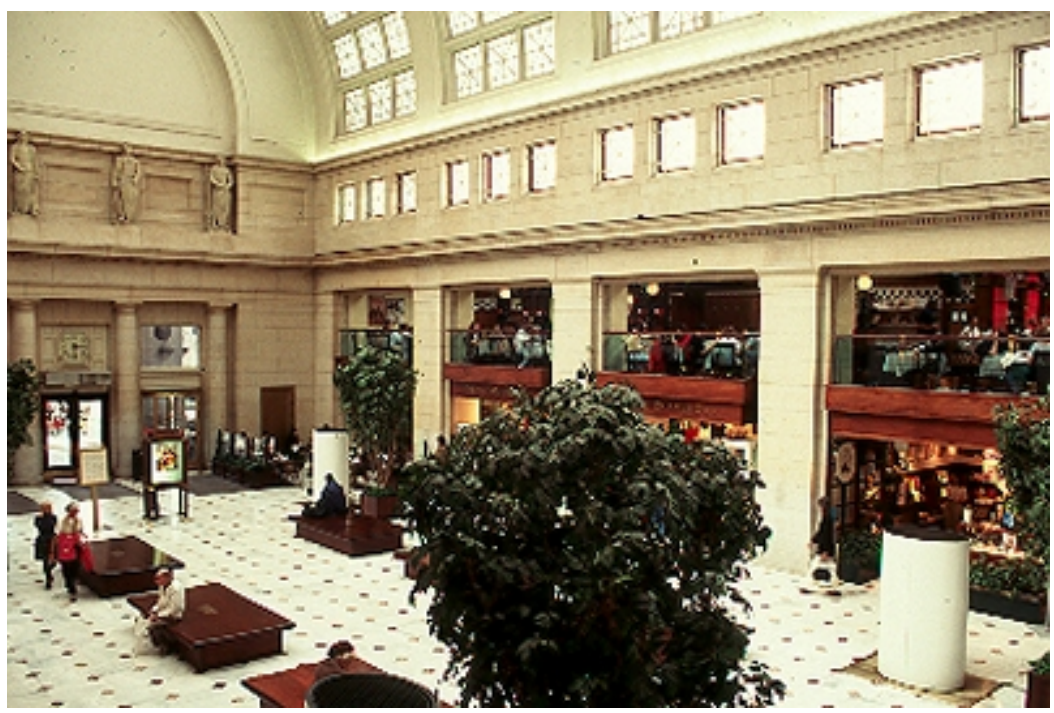

C

B. You decide to do something different and you take the Metra to the DuPont Circle station and you meet your friend at the Asian/French fusion restaurant that they mentioned. You figure that you will return to D.C. in a few months and you can see Union Station then.

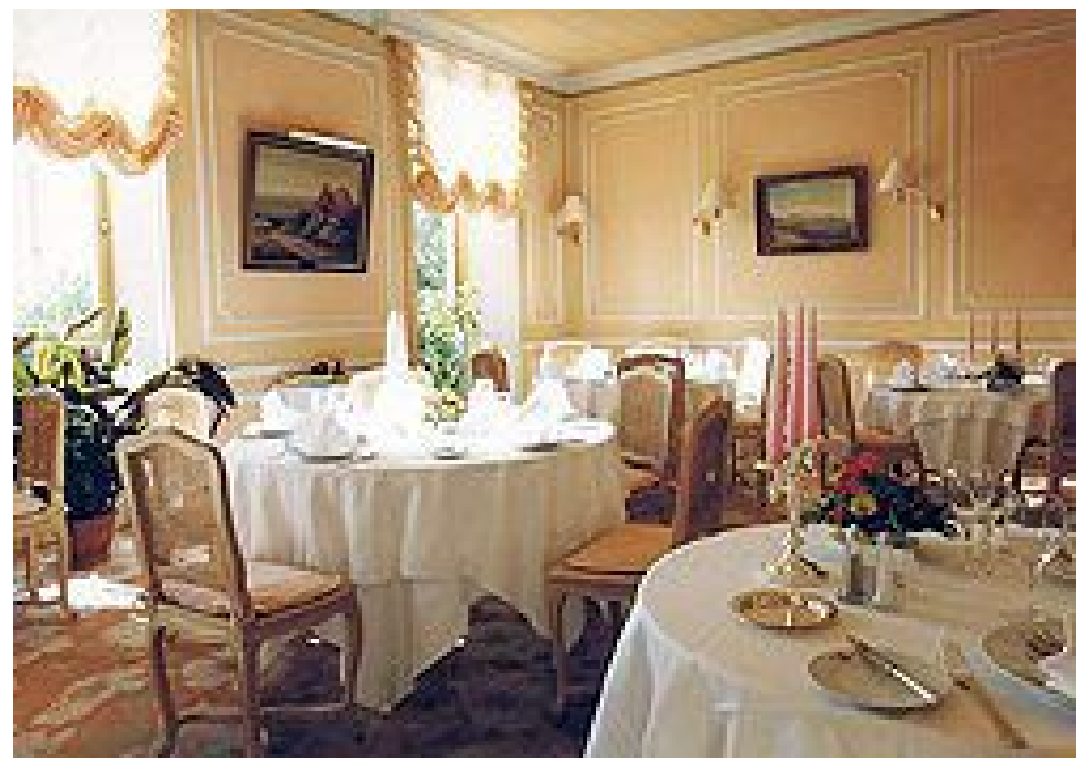

Directions: Please answer the following questions for this situation. For each of the following questions 1 is the lowest and 5 is the highest rating.

How attractive was route ${ }_{4}{ }^{C}{ }_{1} C_{2} C_{3} C_{4} C_{5}$

How attractive was route $B$ ? ${ }_{1} C_{2} C_{3} C_{4} \square_{5}$

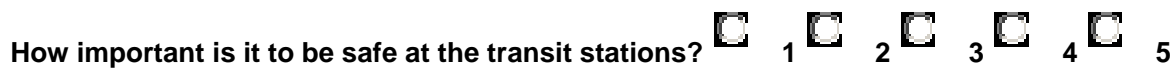

How important is it to please your friend by trying the new restaurant? 


\section{$\square_{1} \square_{2} \square_{3} \square_{4} \square_{5}$}

How important is it for you to see the nice architecture and buildings around the Union Station area?

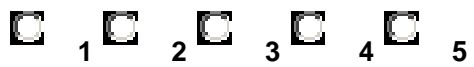

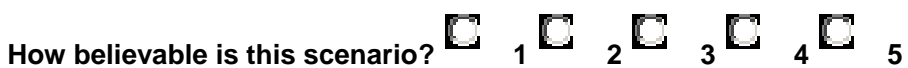

\section{Question RG9}

You are going on a walk with your parents down Bayshore Boulevard in Tampa. You have the choice of two routes. One route is significantly longer than the other route. The shorter route takes you past a vacant lot that just is so ugly you feel it spoils the walk for you. The longer route has some areas that aren't as beautiful as you would like, but not as blighted as you think the vacant lot is. However, your parents do not want to walk two miles instead of one mile just so that you don't have to look at the vacant lot. It's not dangerous, it's just ugly, they tell you, and they want to get to beautiful Bayshore more quickly. You know that your parents are capable of walking the two miles, but it means that they will not be able to enjoy the walk along Bayshore for as long. The main goal of the walk is to enjoy the beauty of Bayshore. What do you do?

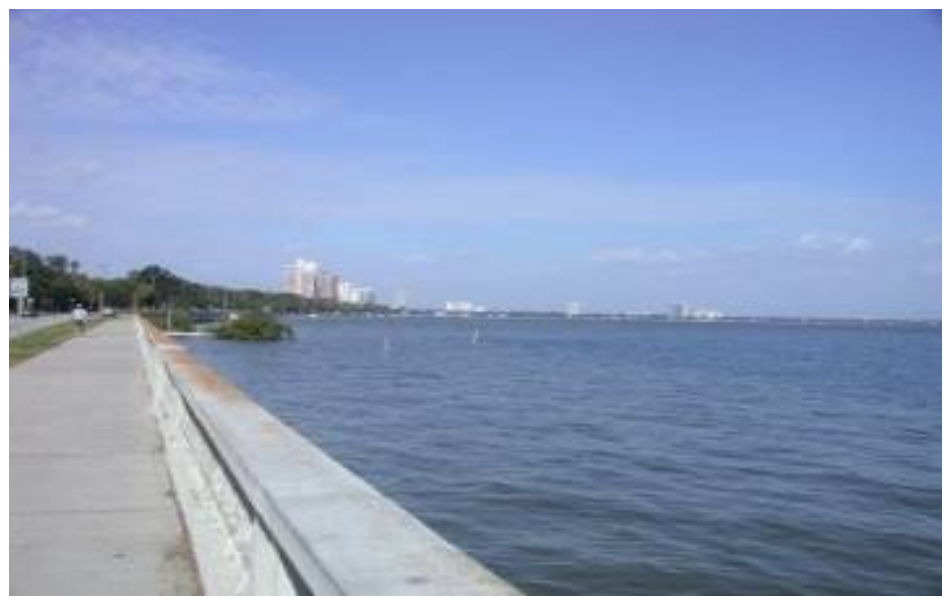

A. You choose to take the route that takes you by the vacant lot, keeping your eyes straight ahead on the sidewalk and diverting them from the ugly lot. You know that your parents appreciate the fact that you will walk past a small blighted area in order for your family to get to Bayshore more quickly for your evening walk. 


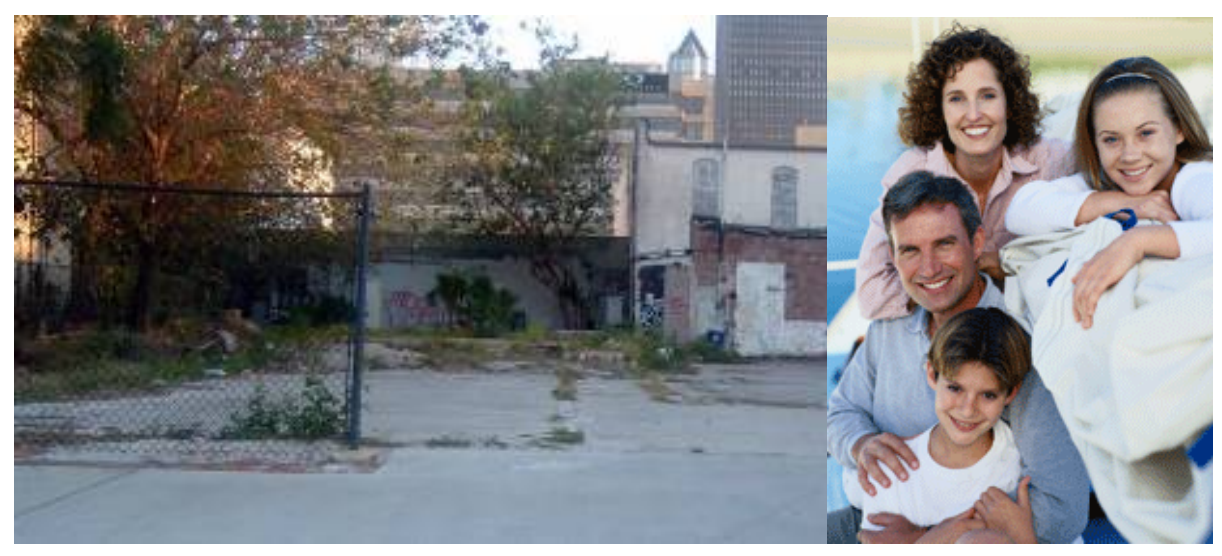

C

B. You decide that you just can't deal with that vacant lot and decide to make your parents walk the two mile route as opposed to the one mile route. Your parents are very unhappy that you are making them waste time that they could spend walking on Bayshore, walking along the Downtown streets in Tampa and aren't very nice company on the walk.

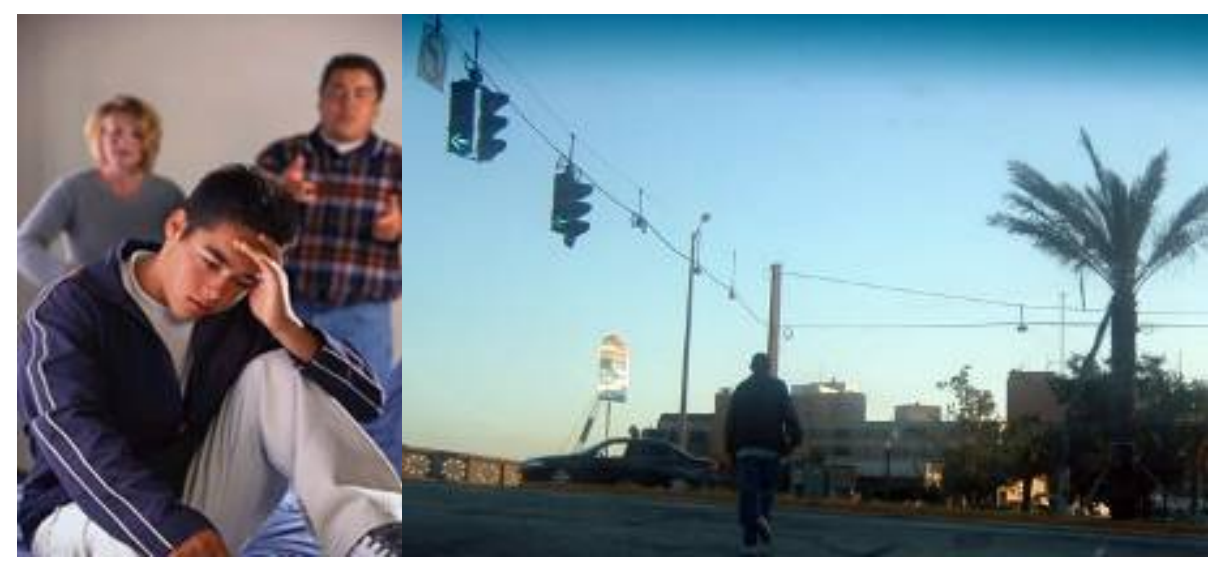

Directions: Please answer the following questions for this situation. For each of the following questions 1 is the lowest and 5 is the highest rating.

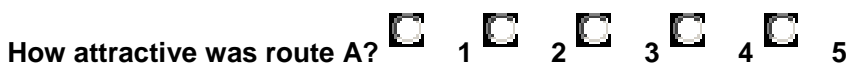

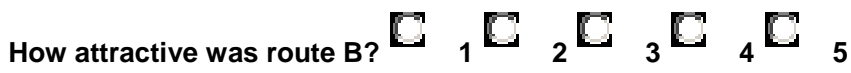

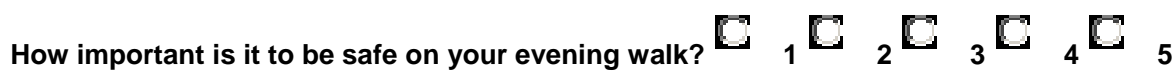

How important is it to make your parents happy with your choice of walking route?

\section{$\mathrm{C}_{1} \mathrm{C}_{2} \mathrm{C}_{3} \mathrm{C}_{4} \mathrm{C}_{5}$}

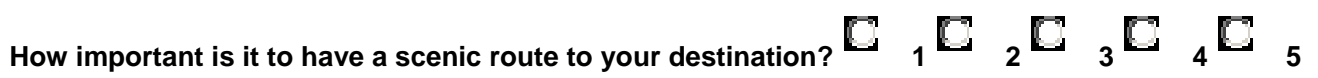


How believable is this scenario? ${ }_{1}{ }_{1}{ }_{2}{ }_{3}{ }_{3}{ }_{4}{ }_{5}$

Question RG10

You are driving to a local campus with your boy/girlfriend. You want to go by and see an exposition presentation. Going by the exposition is inconvenient and your boy/girlfriend doesn't want to go to it. But, you do have time before your classes start and you think that it would be fun for the both of you to go by the exposition. You know that your boylgirlfriend just wants to get to class and will be angry if you go by the exposition. What choice do you make?

A. You choose to go straight to your classes, missing the exposition that you wanted to see, but pleasing your boylgirlfriend.

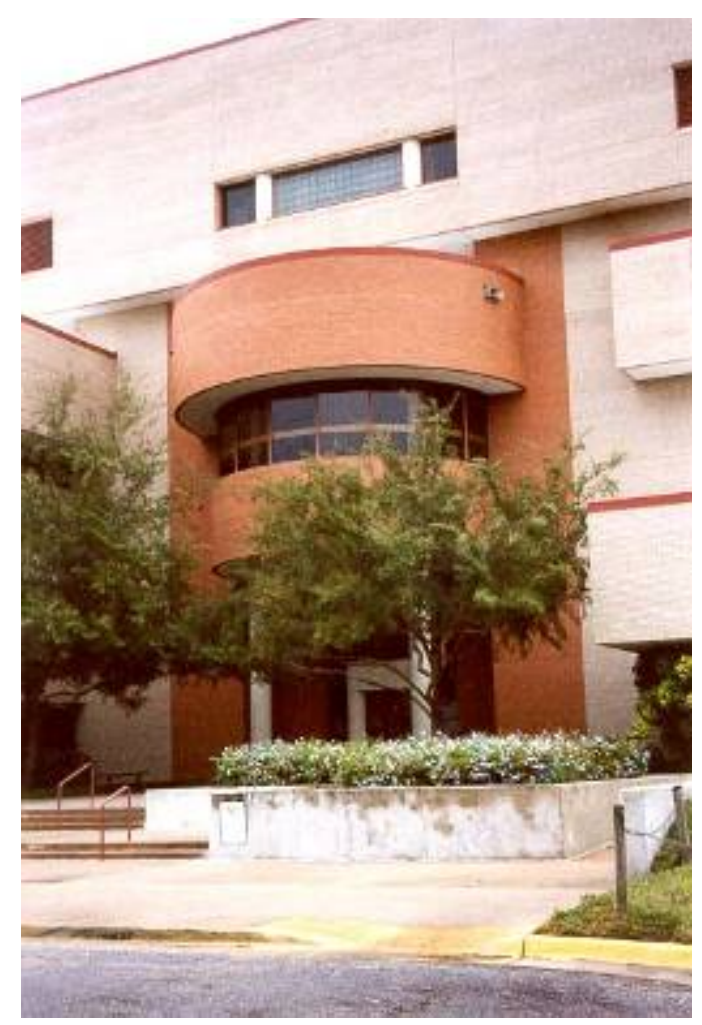

a

B. You choose to ignore your significant other's wishes and you take him/her to see the exposition anyway, thinking that they will like it once they get there. 


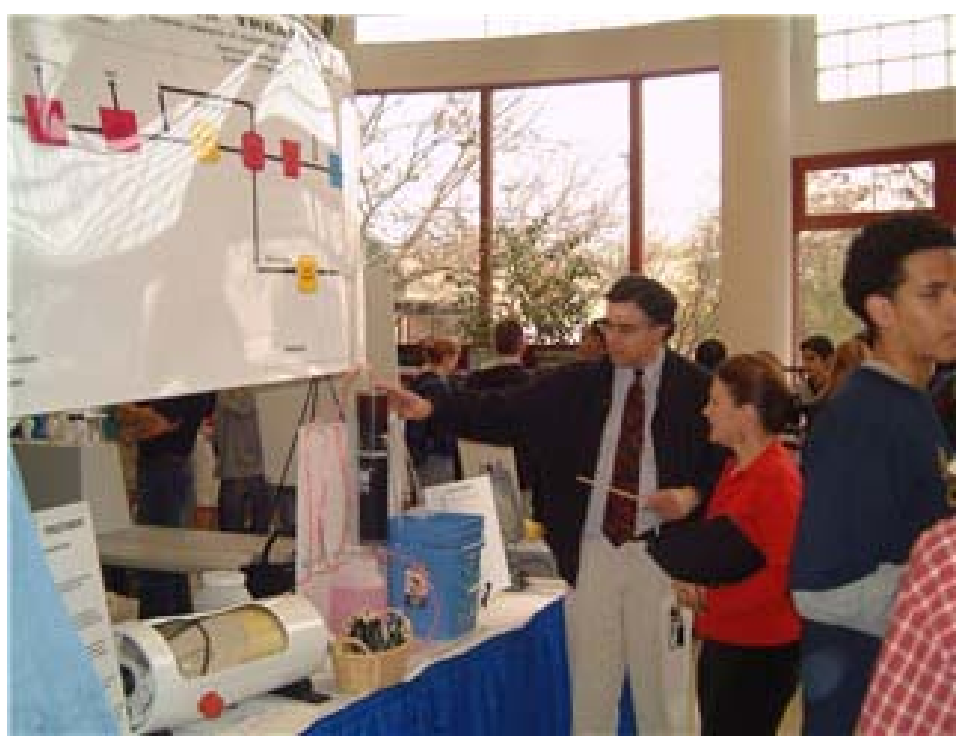

Directions: Please answer the following questions for this situation. For each of the following questions 1 is the lowest and 5 is the highest rating.

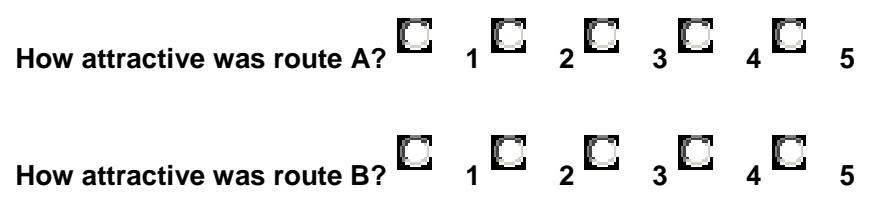

How important is it to be able to safely get to your destination? ${ }_{1}{ }_{2}{ }_{2}{ }_{3}{ }_{4} C_{5}$

How important is it to please your boylgirlfriend with your choice of route? ${ }^{C_{1}}{ }_{1}{ }_{2} C_{3} C_{4} C_{5}$

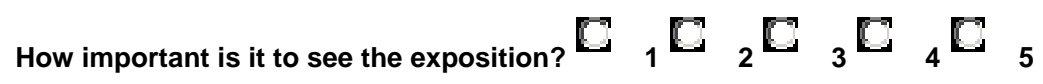

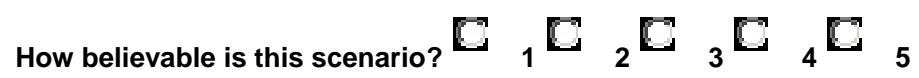





\section{Appendix B}

\section{A.1 Question ER1}

Before the 9/11/2001 terrorist attacks, you took the subway from the PATH station in New Jersey into work in Lower Manhattan every day and it was very convenient. The PATH station in Lower Manhattan was damaged in the WTC terrorist bombings and had to be reconstructed. During this time, you used a longer route to access your workplace, which took you twice as long as your original commute. Due to your longer commute, the responsibility of picking up your children fell to your spouse. The reconstructed PATH line has opened up and you can now resume your commute on the PATH line. Your spouse wants you to take the new route because it would be easy for you to pick up the children on your way home if you took the reconstructed PATH line. Which do you choose?

A (Relatedness choice): You resume your old commute and take the new PATH line. This allows you to pick up your kids, making your spouse very happy and also cutting your commute time in half. 80 percent/ 3.49

$B$ (Existence choice): You continue to ride the longer route that you feel is safer, even though this means that you won't be able to help your spouse pick up the children before dinner time. You want to help your spouse, but the thought of returning to the PATH line terrifies you. 20 percent/ 2.88

No significant difference between ratings for $A$ and $B$.

Existence rating: 4.38

Relatedness rating: 4.23

Growth rating: 3.38

Believability: $\mathbf{3 . 7 0}$

\section{A.2 Question 2 ER}

You will be taking a train this evening to eat dinner with your family. You have a choice of two trains, an express train that will get you to the stop at the same time your mother arrives to her park and ride lot at the train station and another train that will get you there 45 minutes later. You know that the later train will be a lot less crowded than the express train and you will have space to sit and be comfortable. Which do you choose?

A (Relatedness choice): You choose to ride the express train so that you can accommodate you mother's schedule, even though you are unable to find a seat and are very uncomfortable during the 40 minute train ride. 81 percent/ 2.97

B. (Existence choice): You choose to go against your parent's wishes and choose to ride on a train that has plenty of seats so that you can be comfortable on for the trip. Your mother is unhappy that she had to wait on you, but you were comfortable for the trip.19 percent/ 3.48

There is a significant difference between ratings for $A$ and $B$.

Existence rating: 3.62

Relatedness rating: 4.14 


\section{Growth rating: 3.36 \\ Believability: 3.16}

\section{A.3 Question ER3}

You are staying on a small island for the summer and you are going to go bike riding to your friend's house and the only route is a soft dirt road. You have a choice of two bikes to ride. The first bike makes it much easier to ride in the sand and the second makes it much harder to ride in the sand on the way to your friend's house. The sand bike, because of its light, large plastic wheels, is fairly easy to maneuver in the sand and will get you to your friend's house quickly and easily. However, your friend thinks that these sand bikes look ridiculous and will probably make fun of you if you ride the sand bike. Your friend likes the bike that you use on the paved roads around the island, but this bike will be very hard to ride in the sand. Which do you choose?

A (Existence choice): You choose the sand bike because you know that it will be easy to maneuver it in the loose sand on the way to your friend's house and you don't care if your friend thinks it looks silly, because you don't want to put yourself through trying to ride a bike that is not designed for use in the sand to impress your friend. 89 percent/

\subsection{5}

B (Relatedness choice): You choose the bike designed for use on pavement, even though you know you'll have a heck of a time trying to maneuver it through the loose sand. You want to impress your friend with the bike you know that he or she likes. 11 percent/ 2.92

There is a significant difference between ratings for $A$ and $B$. Existence rating: 4.28

Relatedness rating: 2.44

Growth rating: 3.36

Believability: 2.91

\section{A.4 Question ER4}

You need to use transit to get to a football game in a place with which you are not extremely familiar. You have a choice between two special event transit pick-up areas. However, the passengers who typically ride this bus line are opposing fans and they have hassled you the few times you have ridden this shuttle service in the past. You understand that there are two shuttle pick-up areas, one for the opposing team and one for the home team. You haven't yet been able to locate the opposing team pick-up area, because you have only ridden the shuttle bus from the home team pick-up area. Which do you choose?

A (Existence Choice): You ride from the home team pick-up into the stadium, because you don't want to get lost looking for this visitor pick-up area. You can handle being harassed, but not being lost. $\mathbf{3 0}$ percent/ 2.86

B (Relatedness Choice): You go looking for visitor's pick-up point so that you don't have to be harassed on your way into the stadium. It took approximately 10 minutes to 
find this area, but you feel more comfortable riding into the game with the fans from your team and now you know you won't get lost again. 70 percent/ 3.76

There is a significant difference between ratings for $A$ and $B$.

Existence rating: 4.20

Relatedness rating: 3.70

Growth rating: 3.14

Believability: 3.22

\section{A.5a Question ER5}

You and your spouse would like to drive a car 50 miles to Glacier National Forest for some hiking. There are two cars available for the drive, your $2004 \mathrm{H} 2 \mathrm{Hummer}$ or your significant other's Toyota Prius, which needs some brake work. You want to take the Hummer because it is in perfect running condition, especially for the steep mountain twists and turns found in the park. Your significant other has never liked the Hummer because it is 'an ostentacious gas-guzzler.' Your significant other would rather take a more 'humble' car, even if it needs brake work, and claims that the Prius is fundamentally sound for mountainous travel. What do you choose?

A (Relatedness Choice). You honor the wishes of your significant other to NOT ride in your $\mathrm{H} 2 \mathrm{Hummer}$ and you take the Prius on the mountain ride, reasoning that their happiness is more important than little brake work. 12 percent/ 2.32

$B$ (Existence Choice). You're worried that the brakes on the Prius might not be safe enough for mountain climbing and so you insist on bringing the car which has the safer equipment, even though your significant other resents having to ride in the 'gas-guzzler.' 88 percent/ 4.31

There is a significant difference between ratings for $A$ and $B$. Existence rating: 4.49

Relatedness rating: 3.49

Growth rating: 3.64

Believability: 3.57

\section{A.6 Question ER6}

You take the train to work each morning. You usually wait 15 minutes for the train to arrive. You have the choice of riding one of two trains, which arrive 5 minutes apart at separate platforms, so that if you decided to take one train, you would not see the people from the other train. The one train arrives on platform $A$ and usually has some unusual types of people waiting to load and these people make you feel nervous about what they might do. However, one of the days when you were waiting on platform A, you noticed a very attractive person getting off the train as you were getting on. If you use the train at platform B, you probably will not see this possible love interest again soon, but you will be waiting with people who make you feel safer. What do you do? 
A (Relatedness Choice). You take the train at platform A, because you want to see that very attractive person again. You can handle the nervousness over the strange people if you can see this potential love interest again. 36 percent/ 3.07

$B$ (Existence Choice). You take the train from platform $B$, because the unusual people just make you feel too unsafe and you want to wait with people who make you feel safer. 64 percent/ 3.64

There is a significant difference between ratings for $A$ and $B$.

Existence rating: 4.14

Relatedness rating: 3.30

Growth rating: 3.46

Believability: 3.12

\section{A.7 Question ER7}

You are going to start riding your bike to work, a commute of 3-4 miles every day. A group of your friends also want to ride into work with you. However, you disagree on which route to take. Your friends want to take a shorter route, that is 3 miles long, that includes some very congested roads on which you don't feel safe. You want to take the 4 mile route which has less congestion and is safer. But, you also really would like to ride with your friends, because it will make the bike ride more fun. What do you choose?

A (Relatedness Choice). You choose to ride with your friends on the congested road, because you would rather ride a shorter route and be with your friends riding into work than alone. 33 percent/ 3.02

$B$ (Existence Choice). You choose to ride in the safer, less congested area, even though you have to ride a longer distance and you can't ride with your friends. $\mathbf{6 7}$ percent/ 3.67

There is a significant difference between ratings for $A$ and $B$.

Existence rating: 4.23

Relatedness rating: $\mathbf{3 . 0 8}$

Growth rating: 3.13

Believability: 3.35

\section{A.8 Question ER8}

You are going to take the bus to the mall. You have the option of two different bus stops which are convenient to your house. The bus stop that is only 2 blocks from your house makes you feel a bit nervous, because there is no shelter or bench, it is very close to the oncoming flow fast traffic, and there is a large overhang from the building next to the bus stop that makes you feel a bit crowded. Most of your friends use this stop. The other stop is a really nice shelter, with plenty of bench space and protection from the elements, as well as protection from the oncoming traffic. This stop makes you feel much safer than the one that is so exposed to traffic. However, you have to walk 3 blocks to access this stop and your friends don't usually use this stop. But, you do like the fact that you have shelter and a place to sit. Which do you choose? 
A (Existence Choice): You choose to walk the extra block to access the safer stop because you like the safety that this stop affords you, as opposed to the corner stop. You don't mind if you don't get to wait with your friends. 70 percent/ 3.69

B (Relatedness Choice). You choose the corner stop because it is more convenient and you can wait with your friends. You are not all that concerned about your safety being in such close proximity to traffic. $\mathbf{3 0}$ percent/ $\mathbf{3 . 1 0}$

There is a significant difference between ratings for $A$ and $B$.

Existence rating: 3.87

Relatedness rating: 3.13

Growth rating: 3.42

Believability: 3.22

\section{A.9 Question ER9}

You are going to walk to the store and you have two paths to choose from. On one of the paths, you must cross a gas station in order to get to the store. This is the shortest and most convenient route and you are able to stop by your friend's Pizzeria on the way. Recently, there have been some gang members hanging out in this gas station lot and you feel afraid to cross by the gas station because of this reason. You used to like to stop by your friend's pizzeria to hang out and have a slice on the way back from the store. But, you have started taking the second route, even though it is longer and more complex and does NOT go by your friend's Pizzeria. You really want to stop by your friend's pizzeria on the way home from the store today. What do you do?

A (Relatedness Choice). You choose to take the route that takes you by the gas station, hoping that the gang members will not notice you crossing in front of 'their' gas station. You want to go hang out with your friend at the pizzeria and you don't want to let the hoodlums scare you off any longer. 24 percent/ 1.62

$B$ (Existence Choice). You choose the second route that is longer, but safe from the gang members. This doesn't allow you to see your friend, but you figure that you can call for carry out if you want some pizza and your friend can come and visit you in your home, where you feel safer. 76 percent/ 4.15

There is a significant difference between ratings for $A$ and $B$.

Existence rating: 4.44

Relatedness rating: 2.72

Growth rating: 2.96

Believability: 3.29

\section{A.10a Question ER10}

You are driving with your boy/girlfriend in a rural area on your way to a local College campus. Your girl/boyfriend thinks that you should take a route into campus that is rural and icy and slippery, because he/she wants to show you this place where you can go 
sledding this weekend. You feel nervous riding on icy roads, but you know that your boy/girlfriend will be angry if you choose not to go by the sledding site. You also know how terrified you were when you lost control of your car on this same slippery route a week ago. Which do you choose?

A (Existence Choice). You choose the local maintained route for your own safety and, since he/she is riding with you, the safety of your boy/girlfriend. Your boy/girlfriend is very upset and unhappy that you won't drive by the sledding site and pouts all the way into campus, but you feel more comfortable on the maintained route. 85 percent/ 3.81

B (Relatedness Choice). You choose to indulge your boy/girlfriend and drive by the sledding site on the way to campus, even though you don't feel safe driving on an unplowed icy road and you are afraid that you might have an accident. But, you are glad that you are making your boy/girlfriend happy. 15 percent/ 2.60

There is a significant difference between ratings for $A$ and $B$.

Existence rating: 4.52

Relatedness rating: 2.83

Growth rating: 2.86

Believability: 3.54

\section{B.1 Question EG1}

You usually ride the EL (elevated train) to work in Downtown Chicago. The Chicago Transit Authority has issued a terrorist warning about which routes may be susceptible because of their location in the city. The route that you usually take to work is on this list and there is another route that you can take to work that is not at risk, but you have to look at the backside of ugly row houses. What do you do?

A (Growth Choice): You choose to ride on your normal route, reasoning that the U.S. State Department issues warnings all of the time about terrorist threats, with none of them happening. You enjoy your ride into work in the morning, and you're not altering your route because of State Department warning that something might happen. $\mathbf{5 0}$

percent/ 3.51

$B$ (Existence Choice): You are really afraid of another terrorist attack in a city such as Chicago, so you choose to alter your route and go the 'ugly' route, even though you miss your 'beautiful' route, in order to feel safer. 50 percent/ 3.22

There is not a significant difference between ratings for $A$ and $B$.

Existence rating: 3.88

Relatedness rating: 3.12

Growth rating: 2.88

Believability: $\mathbf{3 . 2 0}$

B.2 Question EG2 
You are going to ride an Amtrak train to see your family. The train ride will last for 5 hours. You have a choice of two trains. The first one is a commuter special train that offers a bargain rate for commuters at certain hours of the day. You know that this train is often very crowded and when you have taken this train before, you've been very uncomfortable and hot from overcrowding. You are somewhat interested in taking this train because it is only $\$ 36$. But, you know that you could take another train that would not be so overcrowded and you would have room to relax or to sleep or work on the train. You like the idea of the extra comfort during your train ride, but the less crowded train is more than twice the price of the commuter special train at $\$ 75$. You want to save money, but you also want to be comfortable. What do you choose?

A (Growth Choice): You choose to save money and ride the crowded train, figuring that you can stand several of hours of discomfort to save half of the fare. 11 percent/ 2.50

$B$ (Existence Choice): You choose comfort over cost and choose to ride the more expensive, but more spacious train. Five hours is a long time to be packed into a small space. 89 percent/ 4.35

There is a significant difference between ratings for $A$ and $B$.

Existence rating: 4.24

Relatedness rating: $\mathbf{3 . 0 0}$

Growth rating: 3.30

Believability: $\mathbf{3 . 2 0}$

\section{B.3b Question EG3}

You want to ride a bike to visit your friend to play a board game. Your friend lives 3 miles from you, down a soft dirt road. You can either use a regular bike that has a basket for a board game, which will be very hard to safely maneuver in soft dirt. Or, you can take the sand bike and the wide and light plastic tires will make riding in loose sand or dirt a breeze. But, the beach bike does not have a convenient basket for your board game, so you will have to figure out a way to carry it on the sand bike. Which do you choose?

A (Existence Choice): You choose the sand bike. You know that if you try to ride the regular bike in the soft dirt, it will be extremely hard and inefficient, even though the regular bike has a carrying basket for your game. You think you can find another way to carry the game if the riding can be made easier. 78 percent/ 3.82

B (Growth Choice): You can't figure out another way to get the board game to your friend's house, so you choose the bike with a basket. You know that it will be hard to ride the regular bike through loose dirt, but you can't figure out how else to carry the game to your friend's house. 22 percent/ 2.95

There is a significant difference between ratings for $A$ and $B$.

Existence rating: 4.30

Relatedness rating: 2.12

Growth rating: 3.07

Believability: 2.49 


\section{B.4b Question EG4}

You are going to a concert in a somewhat unfamiliar city. You have a choice between two transit lines. The bus line has published extensive maps and other documentation that allow you to easily use the bus line. However, you will have to switch buses two times in order to reach your destination. There is also a trolley service that you noticed, but you are not sure of where this trolley goes or if it will take you to the concert. A stranger in the parking lot tells you that the trolley will take you to the concert. Do you choose to take the bus, because you are certain of where it goes, even though it might be inconvenient, or do you take the Trolley based on word of mouth information? Which do you choose?

A (Existence Choice): You love this group and you don't want to miss the concert and you know for sure that the bus system will get you there and you have solid information about where it goes and what time it will get to the event center. So, you discount what the stranger in the parking lot said and go for the sure thing. 61 percent/ $\mathbf{3 . 4 3}$

B (Growth Choice): You decide to take the word of the stranger in the parking lot and you catch the Trolley to see where it goes. You figure that the stranger in the parking lot was trying to be helpful and save you some time. So, you jump aboard the Trolley, hoping that it will take you to the concert. 39 percent/ $\mathbf{3 . 4 0}$

There is not a significant difference between ratings for $A$ and $B$.

Existence rating: 3.97

Relatedness rating: 3.64

Growth rating: 3.63

Believability: 3.33

\section{B.5b Question EG5}

You are going to take a 200 mile trip with your family to go camping and hiking in a national forest this weekend. You have a choice of two cars. You have a Jeep Grand Cherokee and a Toyota Prius. In the past few days, the Jeep seems to be having some engine trouble and you really don't have time to take it into the shop prior to your trip. The Jeep has a lot more space for your passengers and hiking gear than the Prius, but you are afraid that the Jeep will have engine trouble up in the mountains. You know for sure that the Prius is in tip top shape because you just had it serviced by your mechanic two weeks ago. You're not sure of what to do, because the Prius really doesn't have a lot of passenger or cargo space and there are four of you. Which do you choose?

A (Growth Choice). You decide that you want to have enough space for people and cargo. You believe that the Jeep can make the trip, even given the recent engine problems, so you go ahead and hope that don't break down 200 miles from home. 14 percent/ 2.85

$B$ (Existence Choice). You decide that you don't want to chance having a major engine breakdown 200 miles from home. You decide to stuff 4 people and cargo in a smaller car that you know for sure will get you roundtrip on your camping trip. 86 percent/ 4.04 
There is a significant difference between ratings for $A$ and $B$.

Existence rating: 4.41

Relatedness rating: 2.14

Growth rating: 3.49

Believability: 3.64

\section{B.6b Question EG6}

You take a train to work each morning and you usually wait approximately 15 minutes for your train to arrive each morning. You live equidistant between two train stations. At one train station, you can have amenities such as a coffee shop, a newsstand and a nice waiting area. Lately, you have noticed that there are some vagrants hanging out in the coffee shop and waiting area. They make you feel uncomfortable and a few have even approached you for money recently and you are worried that they may become violent. The other station only has vending machines and plastic chairs. You have complained to the management of the nicer station about the vagrants several times, but they have a hard time keeping them out, especially if they pay for a cup of coffee. What do you do?

A (Growth Choice). You keep on taking the train from the nicer station. You don't want to let the vagrants keep you from enjoying the amenities of the nicer station. $\mathbf{3 6}$

percent/ 3.51

$B$ (Existence Choice). You go to the station with less amenities, because the vagrants at the nicer station make you feel too vulnerable and nervous during your wait. At least you can get coffee out of the vending machine. 64 percent/ 3.29

There is not a significant difference between ratings for $A$ and $B$.

Existence rating: 4.26

Relatedness rating: 3.43

Growth rating: $\mathbf{3 . 4 8}$

Believability: 3.25

\section{B.7 Question EG7}

You are going to start riding your bike to work, a commute of 3 miles every day. One of the routes is through a rural, unpopulated area, which runs by a cemetary, but there is nice scenery along the way. However, you have heard about some strange supernatural activities in that area in recent weeks that have everyone concerned (i.e., Blair Witch). The other route is also around 3 miles in length and runs through a very populated area, but it is not very scenic. Which do you choose?

A (Existence Choice). You choose to ride where there are people, because you are afraid of riding alone in the rural, deserted area, especially by the cemetery. $\mathbf{5 0}$ percent/ 3.34 
B (Growth Choice). You choose to take the more scenic route and you think that the supernatural rumors are just to drum up tourist trade. It's a beautiful ride. $\mathbf{5 0}$ percent/ 3.62

There is not a significant difference between ratings for $A$ and $B$. Existence rating: 4.23

Relatedness rating: 2.97

Growth rating: 3.52

Believability: 3.17

\section{B.8 Question EG8}

You are going to meet a friend in Washington D.C. for a night out on the town. Your really want to go to a restaurant that is off of the transit stop in DuPont Circle, but you don't like the DuPont Circle station because there is a very steep escalator into and out of the station and you are afraid of both heights and escalators. You also heard that a person was seriously injured recently when their coat got caught in the escalator. Union Station does not have steep escalator entries or exits in the transit area, so you feel much safer there, but there are only chain restaurants in and around Union Station area. You really want to go to this restaurant which is off of the DuPont Circle Metra stop, but you're scared of the steep escalators and it will cost $\$ 10$ (versus a $\$ 2.50$ transit fare) to catch a taxi from Union Station to the restaurant at DuPont Circle. What do you choose?

A (Existence Choice): You decide to stay at Union Station to have dinner and to go to a movie later. You are very disappointed, because you wanted to try the new restaurant, but you know that you would have felt very panicked and unsafe entering/exiting the DuPont Circle Station. 27 percent/ 2.85

B (Growth Choice): You decide to venture outside of the relative safety of Union Station and go to DuPont Circle to the new Asian/French fusion restaurant that you want to try. You decide to pay the $\$ 10$ to take a cab from Union Station to DuPont Circle area, instead of transit. 73 percent/ 3.96

There is a significant difference between ratings for $A$ and $B$.

Existence rating: 4.04

Relatedness rating: 3.65

Growth rating: 3.62

Believability: $\mathbf{3 . 2 0}$

B.9 Question EG9 
You are going on a walk down to Bayshore Boulevard. You have the choice of two routes. The one route is safer from traffic, but you also think it's a tremendously ugly, industrial part of town. The more scenic route has a lot of traffic on it and you have been nearly run down by cars crossing the street on this route. What do you do?

A (Growth Choice). You choose the route that takes you into the more congested traffic route, because you prefer the more scenic route. 24 percent/ 2.91

$B$ (Existence Choice). You choose the less congested, safer route, even though you don't like the scenery. 76 percent/ 3.62

There is a significant difference between ratings for $A$ and $B$.

Existence rating: 4.38

Relatedness rating: 2.99

Growth rating: 3.02

Believability: $\mathbf{3 . 3 0}$

\section{B.10 Question EG10}

You are driving in a rural area on your way to a local Campus. You need to take a route into campus that is rural and icy and slippery, because you want to see where you can go sledding on the weekend. You are not comfortable or experienced at driving in the snow, but you want to see the sledding site, so you will know how to get there this weekend. You lost control of your car in a similar rural area the week before and you are a bit apprehensive about driving on unmaintained, icy roads. Which do you choose?

A (Existence Choice). You choose the local maintained route for your own safety and you tell yourself, that for safety's sake, you might not go out to the sledding site at all. 78 percent, 3.67

B (Growth Choice). You choose to ride the unmaintained, rural route, so that you can see where to go sledding this weekend. You are nervous, but you think that the area will be very nice to sled around in. 22 percent/ 3.20

There is a significant difference between ratings for $A$ and $B$.

Existence rating: 4.56

Relatedness rating: 2.95

Growth rating: 2.91

Believability: 3.24

C.1 Question RG1 
You take the bus into work every day. You have a choice of two bus routes. On the one bus route, there are some people with whom you don't really like to ride the bus, mostly because many are vagrants and while not dangerous, offensive to your sense of smell. However, there is one reason why you enjoy riding this route, the fact that you can see the beach and the water as well as some very beautiful and historic buildings. It seems to make going to work more pleasant and worthwhile when you see the beach. The other route passes industrial areas and housing projects. However, the people on the less beautiful route are other working people like yourself. You really like to see the beach every morning, but you can hardly stand the smells of the people who ride the bus out to the beach every morning. Which route do you choose?

A (Growth Choice): You decide that you need your 'beach fix' on the way to work in the morning, so you put up with the stinky vagrants. You figure that you can sit as far away as possible from those with the most offending odors and maybe you can ask the bus driver if you could crack open a window. 43 percent/ 3.66

B (Relatedness Choice): You decide that the vagrants make you so disgusted that you will have to forego your daily beach route and opt for the less beautiful route that passes housing projects. You can go to the beach and enjoy the sights on your days off. 57 percent/ 2.95

There is a significant difference between ratings for $A$ and $B$. Existence rating: 3.96

Relatedness rating: $\mathbf{3 . 7 5}$

Growth rating: 3.14

Believability: 2.91

\section{C.2 Question RG2}

You want to ride a train visit your family for the weekend. Your family wants you to ride the express train, because it gets in at $7 \mathrm{pm}$ and it will be more convenient for them to pick you up at this time. However, you want to ride a later train that gets in at $10 \mathrm{pm}$ because this train is less expensive than the other train, $\$ 36$ versus $\$ 46$. You know that your family will be unhappy for most of your visit if you choose the later train. What do you do?

A (Relatedness Choice): You choose to honor your family's wishes and to take the earlier and more expensive train, because you want to make your family happy. $\mathbf{8 0}$ percent/ 3.70

B (Growth Choice): You choose to save yourself some money and ride the later train. Your family is very unhappy over this, but you saved money. 20 percent/ 3.62

There is not a significant difference between ratings for $A$ and $B$.

Existence rating: 4.32

Relatedness rating: 3.73

Growth rating: 2.73

Believability: 3.46 


\section{C.3 Question RG3}

You want to ride your bike 2 miles to visit your friend to play a board game. You have a choice of two bikes, one that your friend thinks is really cool and one that has a polka dotted basket on the front that your friend ridicules you about. However, the basket would help you to carry the board game. What do you choose?

A (Relatedness Choice): You choose the bike that your friend thinks is cool, even though it's hard to manage riding the bike and carrying the board game without the basket on the other bike. 18 percent/ 2.59

B (Growth Choice): You choose the polka-dotted basket bike that your friend thinks is really silly-looking, because it is easier to carry the board game using this bike. $\mathbf{8 2}$ percent/ 3.70

There is a significant difference between ratings for $A$ and $B$. Existence rating: 4.16

Relatedness rating: 2.33

Growth rating: 3.78

Believability: 2.66

\section{C.4 Question RG4}

You are going to take a bus to get to a concert taking place in a town that you are not super familiar with. You have a choice between two routes in the town. On one of the routes you will only have to make one transfer to get to the concert. However, you have taken this route before and the people on it were obnoxious and possibly intoxicated. You don't think that these people are dangerous, just annoying. The other route has more considerate and friendlier people, but you will have to make two transfers to get to your concert if you take this route. Which route do you choose?

A (Relatedness Choice): You choose the route with the nicer people. You would rather be inconvenienced by the transfers than have to ride the bus with a bunch of obnoxious people. 54 percent/ 3.72

B (Growth Choice): You choose the route with only one transfer, figuring that you can deal with the obnoxious people for the convenience of not having to transfer. 46

percent/ 3.09

There is a significant difference between ratings for $A$ and $B$.

Existence rating: 4.18

Relatedness rating: 3.50

Growth rating: 4.04

Believability: $\mathbf{3 . 3 0}$ 


\section{C.5 Question RG5}

You are going to drive 200 miles to go hiking in a national forest. You have a choice of two different cars. Your significant other doesn't like your hybrid car that you want to take and wants to bring his/her Jeep. You think that the hybrid will do just as well and will be better for the environment. Which do you choose?

A (Growth Choice). You choose to bring the hybrid, even though your significant other doesn't really like it all that much. He/she thinks that it's really uncool next to his/her Jeep and complains the whole time that he/she doesn't have enough space for the hiking gear. 24 percent/ $\mathbf{3 . 3 0}$

$B$ (Relatedness Choice). You choose to make your boy/girlfriend happy by bringing the Jeep, so that he/she will have enough space for his/her hiking gear, even though it will use a lot of gasoline and produce a lot of emissions. 76 percent/ 3.81

\section{There is a significant difference between ratings for $A$ and $B$.}

Existence rating: 4.36

Relatedness rating: 3.15

Growth rating: 3.43

Believability: 3.58

\section{C.6 Question RG6}

You take the train to work each morning. You usually wait 15 minutes for the train to arrive. You have the choice of two train stations, which are equal distance from your home. Train station $A$ is a hub and it has shopping and restaurants and nice waiting areas. Train station $B$ is nicely landscaped and attractive and offers shelter from the elements, but does not have all of the shops, restaurants, and other amenities that Train station $A$ has. However, while waiting for train $B$, you noticed and had a nice interaction with a very attractive person, who you would like to get to know better. Which do you choose?

A (Relatedness Choice). You choose train B, because you want to use your 15 minutes of waiting time to get to know this person better. 66 percent/ 3.79

B (Growth Choice) . You choose train A, because you like having all of the amenities and you hope that you will find another attractive person at this stop. $\mathbf{3 4}$ percent/ $\mathbf{3 . 3 9}$

There is a significant difference between ratings for $A$ and $B$.

Existence rating: 4.32

Relatedness rating: 3.70

Growth rating: 3.31

Believability: $\mathbf{3 . 3 4}$ 


\section{C.7 Question RG7}

You are getting ready for a 5-day bike trip to the Grand Tetons. You and your spouse are avid cyclists and enjoy these types of trips. You are trying to decide between two different paths. You want to bike in the Grand Tetons and it's a very mountainous area. But, you like this one route that is full of natural potholes and your spouse likes the route that will be easier to ride on. You tell your spouse that it will be a fun adventure and that the scenery will be much better on the more strenuous route, especially the wildlife. Your spouse is an avid cyclist, too, and does enjoy a good ride, but feels that the difficulty of the route isn't worth the tradeoff for scenery. According to your guide, both routes are equally safe, it's just that one is much more strenuous than another. The guide agrees with you that the more strenuous route is also slightly more scenic than the less strenuous route, mainly that you get to be closer to wildlife such as moose and bison. What do you choose?

A (Growth Choice). You choose the more strenuous route, because you want the better scenery and vistas, even though your spouse is a bit resentful that you didn't take his/her feelings into consideration. You figure that your spouse is in really good physical shape and they can handle the harder route. You think they'll thank you later for choosing the better scenery. 25 percent/ 3.46

B (Relatedness Choice). You choose the less strenuous ride, because you know that 5days is a long time to be with an unhappy spouse and you want for him or her to enjoy the ride just as much as you do. In the Grand Tetons, the scenery never disappoints and maybe if your spouse has a good time on this bike trip he or she will agree to the harder one next time. 75 percent/ 4.14

There is a significant difference between ratings for $A$ and $B$. Existence rating: 4.38

Relatedness rating: 4.21

Growth rating: 3.46

Believability: 3.34

\section{C.8 Question RG8}

You are going to meet a friend in Washington D.C. for a night out on the town. Your friend wants to meet at a transit stop in DuPont Circle and you want to meet at Union Station. DuPont Circle is just a concrete hole in the ground that you take an escalator into and out of. It is not nearly as nice as you think Union Station is. But, your friend is very insistent on going to DuPont Circle to their favorite restaurant. You're not sure if you want to leave Union Station, which is also surrounded by beautiful and historical buildings to go to a local neighborhood that may not be as lovely. You are also only in town for the one night and it is your tradition to go to Union Station and people watch and enjoy the atmosphere and shopping and restaurants. But, you also only see your friend a few times a year when you're in D.C. on business and you want to make him or her happy as well. What do you choose?

A (Growth Choice): You tell your friend that you don't live in D.C., so you get to decide where you go and you want to visit Union Station on your only night there. You know 
that your friend will be disappointed, but you really enjoying seeing the surrounding areas of Union Station. 13 percent/ 3.35

B (Relatedness Choice). You decide to do something different and you take the Metra to the DuPont Circle station and you meet your friend at the Asian/French fusion restaurant that they mentioned. You figure that you will return to D.C. in a few months and you can see Union Station then. 87 percent/ 3.91

There is a significant difference between ratings for $A$ and $B$. Existence rating: 3.89

Relatedness rating: 3.12

Growth rating: 3.54

Believability: 3.54

\section{C.9 Question RG9}

You are going on a walk with your parents down Bayshore Boulevard in Tampa. You have the choice of two routes. One route is significantly longer than the other route. The shorter route takes you past a vacant lot that just is so ugly you feel it spoils the walk for you. The longer route has some areas that aren't as beautiful as you would like, but not as blighted as you think the vacant lot is. However, your parents do not want to walk two miles instead of one mile just so that you don't have to look at the vacant lot. It's not dangerous, it's just ugly, they tell you, and they want to get to beautiful Bayshore more quickly. You know that your parents are capable of walking the two miles, but it means that they will not be able to enjoy the walk along Bayshore for as long. The main goal of the walk is to enjoy the beauty of Bayshore. What do you do?

A (Relatedness Choice). You choose to take the route that takes you by the vacant lot, keeping your eyes straight ahead on the sidewalk and diverting them from the ugly lot. You know that your parents appreciate the fact that you will walk past a small blighted area in order for your family to get to Bayshore more quickly for your evening walk. 96 percent/ 3.64

B (Growth Choice). You decide that you just can't deal with that vacant lot and decide to make your parents walk the two mile route as opposed to the one mile route. Your parents are very unhappy that you are making them waste time that they could spend walking on Bayshore, walking along the Downtown streets in Tampa and aren't very nice company on the walk. 4 percent/ $\mathbf{3 . 1 0}$

There is a significant difference between ratings for $A$ and $B$.

Existence rating: 4.42

Relatedness rating: 4.09

Growth rating: 3.21

Believability: $\mathbf{3 . 3 0}$ 
You are driving to a local campus with your boy/girlfriend. You want to go by and see an exposition presentation. Going by the exposition is inconvenient and your boy/girlfriend doesn't want to go to it. But, you do have time before your classes start and you think that it would be fun for the both of you to go by the exposition. You know that your boy/girlfriend just wants to get to class and will be angry if you go by the exposition. What choice do you make?

A (Relatedness Choice). You choose to go straight to your classes, missing the exposition that you wanted to see, but pleasing your boy/girlfriend. 50 percent/ 3.33

B (Growth Choice). You choose to ignore your significant other's wishes and you take $\mathrm{him} /$ her to see the exposition anyway, thinking that they will like it once they get there.

50 percent/ 3.79

There is not a significant difference between ratings for $A$ and $B$.

Existence rating: 4.79

Relatedness rating: $\mathbf{3 . 3 0}$

Growth rating: 2.62

Believability: 3.79 
